\title{
Cool and Dry Climates
}

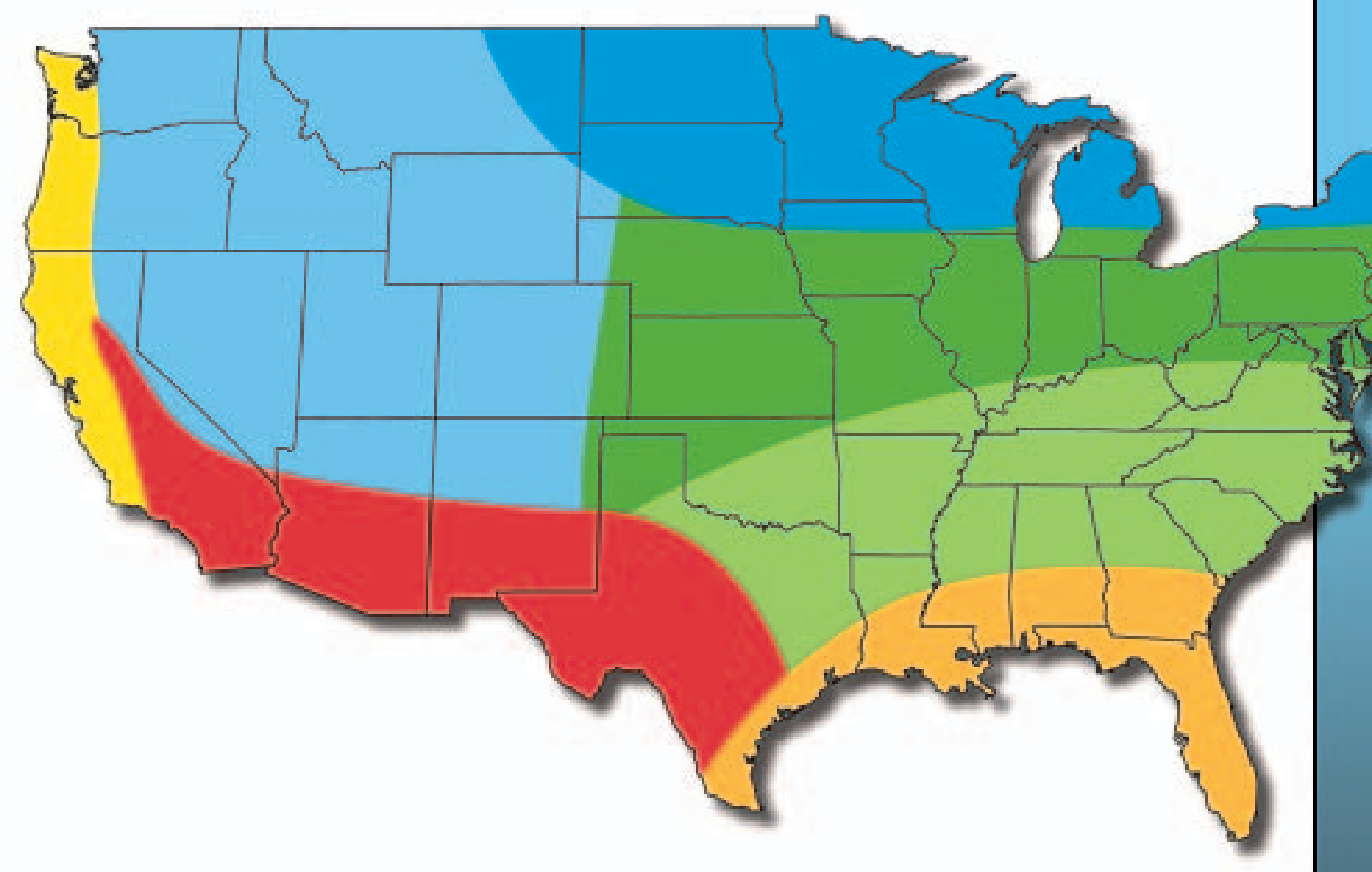

Energy Design Guidelines

for High Performance Schools 
This document was developed by the National Renewable Energy Laboratory with subcontractor Innovative Design. Technical assistance came from Padia Consulting, BuildingGreen, and the Sustainable Buildings Industry Council.
This report was prepared as an account of work sponsored by an agency of the United States government. Neither the United States government nor any agency thereof, nor any of their employees or subcontractors makes any warranty, express or implied, or assumes any legal liability or responsibility for the accuracy, completeness, or usefulness of any information, apparatus, product, or process disclosed, or represents that its use would not infringe privately owned rights. Reference herein to any specific commercial product, process, or service by trade name, trademark, manufacturer, or otherwise does not necessarily constitute or imply its endorsement, recommendation, or favoring by the United States government or any agency thereof. The views and opinions of authors expressed herein do not necessarily state or reflect those of the United States government or any agency thereof.

\section{Acknowledgements}

The US Department of Energy would like to acknowledge the help and assistance of the EnergySmart Schools team and the many reviewers who provided input and feedback during the process of developing this report. Those include:

\section{National Laboratories \\ Lawrence Berkeley National Laboratory: Dariush Arasteh, Doug Avery; National Renewable Energy Laboratory: Ren Anderson, Zahra Chaudhry, Kate Darby, Kyra Epstein, Patty Kappaz, Bryan King, Patricia Plympton, Amy Vaughn; Oak Ridge National Laboratory: Sherry Livengood, Ron Shelton; Pacific Northwest National Laboratory: Michael Baechler, Kim Fowler, Eric Richman, David Winiarski \\ US Department of Energy \\ David Hansen, George James, Arun Vohra; Chicago Regional Office: John Devine, Peter Dreyfuss; Seattle Regional Office: Richard Putnam; Office of Policy and Management: John Ruckes; EnergySmart Schools Team: Larry Schoff, Blanche Sheinkopf; Rebuild America Products and Services: Greg Andrews, Ken Baker, Chip Larson, Bill Mixon, Sue Seifert}

Advance Transformer Co.: Gary Sanders; AndersonMasonDale Architects: Peggy Kinsey; Ashley McGraw Architects, PC: David Ashley; Atelier/Jilk: Bruce Jilk, AIA; Austin Independent School District: Dan Robertson; Building America: Mark Halverson; Building Science Corporation: Joseph Lstiburek, Betsy Pettit; Cutler-Hammer: David DePerro; D \& R International: Bill Zwack; Donald Aitken Assoc.: Donald Aitken; Eley Assoc.: Charles Eley; Energy Design \& Consulting: Ed Mangan; Environmental Support Solutions: Dana Johnson; Facility Improvement Corp.: John Phillips, PE; Hickory Consortium: Mark Kelley; Horst, Terrill \& Karst Architects, P.A.: Mark E. Franzen, AIA; IBACOS Inc.: Brad Oberg; Innovative Design: Mike Nicklas, Pascale Rosemain; John Portman \& Associates: Jeff Floyd, AIA; Kansas State University: Bruce Snead; Kinsey Shane and Assoc.: William T. Traylor, AIA; Lithonia Lighting Co.: Richard Heinisch; Margo Jones Architects: Margo Jones; Maryland Energy Administration: Fred Hoover; National Institute of Building Sciences: Bill Brenner; Noack Little Architects: Chris Noack NORESCO: John Rizzo, PE; Northeast Energy Efficiency Partnerships Inc.: Jim Rutherford; Oregon Office of Energy: George Churchill; Poudre School District: Mike Spearnak; Power Correction Systems: Brahm Segal; SAFE-BIDCO: Mary Jo Dutra; Sarnafill Inc.: Peter D'Antonio; Sherber Assoc. Inc.: Michael S. Sherber; SHW Group: Gary Keep; Stanley Architects: Lars Stanley; TechBrite: Michael Boyd; Texas State Energy Office: Robin Bailey; TRACO: Tony Bartorillo:, Scott Roy; University of Wisconsin-Madison: Jeffrey Lackney; US Department of Education: Jack Lyons, Sylvia Wright; US EPA: Melissa Payne; WaterLess Co. LLC: Klaus Reichardt; WattStopper: Dorene Maniccia; Weller and Michal Architects Inc.: Charles J. Michal, AIA

In addition to the reviewers, many participated in the roundtable discussions leading to the publication of this document:

Association of School Business Officials, International: Don Tharpe; Burr Lawrence Rising + Bates Architects: Tom Bates; California Energy Commission: Darryl Mills; Charles Michal AIA PE LC: Charles Michal; CMD Group: Michelle Hesler; Council on Educational Facility Planners International: Elisa Warner; Dry Creek Elementary Schools: Kelvin Lee; Energy Center of Wisconsin: Abby Vogen; Estes McClure \& Assoc. Inc.: James McClure; Florida Solar Energy Center: Danny Parker; Hanson Design Group LTD: Henry Hanson; Heschong Mahone Group: Lisa Heschong; HL Turner Group Inc.: Harold Turner; Loudon County Public Schools: Evan Mohler; Lawrence Berkeley National Laboratory: Rick Diamond; Manheim Township School District: David Arnstrad; National Association of State Energy Officals: David Terry; New York State Energy Research and Development Authority: Don LaVada; Padia Consulting Inc: Harshad Padia; Portland Public Schools Environmental Services: Patrick Wolfe; Public School Construction Program: Yale Stenzler; Simon and Assoc.: Lynn Simon; Southern California Edison: Gregg Ander; Sustainable Buildings Industry Council: Deane Evans and Ellen Larson; US DOE: Mark Bailey; US Department of Education: Tom Corwin; US EPA: Bob Thompson; Washington State University Energy Program: Michael McSorley

This document was produced by the US Department of Energy's Office of Building Technology, State and Community Programs, led by Deputy Assistant Secretary Mark Ginsberg, National Program Manager Daniel Sze, and Outreach and Communications Manager Lani MacRae.

Available electronically at http://www.doe.gov/bridge 


\section{Creating High Performance Schools}

School districts around the country are finding that smart energy choices can help them save money and provide healthier, more effective learning environments. By incorporating energy improvements into their construction or renovation plans, schools can significantly reduce energy consumption and costs. These savings can then be redirected to educational needs such as additional teachers, instructional materials, or new computers.

The US Department of Energy's (US DOE's) EnergySmart Schools provides school boards, administrators, and design staff with guidance to help them make informed decisions about energy and environmental issues important to school systems and communities. These design guidelines outline high performance principles for the new or retrofit design of your K-12 school. By incorporating these principles, you can create an exemplary building that is both energy- and resource-efficient - a school that is a teaching tool in and of itself.

\section{The Importance of Connecting Energy and Environmental Issues}

Across our country we are again seeing signs that the supply of energy is not keeping up with rising demand. Brownouts are becoming more commonplace. The price of natural gas is twice what it was in the 1990s. We are moving from a period of less expensive energy and seemingly plentiful resources to a time in which building-related decisions will be more strongly influenced by energy and water availability. There is a growing concern about the environmental and societal implications of energy. Today, energy costs over the life of a school will far exceed the initial cost of the building. As prices rise, it will become even more critical to comprehensively address this issue.

This guide was developed to promote long-term thinking and building our schools in ways that reflect values supportive of our planet. Our schools can make a strong statement that saving energy and resources, while protecting our environment, is important. The message that we give to future generations should be embodied in the buildings we use to teach them.

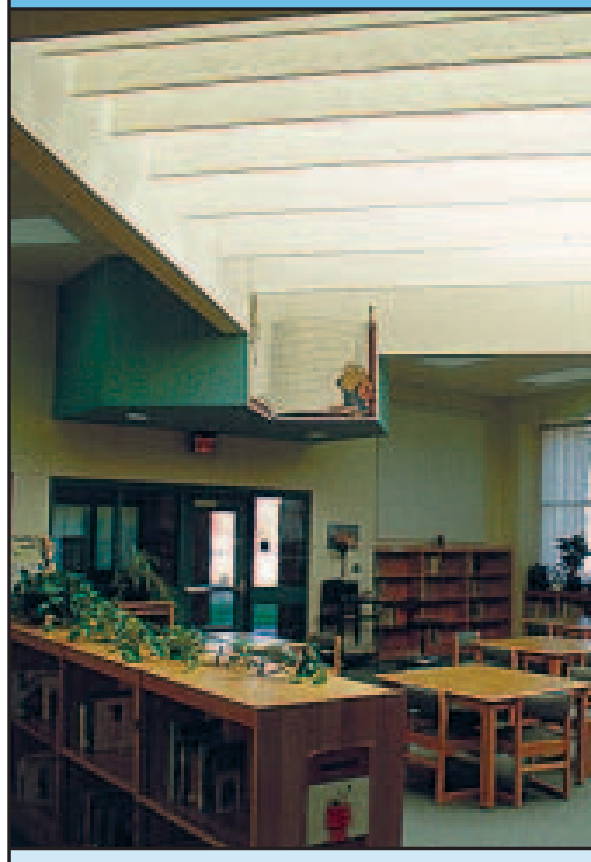

"Good teachers never teach anything. What they do is create conditions under which learning takes place."

- S.I. Hayakawa

By implementing the high performance practices included within these guidelines, you will be taking a significant step forward in creating the physical conditions in which the learning process can thrive.

For more information, visit the EnergySmart Schools Web site: 

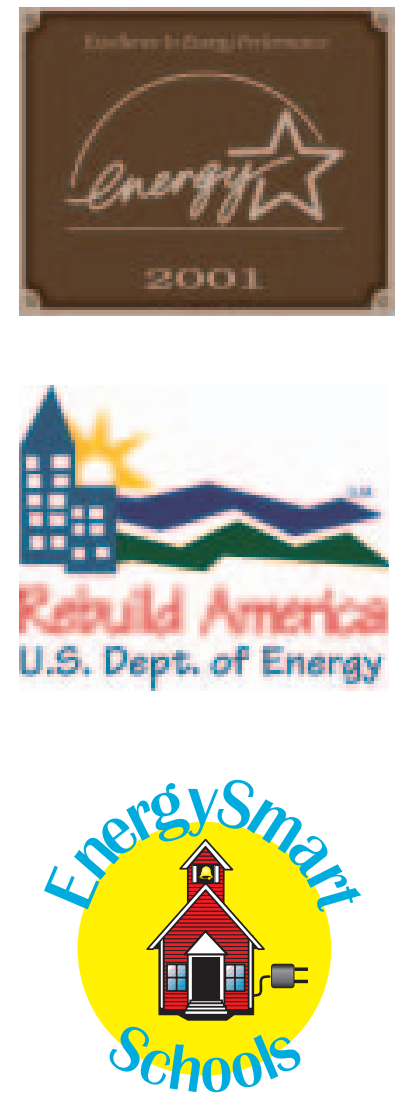

Rebuild America Schools U.S. Department of Energy

\section{Help Your School Earn the Energy Star Label}

The ENERGY STAR label on a school building wall tells an important story. The label not only identifies a school building whose energy performance is among the nation's top $25 \%$ — but it also lets taxpayers know you're using money wisely, spending the resources on education instead of high energy bills. The label tells students that their school cares about the environment, that you're doing your part to reduce energy-related pollution. And it indicates that your school has the great lighting, comfortable temperatures, and high-quality air that go hand in hand with smart energy use.

ENERGY STAR, a registered trademark of the US Environmental Protection Agency (US EPA) and the US DOE, is the mark of excellence in energy performance. It is a trusted national brand symbolizing superior energy performance in more than 30 categories of consumer electronics and appliances, as well as office buildings, schools, supermarkets, hospitals, and homes. The ENERGY STAR benchmarking tool is a powerful way to manage building energy performance and to earn recognition for excellence in building energy performance. The rating system measures the energy performance of each building on a scale of 1 to 100 and shows how a building compares with other buildings in your portfolio or nationwide. The rating system provides useful baseline information to help organizations set energy performance targets and plan energy-efficiency improvements. Buildings whose energy performance places them in the top $25 \%$ among similar buildings nationwide, and that meet industry standards for indoor environment, are eligible to apply for the ENERGY STAR label, a large bronze plaque that can be displayed on the building.

Determining if your buildings qualify for this label is easy. All you need is data about your school's energy use over the past 12 months, the square footage of your buildings, and the number of students enrolled. You can then establish an account for your school district and enter your energy data into the ENERGY STAR computer analysis tool available on the Internet. Each school building that scores 75 or higher, while maintaining indoor air quality that meets industry standards, can apply for the ENERGY STAR label.

By incorporating the energy design guidelines detailed in this document into your school's construction or renovation plans, you can take the first essential steps toward earning the ENERGY STAR label for your school. 


\section{An Introduction to the Energy Design Guidelines}

This document presents recommended design elements in 10 sections, each representing a key interrelated component of high performance school design. To effectively integrate energy-saving strategies, these options must be evaluated together from a whole-building perspective early in the design process. A "high performance checklist" for designers is located at the end of the document. The checklist is a quick reference for key architectural and engineering considerations. Case studies can also be found at the end of the document.

Site Design . . . . . . . . . . . . . . . . .

Daylighting and Windows $\ldots \ldots \ldots \ldots \ldots \ldots \ldots \ldots \ldots \ldots \ldots \ldots$

Energy-Efficient Building Shell . . . . . . . . . . . . . . 19

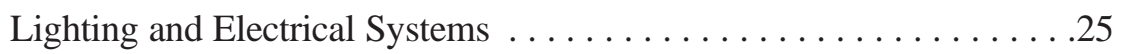

Mechanical and Ventilation Systems $\ldots \ldots \ldots \ldots \ldots \ldots \ldots \ldots . \ldots \ldots$

Renewable Energy Systems . . . . . . . . . . . . . . . . . . . 39

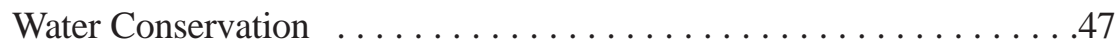

Recycling Systems and Waste Management . . . . . . . . . . . 51

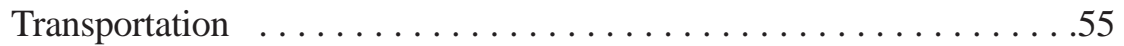

Resource-Efficient Building Products . . . . . . . . . . . . . . .59

Checklist of Key Design Issues $\ldots \ldots \ldots \ldots \ldots \ldots \ldots \ldots \ldots \ldots \ldots \ldots \ldots \ldots \ldots \ldots \ldots \ldots \ldots . .677$

Case Studies . . . . . . . . . . . . . . . . . . . . . . . . . . . . .77

\section{Climate Zones for Energy Design Guidelines}

These guidelines contain recommendations generally appropriate for cool and dry climates, for which Denver, Colorado, served as a model city. Other guidelines have been developed for the other climate zones, shown on the map below.

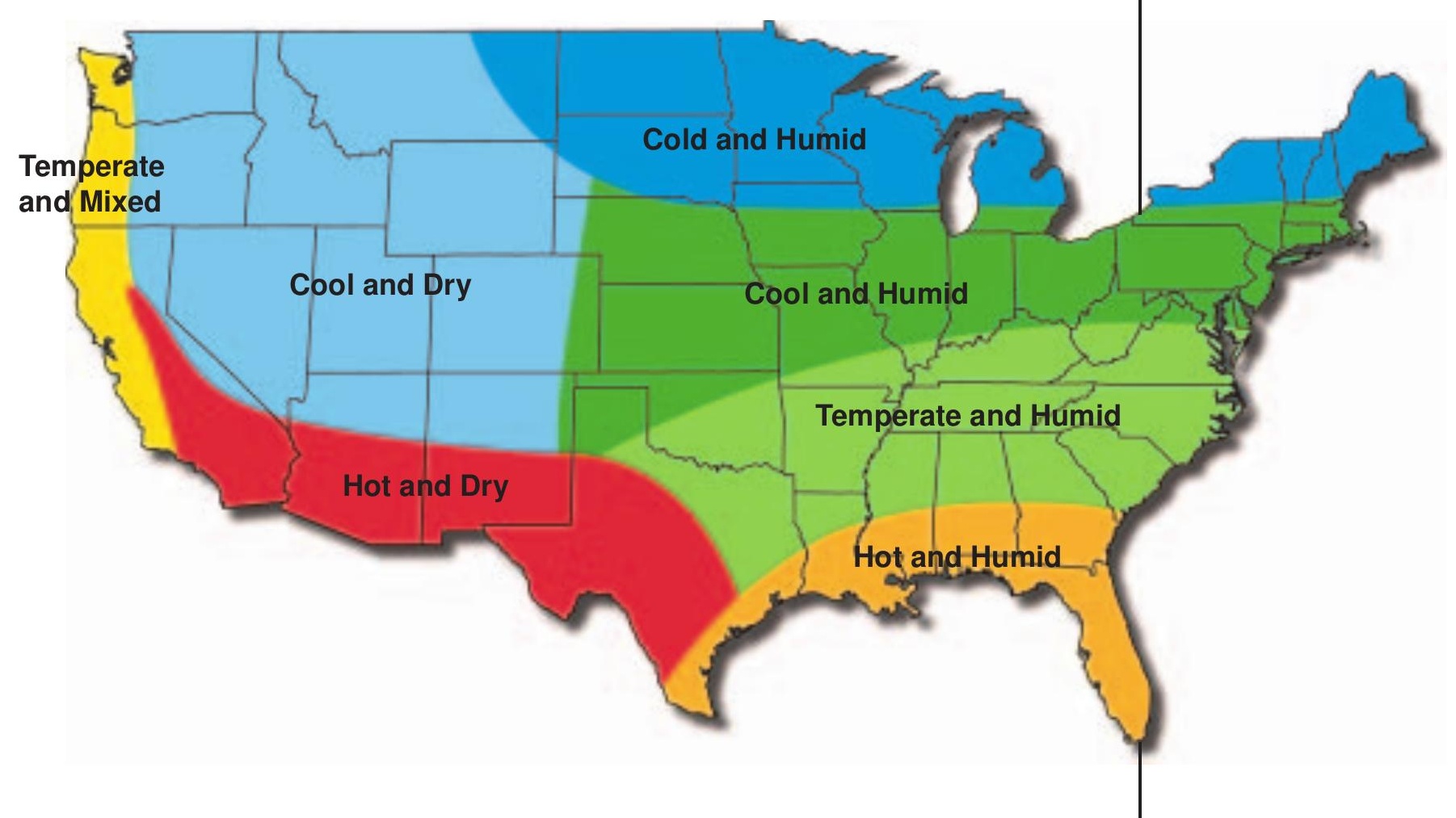


Establishing daylighting objectives will also improve classroom conditions and can help improve performance if you:

- Include controlled daylighting in all classrooms, administrative areas, the gymnasium, and other significantly occupied spaces

- Develop intentional visual connections between the indoor and outdoor environments.

\section{Protecting Our Environment}

High performance school design takes into consideration not only the economic and academic impacts of design but also environmental impacts. Environmentally sound design elements are those that:

- Use renewable energy systems and energy-efficient technologies

- Incorporate resource-efficient building products and systems

- Promote water-conserving strategies

- Use less polluting transportation alternatives

- Establish recycling systems

- Incorporate environmentally sound site design.

\section{Designing for Health, Safety, and Comfort}

You cannot design a high performance school without including design strategies that address health, safety, and comfort issues. Goals should include objectives that:

- Implement daylighting and indoor air quality solutions to make the school a healthier place to teach and learn

- Address acoustical and thermal comfort.

\section{Supporting Community Values}

Incorporating high performance strategies in your school's design results in a win-win situation for the community and the school. Through the implementation of energy-savings strategies, the school saves money and taxpayers benefit.

Additionally, the energy dollars saved don't leave the immediate region but stay within the community and help to build a stronger local economy.

Building to high performance standards implies the purchase of locally manufactured products and the use of local services. This approach is effective because much of the environmental impact associated with materials, products, and equipment purchased for construction involves transportation. The more transportation, the more pollution. Specifying local products benefits the community in the same way that retaining energy dollars helps: it strengthens the local economy. Implementing energy-efficient, environmentally sound practices also has a direct impact on the local air and water quality. By establishing goals to positively address these issues, you are taking the first step toward creating a better community in which to live. 


\section{"Whole Building" Energy Analysis}

Determining the relative merits of one energy strategy versus another can only be accurately determined by analyzing the specific measure in the context of the "whole building." Each component or system is continually impacted by changing climatic conditions and occupancy demands. Each component has an effect on another.

When evaluating energy options, it is essential that the design team use computer energy analysis programs that can simulate the impact the specific measure has on the overall energy consumption and peak load. The program must be able to provide hourly, daily, monthly, and yearly energy profiles and be able to accurately account for the benefits associated with daylighting. The US DOE has two programs to assist with this analysis: DOE-2 and Energy Plus. More information can be found on these programs in the resources section at the end of this document.

\section{Considering Emerging Solutions}

The recommendations listed within this document reflect proven technologies that have been successfully incorporated into school applications in this climate zone and across the country. However, every year, new solutions are developed that will be able to make your facilities more energy-efficient and environmentally sound. As these new systems, materials, and products become commercially available, designers should exercise care in selecting those that are viable but should not be discouraged from implementing technologies just because they are not commonplace.

"We will insist on protecting and enhancing the environment, showing consideration for air and natural lands and watersheds of our country."

National Energy Policy, 2001
Because of their dynamic nature, these emerging solutions will be addressed on the Web site, which provides cost information and examples of current projects where the solution is already in use. 


\section{Site Design}

\section{Site Design}

By orienting your school building effectively, you can maximize solar access and boost the effectiveness of daylighting strategies, reducing the need for electrical lighting as well as heating and cooling loads. Designing the site to reduce or eliminate vehicular travel to the school helps to reduce fuel usage and emissions, improving the air quality in and around the school. And water requirements can be reduced by incorporating vegetation native to the local ecosystem in the site design.

Decisions made early in the design can often have a significant impact on many other aspects of the design. Orienting the building linearly on an east-west axis is one important example. By maximizing well-controlled, south-facing glass and minimizing east- and west-facing glass, energy performance is greatly enhanced, comfort conditions are improved, and initial costs associated with cooling are reduced.

The educational potential of high performance design can also be greatly emphasized by integrating effective indoor-outdoor relationships between the building, the site, and the design of outdoor spaces as educational resources and venues.

When considering the location for a school site, it is critical not only to consider your initial cost but also to evaluate environmental implications, how health and safety are influenced, and how well the school design is integrated into the fabric of the community.

Students enjoy the outdoor teaching courtyards and "eco-gardens" that allow them to plant native vegetation, view natural habitat and wildlife, and better understand ecocycles.

Retaining ecosystems and wildlife habitat surrounding schools and incorporating them into outdoor learning activities enhances student interest in the environment. 


\section{Guidelines for Site Design}

\section{Selecting a Site}

When selecting a school site, the highest priority should be given to appropriately located sites that enable the school to be built cost effectively and in a resourceefficient manner.

Before - Photo: Davis, Carter, Scott

The rehabilitation of a vacant commercial building into the new \$1.8-million, 24,000-square-foot Arlington Mill School and Community Center in Virginia was the solution adopted by Arlington Public Schools to meet its urgent need for a new high school facility.

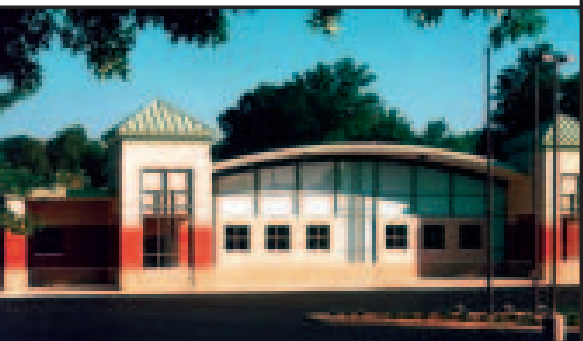

After — Photo: Estate of Doug Brown

\section{- Cost}

- Consider the rehabilitation of an existing site or an urban in-fill area before choosing an undeveloped site.

- Select a site that can maximize solar access for daylighting and other solar systems and minimize east and west glass.

- Consider the wind resources at the site and the potential for implementing wind energy systems.

- Consider the availability and cost of utilities at the site.

- Analyze mass transit and pedestrian accessibility as well as potential bus routes.

\section{- Environment}

- Avoid selecting sensitive ecosystems, such as wildlife habitats.

- Consider geological, micro-ecological, and micro-climatic conditions.

- Evaluate the potential implications of erosion control and rainwater management.

- Determine the presence of historic landmarks or archeological features on the site.

- Conduct an assessment of the impact the school will have on the local environment.

- Consider the ability to protect and retain existing landscaping.

\section{- Health/Safety}

- Determine the existing and projected air, soil, and water quality.

- Evaluate the physical relationships to industries or utilities that may pollute the air.

- Evaluate noise levels typically experienced at the site.

\section{- Community}

- Determine the ease with which the school could be linked into local communities through safe pedestrian walkways.

- Evaluate the potential for recycling with the city or county.

- Consider sites where local developers are interested in working together to integrate the school into the overall community design. 


\section{Site Design}

\section{Protecting Local Ecosystems}

The protection of local ecosystems is critical to an environmentally sensitive site design.

- Protect or restore ecosystems and wildlife habitats on the site.

- Develop a landscaping design that is compatible with existing plants and that uses native plants.

- Protect areas for viewing natural habitat.

- Develop interpretive nature trails through preserved wildlife habitats and ecosystems.

- Use explanatory signage for different plants and trees.

- Consult with local universities, cooperative extension offices, and master gardeners about local ecosystems, how to protect them, and ways to maximize their educational value.

\section{Water-Conserving Strategies}

The implementation of these commonsense ideas will help to drastically reduce school water use and conserve water in the community.

- Use native planting materials and xeriscape principles to minimize the need for site irrigation.

- Employ a rainwater catchment system for irrigation and toilet flushing.

- Use graywater from sinks and water fountains for site irrigation.

- Use soaker hoses and drip irrigation techniques that minimize evaporative losses and concentrate water on the plants' roots.

- Use timers on irrigation systems to water at night.

\section{Erosion Control and Off-Site Impacts}

Developing on-site erosion control and stormwater management strategies will better ensure that off-site impacts can be minimized.

- Employ site contours and natural drainage strategies.

- Minimize surfaces impervious to water.

- Determine the key pollutants that are impacting your watershed and develop strategies to reduce the likelihood that the pollutants will reach the watershed. 
The cost effectiveness of the daylighting strategies implemented at East Clayton Elementary School in Clayton, NC, is greatly enhanced by the elongation of the school on an east-west axis. This layout increases the potential for capturing winter gain while reducing unwanted summer sun that more often strikes on east-west surfaces.

\section{Building Orientation}

To minimize energy use, maximize your potential by siting the school correctly.

- Establish the building on an east-west axis.

- Develop a floor plan that minimizes east- and west-facing glass.

- Emphasizing one-story designs to maximize daylighting increases the foundation perimeter and roof area. Both of these are significant contributors to heat losses and therefore detrimental to low energy use in heating-dominated climates. Larger building footprints increase site impacts and consume more scarce buildable land, especially in urban areas.

- In multiple-story schools, minimize the depth of the rooms to maximize the daylighting contribution.

- Consider seasonal variations in wind speed and direction.

\section{Renewable Energy}

When evaluating site design issues, it is essential to investigate renewable systems early in the process. Solar systems need to have solar access, and wind systems require proper placement to be maximized.

- Consider climatic conditions at the site.

- To improve safety and save energy, consider non-grid-connected photovoltaic systems for:

- crossing and caution lights

- lighting at walkways and parking areas

- telephone call boxes for emergencies.

- Consider installing building-integrated solar thermal systems for domestic hot water, space heating, and absorption cooling.

- Consider building-integrated photovoltaic systems for electricity production.

- Ensure that solar systems are not shaded and that they are positioned to be visible to the students, teachers, and parents.

- Consider wind energy systems for electricity or well water.

- Consider geothermal heat pumps. 


\section{Design Guidelines for Daylighting and Windows}

\section{Building Orientation and Solar Access}

By elongating the school design on an east-west axis, the potential for cost-effective daylighting is maximized.

- Consider daylighting strategies that primarily use south-facing glass and secondarily incorporate north-facing glass. An elongated building that has its major axis running east-west will also increase the potential for capturing winter solar gain through south glass as well as reducing unwanted summer sun that more often strikes on the east and west surfaces. Exposed, eastern- and westernfacing glass should be avoided wherever possible because it will cause excessive summer cooling loads. South glass should incorporate properly sized overhangs that limit radiation in warmer months.

- Verify that other exterior design elements or existing site features do not negatively affect the daylighting design.

- Make sure other building elements do not unintentionally shade glazing areas that are designed as daylighting elements.

- Consider the reflectance of the materials in front of the glazing areas. The use of lighter roofing colors can reduce the glass area needed for roof monitors, while a light-colored walkway in front of a lower window may cause unwanted reflections and glare inside the classroom.

\section{Daylighting Strategies}

Because lighting is a significant component of a school's energy consumption, efforts to use daylighting should be given a high priority. Properly designed daylighting reduces the need for electric lighting and helps to create a more pleasant environment.

Source: Lawrence Berkeley National Laboratory Lighting Market Source Book for the United States

Sunlight provides more lumens per watt than electrical lamps.

- Good daylighting design can reduce the electricity needed for both lighting and cooling a school. The reason is simple: daylight provides a higher ratio of light to heat than electrical sources. This ratio, known as lighting efficacy, means that daylight provides more light and less heat, which can greatly reduce cooling loads. The chart to the left compares the efficacy (measured in lumens per watt) of various light sources. 
- In cool and dry climates, it is important to consider how passive heating can provide benefits without negatively impacting summer cooling. Properly designed south-facing monitors or windows with lightshelves can accomplish both. By facing the glass south and providing overhangs that maximize winter gain and block the majority of direct solar gain during summer peak cooling times, an optimum solution is possible. Because cooling loads are a great concern, it is very important to size the glass area so that during times of peak cooling no more solar gain is allowed to enter into the space than is necessary to provide the required lighting levels. If designed correctly, this sunlight will generate less heat for the same amount of light. This means that, in addition to the lights being off, the peak cooling mechanical load will be reduced.

- Consider daylighting apertures to limit the amount of beam radiation entering during the hottest part of the day in the cooling season. East- and west-facing glass should be minimized. In cool and dry climates, south-facing vertical glazing is typically better because roof overhangs can be designed to effectively admit low-angle winter radiation for daylighting and exclude excessive higher-angle sunlight in the warmer months. North glazing is second best because it doesn't create overheating problems during the cooling seasons, but it also doesn't provide any passive heating benefits. For example, the charts below indicate seasonal sun angles for Denver.

For more information on sun angles, see the resource section in this report.
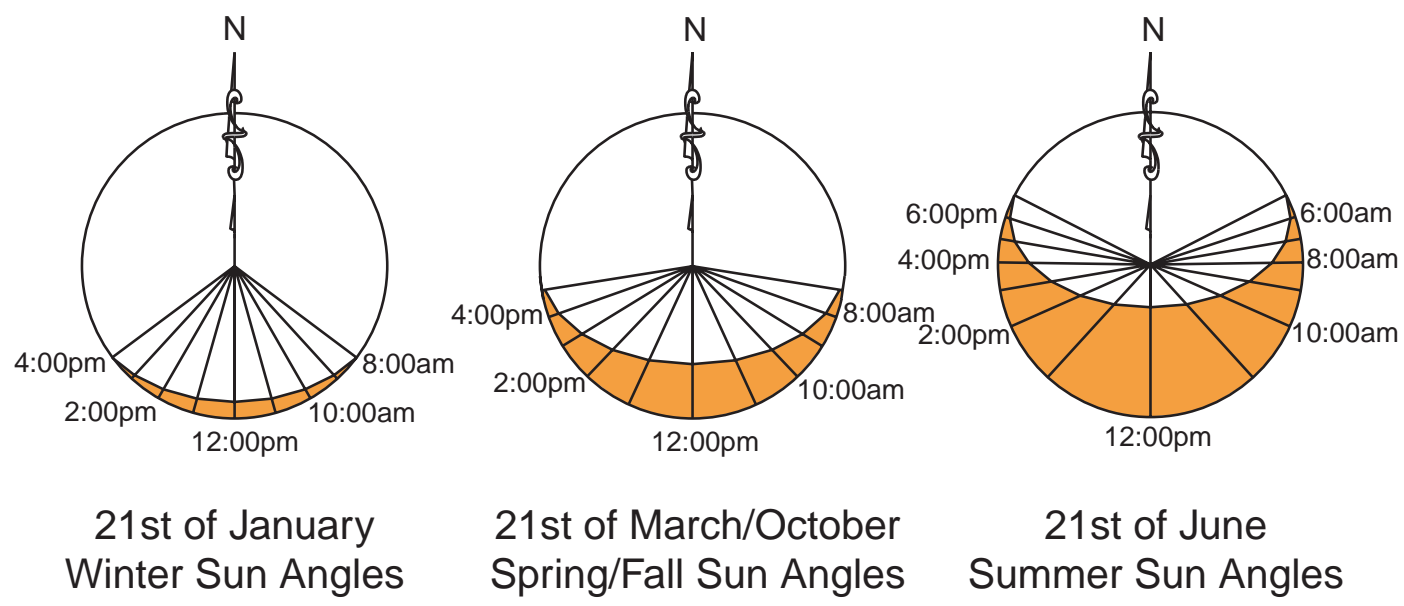

\section{1 st of June Summer Sun Angles}

Sun Angles for Denver, CO

Sun angle charts indicate the location (azimuth) of the sun at various times of the year.

- Use a well-designed overhang to mitigate the potential drawbacks of summertime solar gains through south-facing glazing. An oversized overhang on the south is not recommended on daylighting apertures since it can block significant amounts of diffuse radiation in addition to the direct beam.

- Develop a daylighting design with primary emphasis on south- (typically best) or north-facing roof monitors and a secondary emphasis on lightshelves. Lightshelves can significantly enhance the natural lighting uniformity within a space and also provide good lighting in narrow rooms (less than 16 feet to 20 feet). Lightshelves may also be the only option on multiple-story schools. 


\section{Roof Monitors and Clerestories}

Roof monitors and clerestories perform two critical functions: they provide uniform light within the room, and they eliminate glare.

- Design daylighting strategies to meet the different lighting needs of each major space, accounting for:

- differing lighting level requirements by time of day

- the ability to darken particular spaces for limited periods of time.

Clear double glazing has to be used to optimize solar access. Overhangs block excessive radiation in the warmer months.
Translucent baffles block direct beam radiation and diffuse the sunlight throughout the space.

- If south-facing roof monitors are employed, they should:

- employ baffles within the light wells to totally block direct beam radiation from striking people, reflective surfaces, or computers

- block high summer sun with exterior overhangs

- reduce contrast between very bright surfaces and less bright areas.

- Optimize the design of roof monitors to enhance their benefits.

- Minimize the size and maximize the transmission of glass to reduce conductive losses and gains.

- Develop an overall building structural design that integrates the daylighting strategies and minimizes redundant structural elements.

- For south-facing monitor glass, select clear double glazing or clear double glazing with argon. Do not use low-e or tinted glass in these windows because it has lower visible light transmission qualities. This adversely affects the daylighting and requires more glass area to achieve the same results.

- Choose light-colored roofing materials in front of roof monitors to reflect additional light into the glazing.

- In roof monitor/lightwell assemblies, incorporate white (or very light-colored) baffles that run parallel to the glass and are spaced to ensure that no direct beams can enter into the space. These baffles should be fire-retardant and UV-resistant. Use light-colored translucent baffles because, in addition to reflecting the sunlight into the space, they eliminate contrast from one side of the baffle to the other.

- At the bottom of the lightwell, provide a transition between the vertical plane surface and the horizontal by either introducing a $45^{\circ}$ transition or, if possible, a curved section. This will decrease the contrast between the higher light level inside the lightwell and the horizontal ceiling.

- Ensure that the walls and ceiling of the roof monitor are well insulated and incorporate appropriate infiltration and moisture barriers. 


\section{Lightshelves}

A south-facing window can be easily transformed into a well-controlled lighting source by adding a lightshelf a couple of feet below the top of the window. The lightshelf, made of a highly reflective material, will bounce the sunlight that strikes the top of the surface deep into the building. The reflected sunlight will hit the ceiling and, in turn, provide light for the room. This is an effective strategy for rooms up to 20 feet deep and can be employed in multi-story schools or where roof monitors are not possible. The lightshelf also serves the vital role of shading the window below.

- Select durable materials for both interior and exterior lightshelves, and design them to be capable of carrying the weight of a person.

- Specify aluminum exterior lightshelves as a good compromise among good reflectance, little or no maintenance, and cost.

- Incorporate white painted gypsum board on top of interior lightshelves. However, aluminized, acrylic sheets applied to the top of a shelf allows light to bounce farther back into spaces and can improve performance in deeper rooms without top lighting.

- Use blinds as a strategy to enhance performance. Even with a combination of interior and exterior lightshelves, direct beam light can, at times, enter into the space, creating unwanted glare. If the lightshelves are located close to perpendicular interior walls and are not deep enough to eliminate this problem (which is the typical case), vertical blinds can provide an excellent option. By using vertical blinds for the window section above the lightshelf, the light can be directed toward the walls, thus eliminating glare and enhancing the bouncing of light deep into the space. White blinds are preferred to increase reflectance. If the lightshelf windows are located near the middle of the space and farther away from perpendicular walls, horizontal blinds (flat or curved but turned upside-down) would allow the light to be reflected up toward the ceiling and deep into the space.

- Control the windows located above and below the lightshelves independently. On the south facade, daylighting can be enhanced by:

- incorporating vertical blinds that can focus radiation to the perimeter walls within a space and away from people within the space

- using horizontal blinds that can be installed to reflect the light up toward the ceiling, thus reflecting it back farther into the space.

- Don't use lightshelves on northern exposures. They are not cost-effective or necessary. However, it is still advisable to use clear double glass or clear double glass with argon (if possible) on high non-view windows on the north.

- When calculating daylighting contribution, don't consider the low north and south windows (view glass) in your calculation, as these windows are often closed or covered.

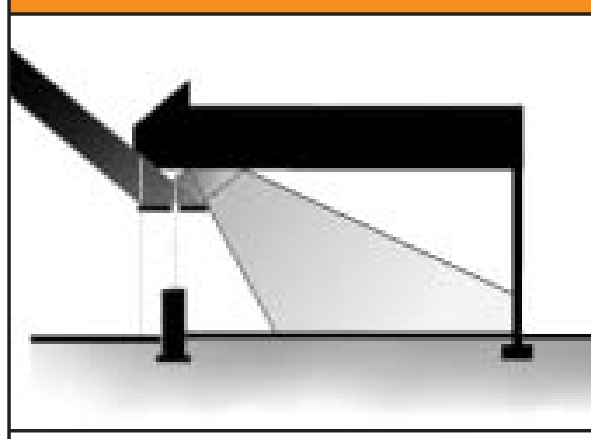

Using lightshelves on south-facing windows allows natural light to bounce deep into the room.

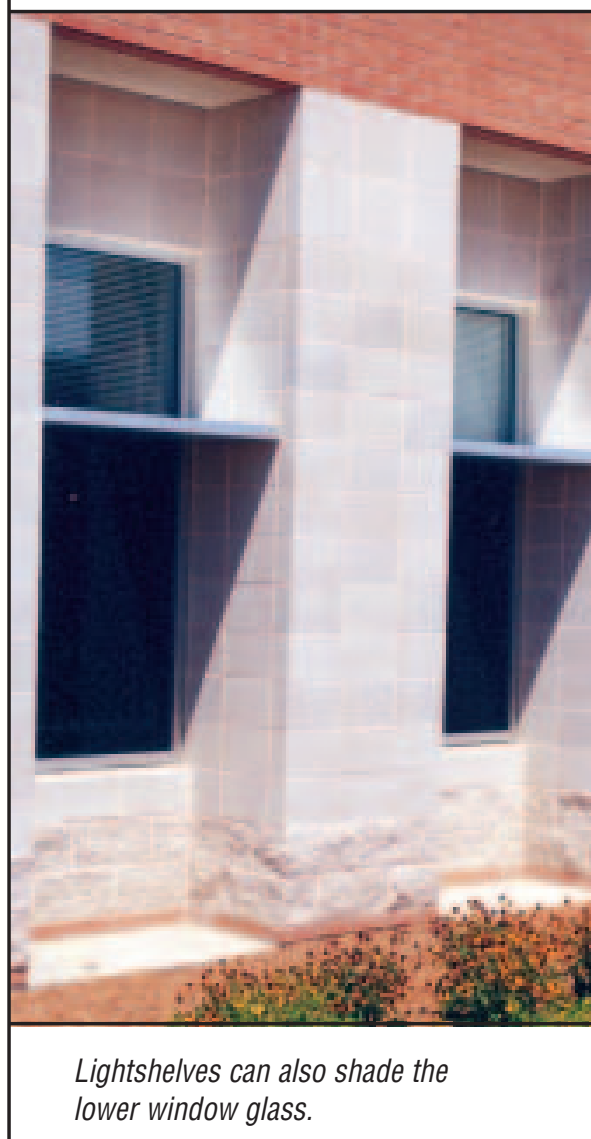




\section{Lighting Controls}

Lighting controls can ensure that students and teachers always have adequate light and that energy efficiency is maintained.

- Enhance the economic benefits and provide for smoother transition between varying light conditions by using multi-staged or dimmable lighting controls. The success of these controls relies on:

- having the sensors mounted in a location that closely simulates the light level (or can be set by being proportional to the light level) at the work plane

- implementing a fixture layout and control wiring plan that complements the daylighting strategy

- providing means to override daylighting controls in spaces that are intentionally darkened to use overhead projectors or slides.

\section{Interior Finishes}

The color of interior finishes will have a dramatic impact on the lighting requirements within each space.

- Use white (or very light-colored) paint inside the lightwell area. Colors inside the room can be slightly darker, but the lighter colors will help the light to reflect deeper into the space. Accent colors (with the majority still white) and beige colors are acceptable inside typical rooms. The tables included within the "Energy-Efficient Building Shell" section of this document provide additional information on the recommended reflectance ranges for different interior finishes.

- Apply carpet or other floor coverings that are as light as is practical for maintenance. This will greatly enhance reflectance and require less glazing to produce the same light levels. If the floor finish is dark, more glass is required to effectively daylight the space.

- If there are television monitors, computers, or whiteboards in the classrooms, locate them so as to minimize glare.

- Enhance the daylighting by placing south-facing windows with lightshelves close to perpendicular interior north-south walls. The color of the walls immediately inside the window should be light to enhance this reflectance. See page 22 for reflectance values of interior paint and wood.

\section{Skylights}

Consider skylights if they can be specifically designed to avoid overheating during the warmer months and perform well with minimum maintenance.

- If skylights are used, specify those that incorporate:

- motorized, louvered systems that seasonally and hourly adjust to allow the optimum amount of radiation to enter the glazing

- a means to reduce glare and diffuse the radiation once inside the space. 


\section{Windows}

Windows will have a significant impact on energy consumption. The characteristics of the windows and their location, design, and purpose will determine, to a great degree, the level of energy efficiency the school achieves.

\section{Appropriate Choice}

In all cases, windows should be made of high-quality construction, incorporate thermal breaks, and include the appropriate glazing for the particular application. Windows should be designed to meet the overall objective and not be oversized. To determine the optimum glazing for each application, the designer should conduct computer simulations that compare options. The US Department of Energy's DOE-2 program is one of the better analytical tools available for this purpose. More information on the DOE-2 program can be found in the resource section at the end of this document.

- Analyze and select the right glazing for each orientation, location, and purpose. For example, if windows are:

- oriented east and west and not externally shaded, the best choice is to use a tinted glazing with low-e or low-e with argon

- well-shaded by building elements (e.g., overhangs) or north-facing, tinting would not be advised since it restricts the transmission of diffuse radiation

- located close to the floor, comfort becomes a more critical issue, and low-e or low-e windows with argon glazing is appropriate

- designed as daylighting components above lightshelves or in roof monitors, the best option is typically clear double glazing or clear double glazing with argon.

Window Selection Considerations

\begin{tabular}{|l|c|c|}
\hline \multicolumn{1}{|c|}{ Application } & Exposure & \multicolumn{1}{c|}{ Type } \\
\hline \multirow{3}{*}{$\begin{array}{l}\text { View Glass } \\
\text { (Non-Daylighting Apertures) }\end{array}$} & South & Clear Double, Low-e with Argon \\
\cline { 2 - 3 } & North & Clear Double, Low-e with Argon \\
\cline { 2 - 3 } & East/West, Unshaded & Tinted Double, Low-e with Argon \\
\cline { 2 - 3 } & East/West, Shaded & Clear Double, Low-e with Argon \\
\hline Windows Above Lightshelves & South & Clear Double or Clear Double with Argon \\
\hline High Windows Above View Glass & North & Clear Double or Clear Double with Argon \\
\hline Roof Monitors & South & Clear Double or Clear Double with Argon \\
\hline
\end{tabular}

The intended application and exposure determines appropriate window selection.

\begin{tabular}{|l|c|c|}
\multicolumn{3}{|c|}{$\begin{array}{c}\text { Solar Transmission Values for } \\
\text { Typical Glass Types }\end{array}$} \\
\hline $\begin{array}{l}\text { Glazing } \\
\text { Type }\end{array}$ & $\begin{array}{c}\text { Solar } \\
\text { Transmission }\end{array}$ & $\begin{array}{c}\text { Equivalent } \\
\text { U-Value }\end{array}$ \\
\hline $\begin{array}{l}\text { Clear, } \\
\text { Single }\end{array}$ & $75 \%-89 \%$ & 1.11 \\
\hline $\begin{array}{l}\text { Clear, } \\
\text { Double }\end{array}$ & $68 \%-75 \%$ & 0.49 \\
\hline $\begin{array}{l}\text { Low-e, } \\
\text { Double, } \\
\text { Clear }\end{array}$ & $45 \%-55 \%$ & 0.38 \\
\hline $\begin{array}{l}\text { Low-e, } \\
\text { Tinted, } \\
\text { Gray }\end{array}$ & $30 \%-45 \%$ & 0.38 \\
\hline $\begin{array}{l}\text { Low-e, } \\
\text { Argon }\end{array}$ & $45 \%-55 \%$ & 0.3 \\
\hline
\end{tabular}

Considering the transmission values of glass by orientation can greatly reduce cooling loads.

Typically, low-e glass is not recommended because the glass, as well as the complementary components of the daylighting system (e.g., lightshelves, baffles, roof monitors, etc.), all have to increase to account for the reduced transmissions. 


\section{Light Transmission Values}

0.9
$0.5-0.9$
$0.4-0.8$
$0.4-0.8$
0.7
0.6
0.5
0.4
0.2
0.2

Standard Double Glazing

Internal Venetian Blinds - Drawn

Internal Curtains - Drawn

Internal Roller Blinds — Drawn

Heat-Absorbing Glass

Tree Providing Light Shade

Internal Blind - Reflective Backing

Solar Control Glass

External Blinds - Drawn

External Shutters - Closed

Transmission of light is greatly impacted by the type of window treatments used.
- Select spectrally selective, low solar gain, low-e glazing for non-daylighting apertures.

- Consider the possibilities of implementing natural ventilation strategies that use operable windows.

\section{Exterior Window Treatments}

The most efficient means of appropriately restricting unwanted solar gain from entering glass areas is to block the radiation before it gets to the glazing.

- Properly size fixed overhangs on south-facing roof monitors and lightshelf glazing to block a large portion of the midday summer sun while still allowing the lower winter sun to reach the glass.

- Incorporate overhangs or other design elements above east- and west-facing glazing so that they effectively block the morning and afternoon sun.

- Consider the advantages of using seasonally adjustable or stationary awnings, solar screens, shutters, or vertical louvers when fixed overhangs are not possible or are impractical.
Clear glass for south-facing roof monitors and low-e glass for view windows are two daylighting and energy-efficient features.

\section{Interior Window Treatments}

If exterior window treatments cannot effectively control the seasonal and daily variations in radiation (and resulting glare), or if it is desirable to be able to darken the particular space, blinds or shades provide better control.

If blinds or rolling type dark-out shades are employed, install types that are either motorized or easily accessible and made of durable construction materials and components. 


\section{Energy-Efficient Building Shell}

Because the building shell is typically responsible for $10 \%-20 \%$ of the total energy consumed in a school, focusing on this area of design can help you reduce energy consumption in your school buildings. Increased insulation in the walls and ceiling helps to reduce heat loss and gain and improve comfort. Light-colored exterior walls and white roofs help to reduce cooling loads. These factors also contribute to reducing the size and cost of the HVAC system you will need. The useful life of building materials, systems, and equipment incorporated in schools can vary considerably, so the building shell decisions you make as a designer will impact the first cost of the school as well as the long-term costs associated with operation, maintenance, and replacement.

Wall insulation should be selected based on the likelihood that it will never be replaced. When selecting your wall and roof systems, it is critical that you choose what is best for the life of the facility. Specify interior and exterior finishes that are durable and as maintenance free as possible, and integrate insulation levels that are appropriate for the life of the facility. Also, incorporate durable strategies that address air infiltration.

If specified correctly, energy-efficient building shell elements can be effective in reducing our impact on the environment, and they will never need to be replaced.

High-mass exterior walls, lightcolored roof finishes, and window treatments including lightshelves and low-e glazing for view windows are among the energy-efficient building shell elements. 


\section{Design Guidelines for an Energy-Efficient Building Shell}

\section{Massive Wall Construction}

In cool and dry climates, high-mass construction can be used to provide both heating and cooling benefits. In the winter, internally exposed mass can be used to store passive solar gain. In the warmer months, it can be employed to moderate the heat gain experienced during the hot days, delaying the impact until the nighttime when ventilation strategies could cool the interior spaces. If adequate mass is incorporated, this strategy is particularly effective since schools are typically not occupied during evening hours.

- By incorporating masonry wall systems that are designed so that the mass is inside the insulation and exposed, the mass can be utilized to store thermal energy from passive heating strategies incorporated in the school.

- Employing high-mass wall construction techniques to lag the heat gains using 16-inch brick-block and block-block cavity walls with rigid cavity insulation can delay thermal gains by up to 12 hours.

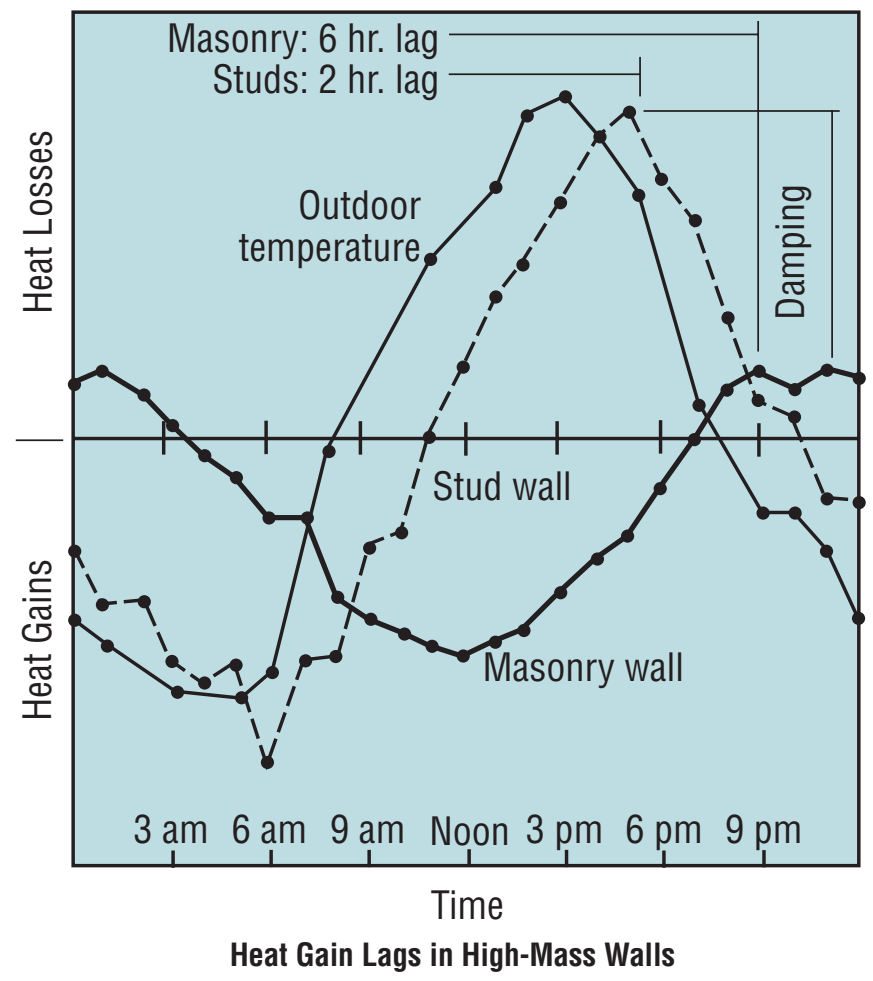

Using high-mass wall construction techniques can delay thermal gains by up to 12 hours. 
- Newer wall systems using insulated concrete forms or tilt-up insulated concrete panels have also proved effective.

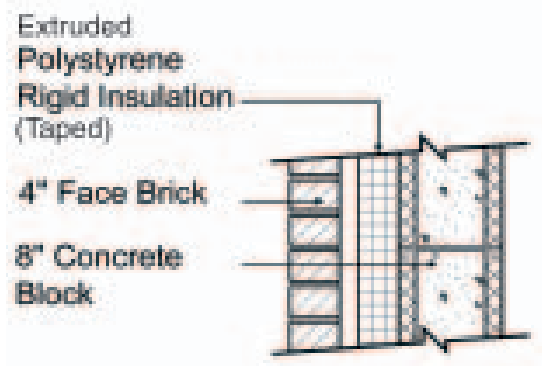

Brick Masonry Wall

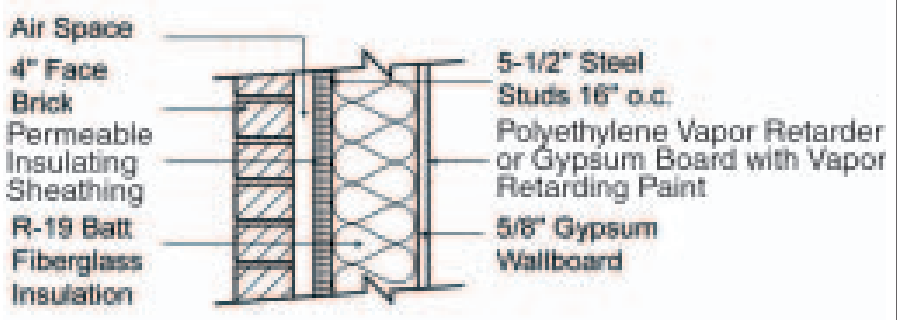

Brick Veneer Wall

High-Mass Wall Sections

By incorporating high-mass construction, cooling loads can be reduced and air conditioning equipment can be downsized.

\section{Moisture and Infiltration Strategies}

Controlling air flow and moisture penetration are critical elements in reducing energy consumption, maintaining structural integrity, and ensuring a healthy indoor environment.

- Because designers in cool and dry climates need to primarily address a heating load, vapor barriers should be placed on the inside of the wall assembly's insulation, allowing moisture to move outward.

- Permeable exterior sheathing materials will keep moisture from being trapped in the wall.

- Since air leakage can carry significant amounts of moisture into the building envelope, caulk and seal any building shell penetrations.

\section{Insulation Strategies}

Energy-efficient building design starts with implementing optimum insulation levels. Evaluating the cost-effectiveness of varying insulation R-values allows you to maximize long-term benefits.

- When selecting insulation levels, refer to ASHRAE Standard 90.1. R-values required by local building codes should be considered a minimum.

- When determining the choice of insulation, you should consider not only energy efficiency and initial cost but also long-term performance. Carefully research insulation products for stability of R-value over time, and make comparisons based on the average performance over the service life. 
Light-colored finishes will significantly reduce lighting demands within interior spaces.

\section{Interior Finishes}

By properly selecting interior finishes, lighting energy demands can be reduced and visual comfort can be improved for no additional cost.

- Select light colors for interior walls and ceilings to increase light reflectance and reduce lighting and daylighting requirements.

- Consider the color and finish of interior walls and ceilings. When placed incorrectly, light-colored, glossy finishes can create glare problems that negatively impact visual comfort.

Reflectance Table: Paints

\begin{tabular}{|lc|}
\hline Color & Reflectance \\
\hline Semi-Gloss White & $70 \%$ \\
Light Green* & $53 \%$ \\
Kelly Green* & $49 \%$ \\
Medium Blue* & $49 \%$ \\
Medium Yellow* $^{*}$ Medium Orange* & $47 \%$ \\
Medium Green* & $42 \%$ \\
Medium Red* & $41 \%$ \\
Medium Brown* & $20 \%$ \\
Dark Blue-Gray* & $16 \%$ \\
Dark Brown* & $16 \%$ \\
\hline
\end{tabular}

* These values are estimated for flat paints. For gloss paints, add 5\%-10\%. Source: SBIC, Passive Solar Design Strategies Careful consideration of interior finishes based on reflectance values can reduce lighting demands.

\begin{tabular}{|lc|}
\hline Type & Reflectance \\
\hline Maple & $54 \%$ \\
Poplar & $52 \%$ \\
White Pine & $51 \%$ \\
Red Pine & $49 \%$ \\
Oregon Pine & $38 \%$ \\
Birch & $35 \%$ \\
Beech & $26 \%$ \\
Oak & $23 \%$ \\
Cherry & $20 \%$ \\
\hline
\end{tabular}




\section{Energy-Efficient}

\section{Stopping Radiant Heat Gains}

In cool and dry climates, creating a building shell that is massive and well-insulated can effectively address conduction gains and losses, but it is critical to also take into account radiant solar gains. In the warmer months, up to $90 \%$ of the cooling load coming from the roof area can be attributed to radiant heat gain. By addressing this problem, you can decrease your cooling load significantly.

- Incorporate radiant barriers in the roof assemblies to reduce up to $95 \%$ of radiant heat gain. When solar radiation strikes a roof, a certain percentage of radiation is reflected away, and the balance is absorbed. When this occurs, it heats up that material, and the material reradiates downward. The low-emissivity properties of the aluminum in the radiant barrier stop this radiant process, allowing only $5 \%$ of the radiation to pass through. Radiant barriers that have coatings to protect against oxidation help ensure long-term performance. These types of radiant barriers are superior to reflective roofing strategies that tend to lose their reflective qualities over time. Dust accumulation on radiant barriers reduces their performance. When possible, they should be suspended from the joists or rafters to reduce dust accumulation.

- To reflect solar gain away before it can create negative radiant impacts within the spaces below, incorporate highly reflective roofing systems. This strategy is important, particularly in areas where radiant barriers cannot practically be installed.

- Select a light color for the exterior finish to reflect solar radiation.

- Shade exterior walls with architectural elements (or landscaping) to enhance performance.

Reflectance Values for Exterior Surfaces

\begin{tabular}{|c|c|c|c|}
\hline & & $\%$ Reflected & $\%$ Absorbed \\
\hline \multicolumn{4}{|l|}{ Roofing Material (1) } \\
\hline \multirow[t]{3}{*}{ Single-Ply Roof Membrane } & Black EPDM & $6 \%$ & $94 \%$ \\
\hline & Gray EPDM & $23 \%$ & $77 \%$ \\
\hline & White EPDM & $69 \%$ & $31 \%$ \\
\hline \multirow[t]{5}{*}{ Asphalt Shingles } & Black & $5 \%$ & $95 \%$ \\
\hline & Medium Brown & $12 \%$ & $88 \%$ \\
\hline & Green & $19 \%$ & $81 \%$ \\
\hline & Gray & $22 \%$ & $78 \%$ \\
\hline & White & $25 \%$ & $75 \%$ \\
\hline \multirow[t]{2}{*}{ Metal Roof } & Aluminum & $61 \%$ & $39 \%$ \\
\hline & Metal White & $67 \%$ & $33 \%$ \\
\hline \multicolumn{4}{|l|}{ Exterior Wall Material (2) } \\
\hline \multirow[t]{3}{*}{ Brick } & Light Buff & $45 \%$ & $55 \%$ \\
\hline & Dark Buff & $40 \%$ & $60 \%$ \\
\hline & Dark Red & $30 \%$ & $70 \%$ \\
\hline \multirow[t]{3}{*}{ Concrete } & Light & $55 \%$ & $45 \%$ \\
\hline & Medium & $20 \%$ & $80 \%$ \\
\hline & Dark & $15 \%$ & $85 \%$ \\
\hline
\end{tabular}

(1) Source: Berdahl 2000. "Cool Roofing Material Database," LBNL

(2) Source: 1981 IES Lighting Handbook

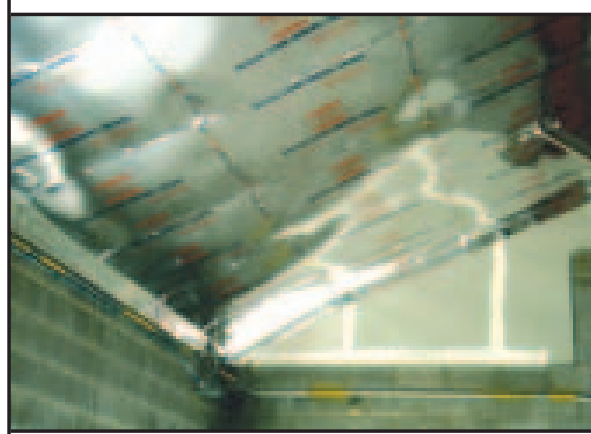

Radiant heat gain can be responsible for $90 \%$ of the heat entering through the roof. The use of a radiant barrier can block up to $95 \%$ of this gain.

This chart indicates the reflectance of various typical roofing materials when first installed. Materials that maintain their reflective characteristics should be preferred.

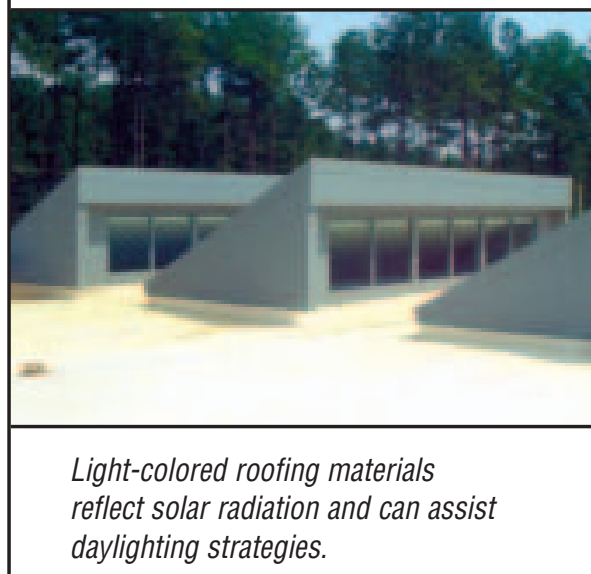




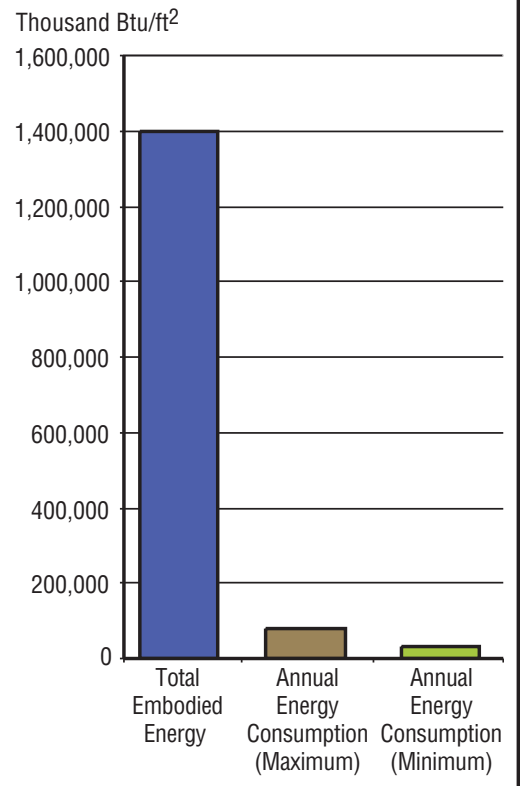

Total Embodied Energy per Square Foot for Educational Buildings

The embodied energy of a school building exceeds the annual energy consumption of the school.

\section{Embodied Energy}

When selecting the building materials, consider that, in many cases, the amount of energy embodied in constructing the school is equal to more than two decades of a school's energy consumption. To seriously address the overall impacts of energy consumption, consider the energy involved in making each product, transporting the product to the site, and implementing the component into the school.

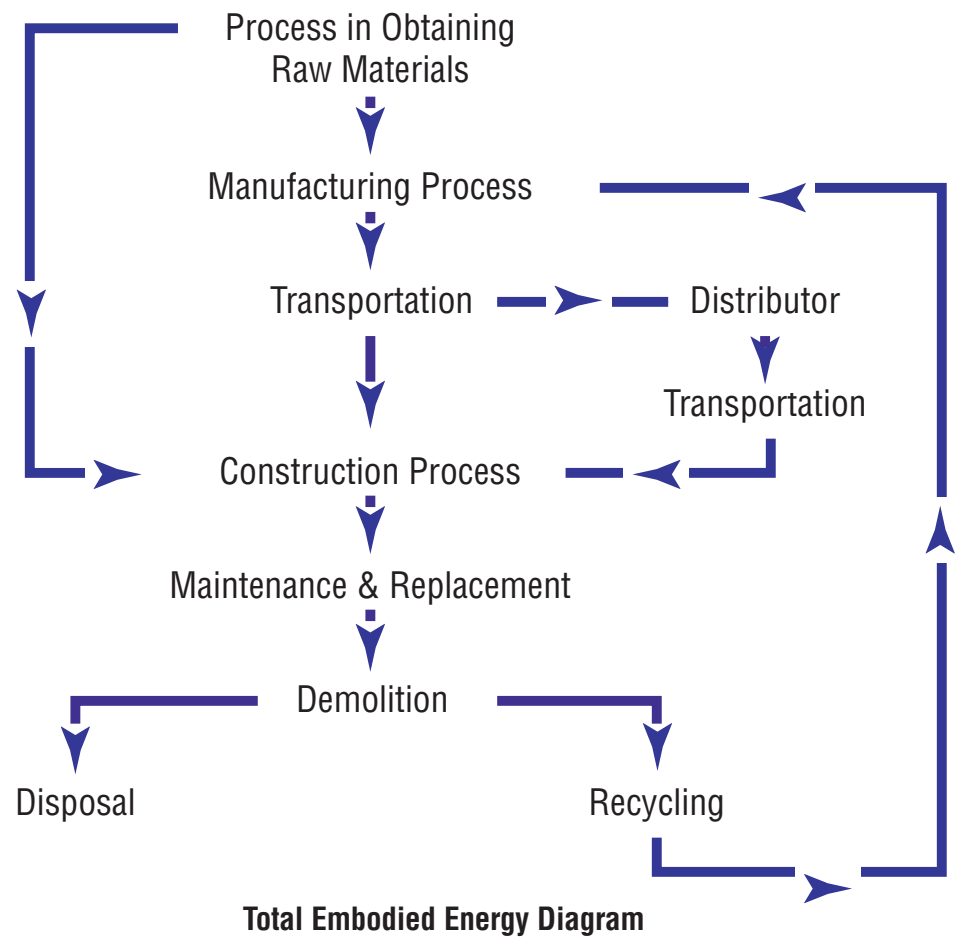

Products, materials, equipment, and processes incorporated into construction

- Because often half or more of the embodied energy involved in constructing a school is related to transportation, select locally made products and construction materials.

- Consider the energy intensity of the manufacturing process involved in making materials and products incorporated in the school.

- Encourage the use of recycled products.

- Evaluate the recyclability of products once the building has passed its useful life.

- If existing structures on the school site are to be demolished, consider how the typically wasted materials could be used in the new construction. 


\section{Lighting and Electrical Systems}

The design of your school's lighting system has direct bearing on the performance of your students and teachers. The ability to read comfortably and perform visual tasks is strongly impacted by the type and quality of the lighting systems implemented. Lighting strategies that reduce glare while still producing the required lumen levels are essential components of a high performance school.

Lighting represents $25 \%-40 \%$ of a typical school's energy costs. An energy-efficient lighting system can save thousands of dollars annually in just one school because improving the efficiency of the overall lighting system reduces the energy requirements for both lighting and air conditioning. Controls in daylit spaces can automatically reduce or increase light levels as needed, and occupancy sensors can automatically turn off lights in unoccupied spaces.

Your design team can create an energy-efficient, high-quality lighting system by following three strategies. First, select efficient lamps, ballasts, lenses, and fixtures that address the needs of each space and achieve the highest output of lumens per input of energy. Second, provide occupancy sensors, time clocks, and other controls that limit the time the lights are on to only hours when the space is occupied and the light is needed. And third, provide automated daylighting controls that dim the electrical lighting when sufficient natural light is present.

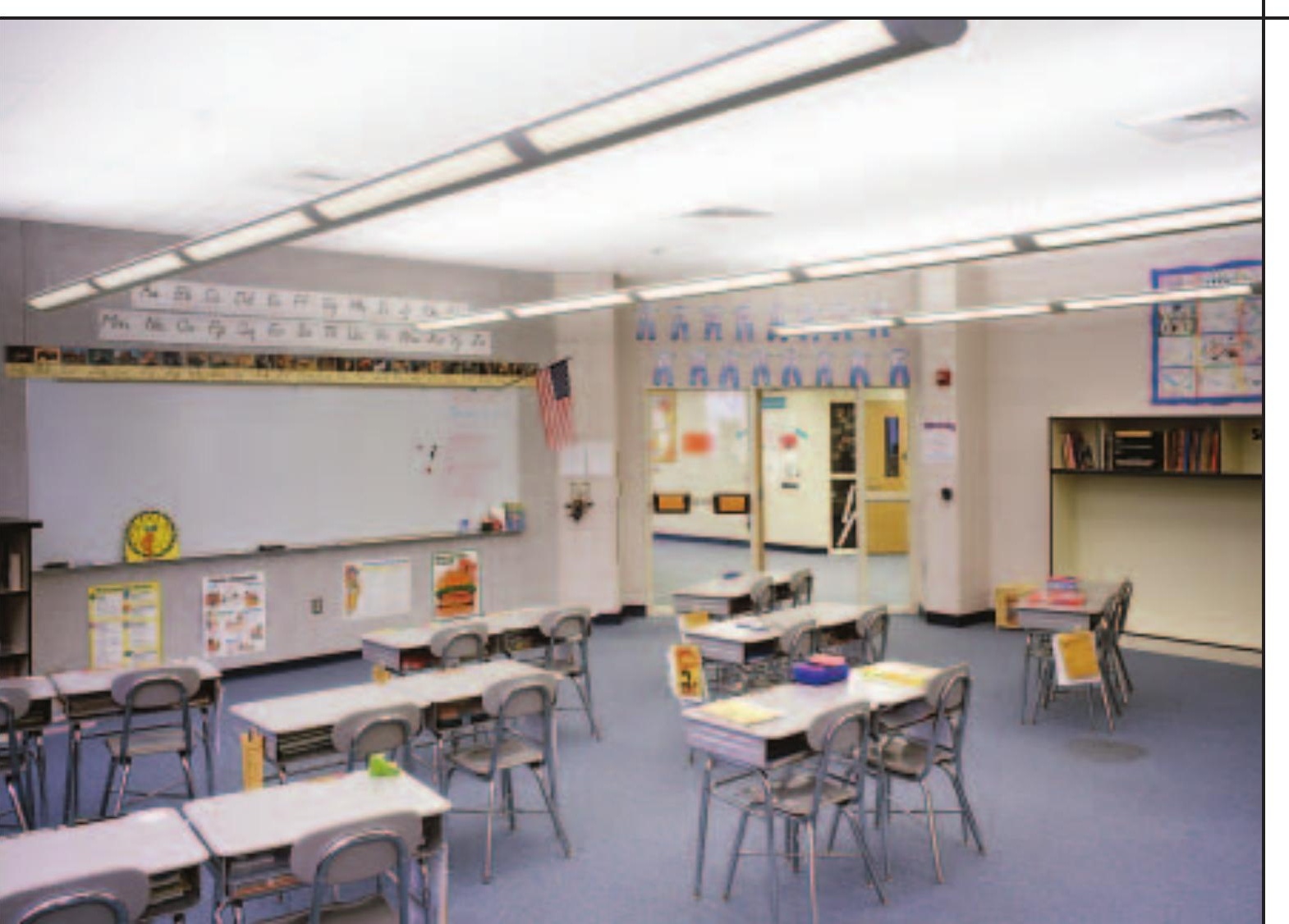

Photo: NREL/PIX03045

Indirect lighting can provide excellent uniform artificial lighting in a classroom, eliminating glare and contrast between bright and dark areas. 


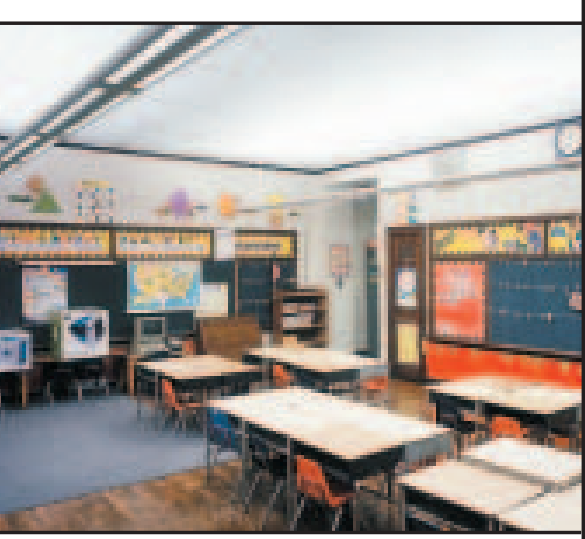

Photo: NREL/PIX03047

Indirect lighting systems provide high-quality artificial lighting in classrooms.

\section{Design Guidelines for Lighting and Electrical Systems}

\section{Lighting Strategies}

In naturally lit spaces, the artificial lighting design should be compatible with the objectives of the daylighting. In non-daylit spaces, the objective should be to implement the most energy-efficient system possible that minimizes glare while providing the proper level and quality of light.

- Maximize the illumination by considering the geometry and reflectances of finishes in each space.

- Implement indirect lighting strategies as a means to complement daylighting.

- Select fixtures that are designed to minimize glare, particularly in rooms with computers.

- Verify the lighting requirements for each space function.

- Consider the option of providing low-level ambient lighting supplemented by task lighting.

- Prefer photovoltaic lighting systems for remote exterior applications such as parking areas or walkways. It is often more cost effective to use a localized photovoltaic system with its own battery storage than to provide underground electrical service.

- In non-daylit spaces, incorporate lamps with high color rendering.

- Design switching circuits to allow spaces that are not commonly used to be switched off.

\section{High-Efficacy Lamps}

Efficacy is an important measure for energy efficiency in light output per unit of energy used. High-efficacy lamps can provide the same illumination and color rendition as standard lamps but at two to six times the efficiency.
High-efficacy lamps produce a high light output per unit of electric input.

\section{Comparison of Lamp Efficencies}

Standard Incandescent Tungsten Halogen Halogen Infrared-Reflecting Mercury Vapor

Compact Fluorescent (5-26 W) Compact Fluorescent (27-40 W)

Full Size \& U-Tube Fluorescent Metal Halide Compact Metal Halide High Pressure Sodium White Sodium
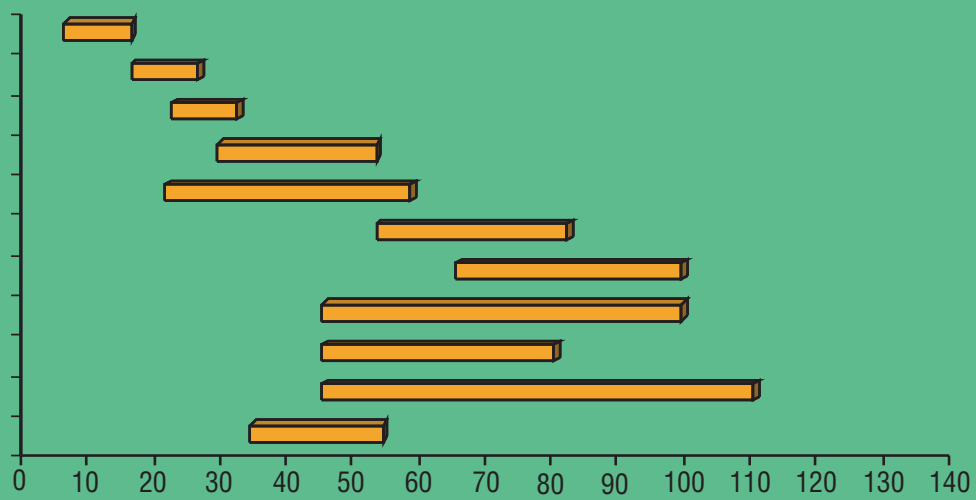

Lamp Plus Ballast Lumens/Watt 
- Minimize the use of incandescent fixtures.

- When selecting lamps, consider the maintenance and lamp replacement costs.

- Select the lamps with the highest lumens of output per watt of input that address the specific need.

Fluorescent Lamp Technologies - Efficacy Comparisons

\begin{tabular}{|l|c|c|c|c|c|l|}
\hline Lamp Type & $\begin{array}{c}\text { Lamp } \\
\text { Life } \\
\text { (hours) }\end{array}$ & $\begin{array}{c}\text { Lumen/ } \\
\text { Watt }\end{array}$ & C.R.I.* & $\begin{array}{c}\text { Lumen } \\
\text { Maint.** }\end{array}$ & $\begin{array}{l}\text { Ballast } \\
\text { Factor }\end{array}$ & Description and Comments \\
\hline $\begin{array}{l}\text { T-5 Fluorescent } \\
\text { (28 W/4 Ft) }\end{array}$ & 20,000 & 104 & 85 & 0.95 & 1 & $\begin{array}{l}5 / 8 \text { " dia. tube, high lamp and } \\
\text { ballast efficiency, high CRI, } \\
\text { similar output to T-8 with a 12\% } \\
\text { reduction in power usage }\end{array}$ \\
\hline $\begin{array}{l}\text { T-5 H0 Fluorescent } \\
\text { (54 W/4 Ft) }\end{array}$ & 20,000 & 93 & 85 & 0.95 & 1 & $\begin{array}{l}5 / 8 \text { " dia. tube, high lumen output, } \\
\text { high CRI, 88\% higher lumens than } \\
\text { standard 4 ft T-8 }\end{array}$ \\
\hline $\begin{array}{l}\text { T-8 Fluorescent } \\
\text { (32 W/4 Ft) }\end{array}$ & 20,000 & 92 & 82 & 0.92 & 0.9 & $\begin{array}{l}\text { 1" dia., standard for efficient } \\
\text { fluorescent lamps, 23\% efficiency } \\
\text { improvement over T-12 }\end{array}$ \\
\hline $\begin{array}{l}\text { T-12 Fluorescent } \\
\text { (34 W/4 Ft) }\end{array}$ & 20,000 & 69 & 72 & 0.89 & 0.88 & $\begin{array}{l}1 \text { 1/2" dia. tube, still being used } \\
\text { where efficiency is not being } \\
\text { considered }\end{array}$ \\
\hline
\end{tabular}

Developed by Padia Consulting from manufacturers' literature (Philips, Osram Sylvania, General Electric)

* Color Rendering Index

** The lumen maintenance percentage of a lamp is based on measured light output at $40 \%$ of that lamp's rated average life. For T-5, after 8,000 hours of lifetime, the lumens/watt will be 98.8 lumen/watt (104x0.95).

Fluorescent lamp selection should be based on the illumination needs of the area and lamp replacement frequency and cost.

\section{Compact Fluorescent Lamps}

- Consider compact fluorescent lamps that are energy-efficient and long-lasting. A 13-watt compact fluorescent lamp (about 15 watts with an electric ballast) provides the same illumination as a 60 -watt incandescent lamp and lasts up to 10 times longer. Additionally, they have excellent color rendering.

- In larger daylit spaces like gymnasiums, provide ganged compact fluorescents as a practical means of addressing the need to implement dimmable lamps.

- Select fixtures with effective reflector design.

\section{Fluorescent Lamps}

- Choose the smaller diameter T-8 and T-5 fluorescent tubes over the traditional T-12s because they have a higher efficacy. The T- 8 system produces 92 lumens per watt as compared with 69 lumens per watt for the T-12 system. The T-5 system produces $33 \%$ more lumens per watt than the T-12 system.

- Specify fixtures that are designed to enhance the efficacy of the T-8 and T-5 lamps by incorporating better optics in the luminaire design. 


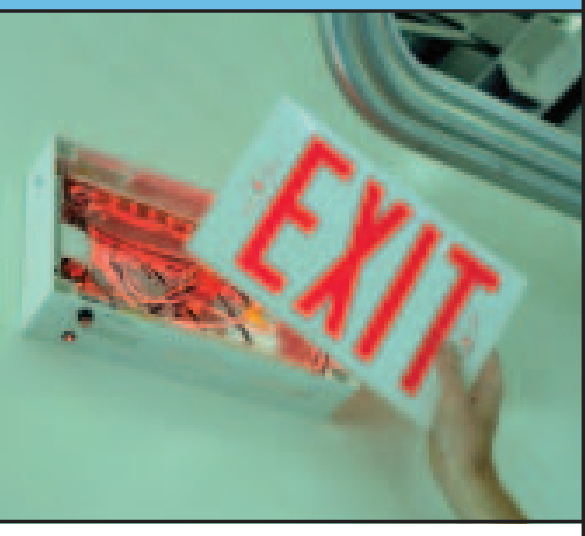

Photo: NREL/PIX07071

LED exit signs last 10-50 times longer than fluorescent and use less energy.

\section{Metal Halide and High-Pressure Sodium Lamps}

- Consider metal halide and high-pressure sodium lamps for exterior lighting applications.

- Use metal halide and high-pressure sodium lamps only in areas where the long warm up and restrike time after a power outage will not affect the safety of students, visitors, and staff.

\section{LED Exit Lights}

- Select light-emitting diode (LED) exit lights. Exit signs operate 24 hours a day, 365 days a year. LED exit signs offer energy savings between 80 kilowatthours/year and 330 kilowatt-hours/year per fixture with little maintenance. LED exit lights have a projected life ranging from 700,000 hours to more than 5 million hours, and the standby battery requires replacement about every 80,000 hours. Typical fluorescent lamps will last only 15,000 hours.

\section{High-Efficiency Reflectors}

High-efficiency fixtures employ two main strategies to minimize the blockage or trapping of light within the fixture housing: high-efficiency lensed troffers and fixtures with parabolic reflectors.

- Incorporate well-designed troffers that use the shape and finish of the inner housing to minimize inter-reflections and maximize the lumens per watt. A highefficiency troffer with two or three lamps can produce the same illumination as a standard four-lamp fixture.

- Select fixtures with parabolic reflectors as an alternative means to improve the optics and increase the performance of the light fixtures.

\section{Ballasts}

Solid state electronic ballasts are available in both rapid-start and instant-start models. The instant-start ballasts have a very high efficiency but should be avoided in applications where sensors are used. Electronic ballasts are identical in shape, size, and external wiring to magnetic ballasts, but electronic ballasts can operate up to four lamps each.

While selecting a dimmable ballast, take into consideration the fact that magnetic ballasts will only dim to about $40 \%$ of full power before the flicker becomes problematic, whereas electronic ballasts may be dimmed to near zero output with no perceptible flicker. Electronic ballasts also have a higher lumen output at reduced power levels than magnetic ballasts.

- Select high-efficiency electronic ballasts because they save energy, have a low propensity to attract dust, incorporate a minimum of hazardous materials, and operate at a cooler temperature.

- Select electronic ballasts because they minimize the characteristic humming from fluorescent lamps. 
- Consider that conventional ballasts cycle at 60 hertz and create a perceptible flicker, whereas electronic ballasts cycle faster, reducing eye strain.

- In areas where daylighting strategies are being implemented, employ electronic ballasts designed specifically for dimming and controlled by photosensors.

\section{Lumen Maintenance}

The output of a fluorescent lamp decreases over its rated life. The strategy used for maintained light level calculations is the initial light output of the luminaires multiplied by factors for lamp depreciation, luminaire depreciation, and room surface dirt depreciation. This will drop the calculated output by $25 \%-30 \%$ or even more.

The better strategy is to measure the light output at the work surface using a light sensor in an "open loop" control. This will save power initially, extend the life of the lamps, and compensate for dirt on luminaires and room surfaces. It is important to establish a program of group lamp replacement. This will ensure that overall lighting levels are even, and maintenance labor costs are reduced by $88 \%$ over "spot" replacement.

\section{Lighting Controls}

Because of changing use patterns in schools, occupancy sensors and photosensors can save considerable energy by simply turning off the lights when not needed. There are two commonly used occupancy sensors: infrared and ultrasonic. Infrared sensors detect occupants by sensing changes in heat as occupants move, while ultrasonic sensors detect movement of solid objects. Sensors that combine both technologies are available. It is also important to implement photosensor controls for outdoor lights to ensure that the lights are only on at night.

- Incorporate infrared, ultrasonic, or a combination of infrared and ultrasonic motion detectors in all major spaces to turn off the lights when the space is not occupied.

- In daylit spaces, incorporate staged or dimmable (preferred) lighting controls tied to photocells located within each space and capable of reading light levels at the work surface.

- Incorporate override switches for automatic daylight dimming controls only where the need to manually control lighting levels is necessary to the function of the space.

- Provide photocells on outdoor lights to ensure that they are off during daytime hours.

\section{Electrical Systems}

An inefficient electrical distribution system in a school can result in degraded power quality, the introduction of wasteful harmonics, and line losses up to $3 \%$ or $4 \%$.

- Evaluate the merits of a high-voltage distribution system, taking into consideration the initial cost and operational savings due to reduced line losses. Analyze the costs of delivering power at 208/120 volts versus $480 / 277$ volts.

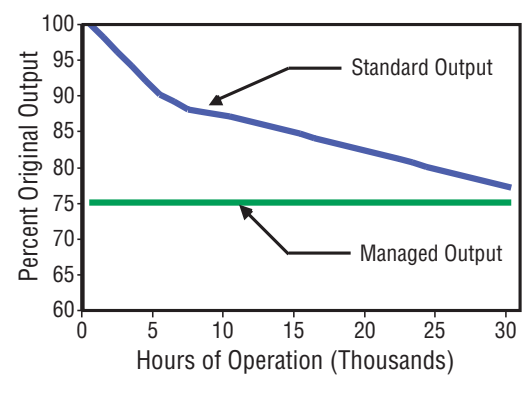

Chart: Padia Consulting

Typical Degradation of Fluorescent Lamp Output Over Time

Lamp output degradation should be managed to maintain constant lighting levels.
Daylight sensors combined with occupancy sensors are used as an energy-saving measure to turn the lights off if the natural light level is sufficient or if the space is unoccupied. 


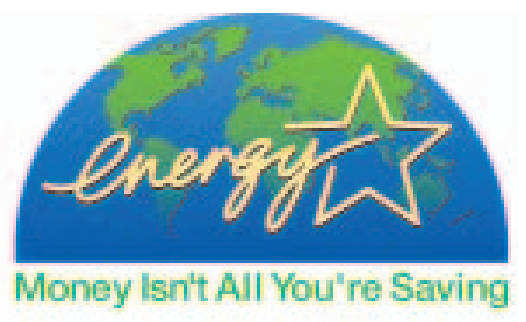

ESTABLISH ENERGY PERFORMANCE GOALS

For new school design (K-12), the US EPA recommends setting a design target and monitoring progress throughout the design process.

The ENERGY STAR label can be used to identify energy-efficient office equipment, exit signs, water coolers, and other products. By choosing these products, your school can save energy and money.
- Correctly size the transformers to fit the load, keep losses to a minimum, and optimize transformer efficiency. The correct sizing of a transformer depends on the economic value and size of load losses versus no-load losses, and consideration of expected transformer life.

- Consider more efficient transformers that operate at lower temperatures. Most transformers range in efficiency between $93 \%$ and $98 \%$. Transformer efficiency is improved by reducing the losses in the transformer. Transformer efficiency standards exist in some states, and efficient transformers are required by code in others. Check with your state energy office for more information.

- Consider using K-rated transformers to serve non-linear equipment. $\mathrm{K}$ factor is a constant developed to take into account the effect of harmonics on transformer loading and losses. A K-rated transformer may initially cost more, and may be less efficient, but it should result in a longer transformer life.

- Evaluate the distribution system to determine if power factor correction is justified. Utilities usually charge users for operating at power factors below a specified level. In addition to causing unnecessary line losses, low power factors create the need for a larger energy source. If power factor correction is necessary, a common method is to place power-factor-corrective capacitors or three-phase synchronous capacitors (motors) in the system, close to the load.

- In some situations, disconnecting the primary side of transformers not serving active loads can save energy. Disconnecting the primary side of transformers is safe provided that critical equipment such as fire alarms and heating control circuits are not affected.

- Where possible, minimize long runs of wire from power distribution panels to electrical equipment. Where equipment would be likely to operate at a low voltage due to distance from the distribution panel, install larger wire to reduce voltage drop.

Because appliances, motors, fans, and other electrical equipment are responsible for a high percentage of building electrical consumption, it is important to select equipment that is properly sized, energy-efficient, and environmentally sound.

- Don't oversize the equipment. It will add to the peak electrical loads, and oversized equipment often does not operate as well at part-load conditions.

- Use high-efficiency motors and, where appropriate, variable frequency drives. Compare motors using No. 112, Method B, developed by the Institute of Electrical and Electronic Engineers (IEEE).

- Select fans and pumps for the highest operating efficiency at the predominant operating conditions.

- Set temperatures on water heaters based on use requirements.

- Use timers to limit the duty cycle of heaters when they are not in full use.

- Select energy-efficient food-service appliances.

- Specify Energy Star-rated appliances. 


\section{Mechanical and Ventilation Systems}

In cool and dry climates, heating, ventilation, and air conditioning (HVAC) systems are typically responsible for 50\%-60\% of the energy consumed in schools. By using the "whole-building" approach - looking at how all the building's design elements work together - your design team can factor in energy-saving choices that reduce heating and cooling loads and downsize the HVAC system needed. By not overdesigning the HVAC system, you can reduce initial equipment costs as well as longterm operating costs.

More importantly, HVAC systems have a significant effect on the health, comfort, productivity, and academic performance of students and teachers. A study by the US General Accounting Office found that half of the more than 90,000 public schools in the country are facing noise control problems, lack of adequate ventilation, physical security issues, poor indoor air quality, comfort issues, and below-standard lighting conditions. A 1999 US Department of Education study found that $26 \%$ of the country's schools had unsatisfactory levels of fresh air. Most of these issues are directly or indirectly linked to HVAC system design and operation and can be corrected by improved mechanical and ventilation systems.

The best HVAC design considers all the interrelated building systems while addressing indoor air quality, energy consumption, and environmental benefit. Optimizing the design and benefits requires that your mechanical system designer and your architect address these issues early in the schematic design phase and continually revise subsequent decisions throughout the remaining design process. It is also essential that you implement well-thought-out commissioning processes and routine preventative maintenance programs.

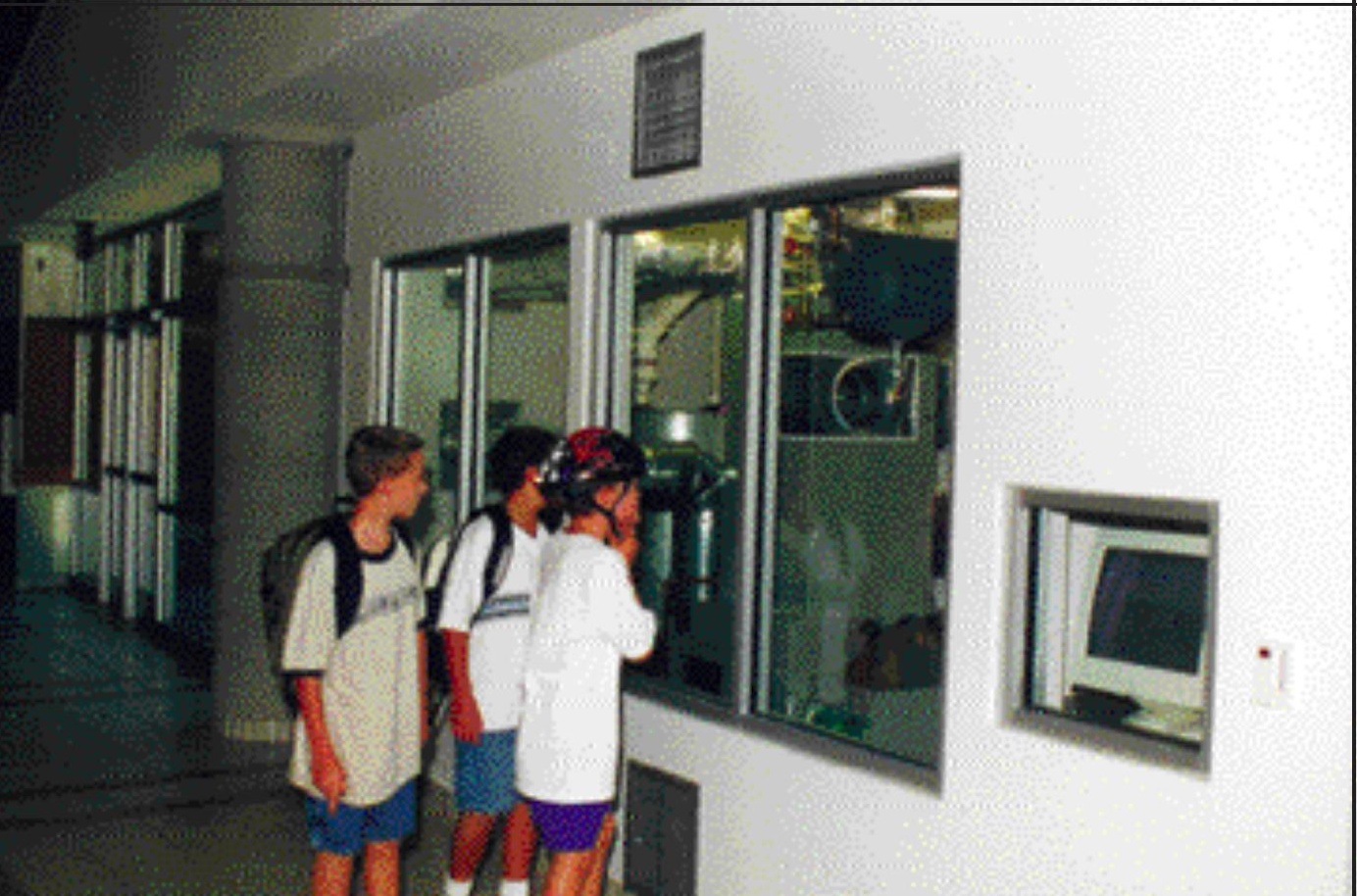

At Roy Lee Walker Elementary School, in McKinney, TX, the energy-efficient mechanical system is exposed to serve as an educational tool for energy conservation. 


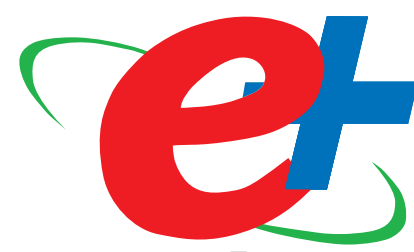

EnergyPlus

EnergyPlus is a new-generation building energy simulation program designed for modeling buildings with associated heating, cooling, lighting, and ventilation flows. EnergyPlus builds on the most popular features and capabilities of BLAST and DOE-2 and includes many advanced and innovative simulation capabilities.

\section{Design Guidelines for Mechanical and Ventilation Systems}

\section{Energy Analysis}

To optimize the selection of efficient, cost-effective mechanical and ventilation systems, perform an energy analysis early in the process, during the schematic design phase. System optimization also improves indoor air quality, allows better humidity control, and potentially lowers construction costs due to a reduction in size of mechanical and electrical systems. Several available computer programs can provide building simulations on an hourly basis to predict the energy behavior of the school's structure, air conditioning system, and central equipment plant.

An energy analysis considers the school's key components - the building walls and roof, insulation, glazing, the lighting and daylighting systems, as well as the HVAC systems and equipment. The analysis program can simultaneously assess and predict the results of choices associated with each component. For buildings in the design phase, computer models are generally useful for comparing alternatives and predicting trends.

Energy analysis computer programs that simulate hourly performance should include a companion economic simulation to calculate energy costs based on computed energy use. This model can estimate monthly and annual energy usage and costs. Some models allow the user to input estimated capital equipment and operating costs so that the life-cycle economics of the design can be evaluated and compared.

- Prior to starting work on the design, establish an "energy budget" for the project that exceeds the minimum building code standards. One consideration is to set an energy budget that would potentially qualify the school for an ENERGY STAR buildings label. An ENERGY STAR designation places the school in the top 25\% of energy performance.

are essential to achieving a clear understanding of how this energy strategy impacts mechanical loads and the "whole building" performance.
Communication among members of the school system, architects, and engineers early in the predesign process is critical for establishing the most energy-efficient "wholebuilding" strategy.
- Develop a clear understanding of how the school system wants to balance initial cost versus life-cycle cost, and point out the long-term advantages of investing in more energy-efficient and environmentally friendly approaches.

- When evaluating life-cycle costs, take into account: 
- the initial cost of equipment

- anticipated maintenance expenses

- projected annual energy costs

- projected energy and labor cost escalation rates

- replacement costs.

- Optimize the mechanical system as a complete entity to allow for interactions between system components.

- In the schematic design phase, determine the mechanical system implications of all related site, building shell, daylighting, and lighting elements.

When energy use and operating expenditures are considered at the outset of the design process, energy- and resource-efficient strategies can be integrated at the lowest possible cost.

\section{Cooling Systems}

Consider cooling systems appropriate for cool and dry climates that match the building loads and are not over-designed.

- Evaluate various cooling equipment sizes and models to select the unit that best matches the demand requirements. To accomplish this, use an hourly computer simulation tool to generate energy consumption profiles and the incidence of coincidental peak cooling loads. Select equipment that achieves a high efficiency at the predominant load but also remains efficient over the range of operating conditions.

- For cool and dry climates, consider the use of direct or indirect evaporative cooling equipment, which can reduce the need for mechanical cooling. The requirements for proper maintenance of these systems should also be evaluated.

- Consider natural gas and/or solar-driven absorption cooling as a method of reducing peak electricity consumption.

- A form of free cooling is nighttime ventilation. Use nighttime ventilation strategies to cool interior mass and flush out stale air prior to morning occupancy. This purging cycle can be effective in dry areas with low nighttime temperatures.

- To reduce upper atmospheric ozone depletion, reduce the use of CFC and HCFC refrigerants.

- Consider thermal (ice or water) storage in situations where peak load avoidance is critical. Thermal storage is a cost-saving technique that takes advantage of offpeak utility rate schedules where applicable. Some electric utilities promote thermal storage by offering an incentive for power usage that can be displaced from peak to off-peak time.

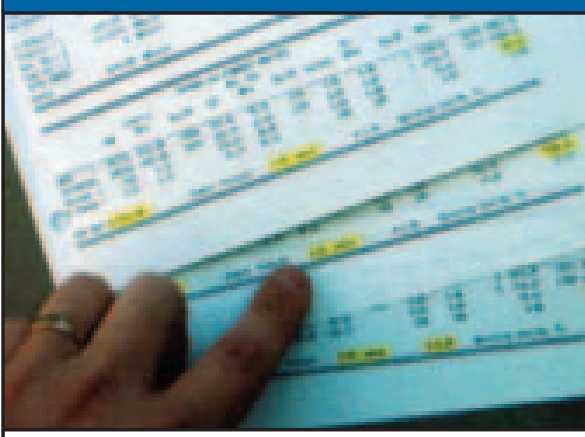

The energy budget and goals should be established prior to the start of the schematic design phase. 


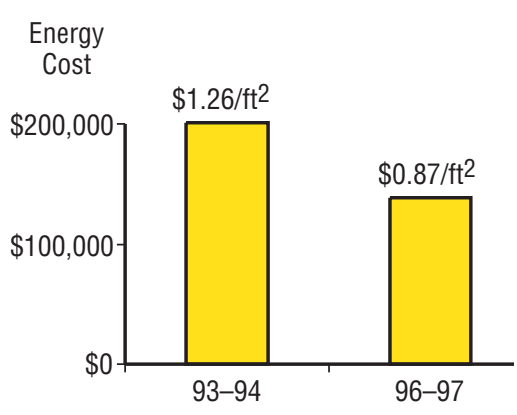

Energy Savings

Built in 1971, the 160,000-squarefoot Daniel Boone High School, in Gray, TN, was heated by electricity and cooled by a two-pipe chilled water system. After analysis of other two-pipe retrofit options, a new geothermal heat pump system was installed in 1995-96. Costing an additional $\$ 197,000$ and saving $\$ 33,000$ versus the next best twopipe system considered, the geothermal system saved Washington County Schools $\$ 62,000$ the first complete year of operation.

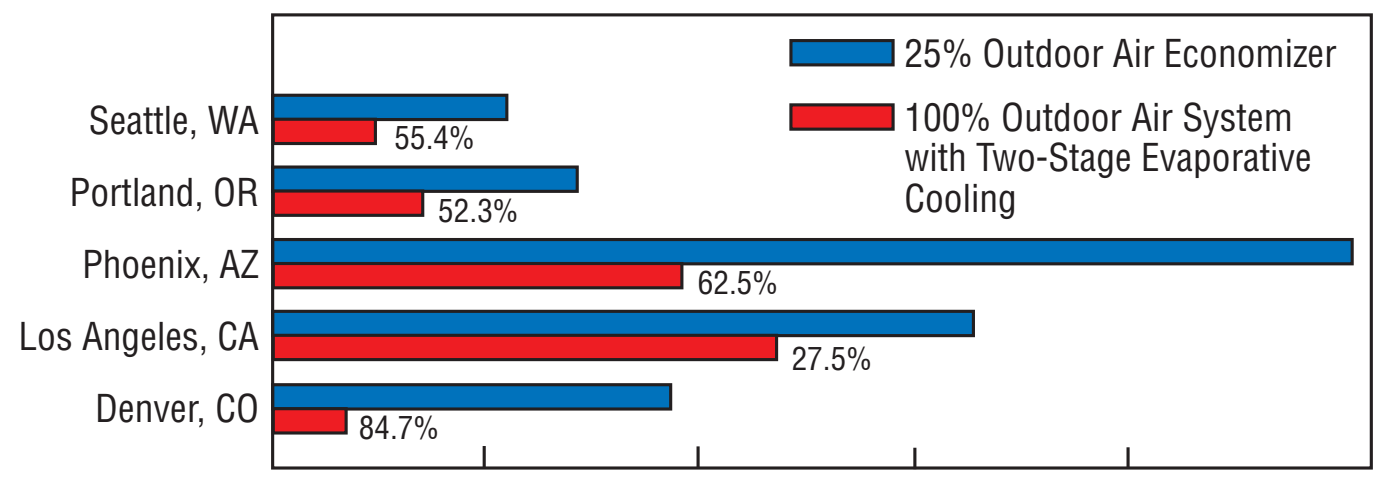

Source: ASHRAE Standard 62E, A Simple Method of Compliance, Oct 97

Thermal Storage Systems and Two-Stage Evaporative Cooling Design

Using an outdoor air system with two-stage evaporative cooling is more efficient than a conventional outdoor air economizer damper design.

\section{Water-Source Heat Pumps}

A water-source heat pump system is well suited to transfer heat from an interior zone, where cooling may be desired, to the perimeter, where heating may be needed. Buildings with simultaneous heating and cooling needs and a use for recovered heat (hot water) are ideal candidates for water-source heat pumps.

- Consider water-source heat pumps when it is necessary to subdivide the school building into many small conditioned zones to provide better comfort control.

- Consider the benefits of the systems for dry climate regions.

- Evaluate the higher maintenance costs associated with multiple compressions and fans.

- Provide separate ducts to introduce fresh outdoor air for ventilation.

- Use make-up air units for treating the ventilation air.

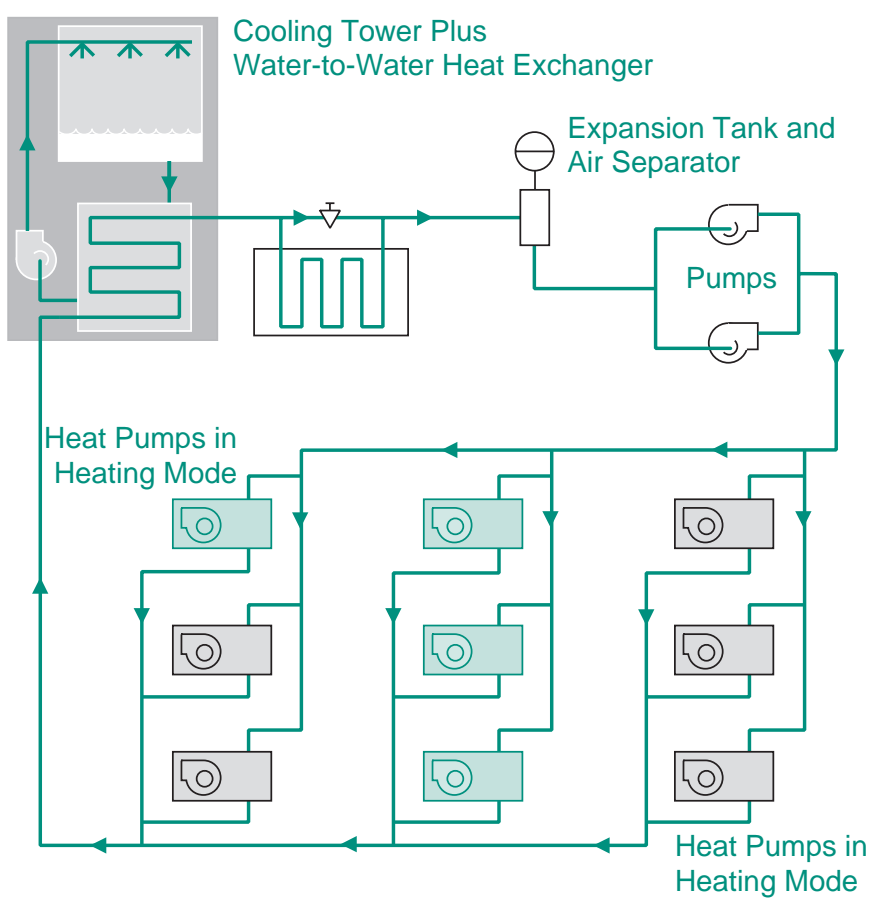

Water-Source Heat Pumps

Water-source heat pumps can provide significant savings in cool and dry climates. 


\section{Boilers}

When considering centralized systems, choose the most efficient heating for the particular need.

- Consider condensing boilers. They are typically $10 \%$ more efficient than conventional boilers.

- Consider multiple, modular boilers that are more efficient at partial load.

- Employ draft control devices that reduce off-cycle losses.

- Design a water reset control that is keyed to the outside air temperature.

- Incorporate burner flame controls.

- For small renovation projects, install time clocks to control night and weekend set-back.

\section{Ventilation and Indoor Air Quality Strategies}

ASHRAE Standard 62 addresses the criteria necessary to meet ventilation and indoor air quality requirements. The outside air requirements for proper ventilation of an occupied school are considerable and have a substantial impact on HVAC system energy consumption and operating costs. The strategy employed to achieve proper ventilation must be carefully considered.

- Implement ventilation strategies that will ensure outside air by complying with ASHRAE Standard 62-1999.

- Consider a dedicated ventilation system such that the quantity of air can be regulated and measured, providing a greater certainty that proper ventilation is maintained. Such a dedicated system can also improve overall energy efficiency.

- Consider the use of a heat recovery system, like an air-to-air heat exchanger, that will transfer the heat between air supplied to and air exhausted from the building.

- Separate and ventilate highly polluting spaces. Provide separate exhaust from kitchens, toilets, custodial closets, chemical storage rooms, and dedicated copy rooms to the outdoors, with no recirculation through the HVAC system.

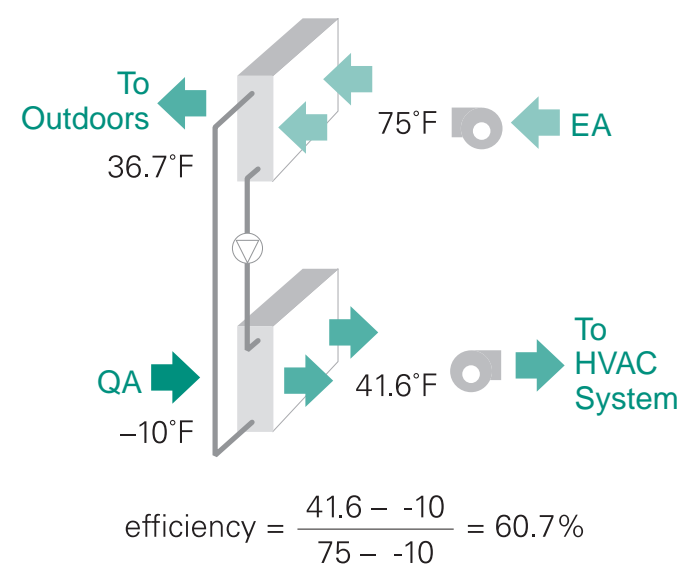

Winter Operation

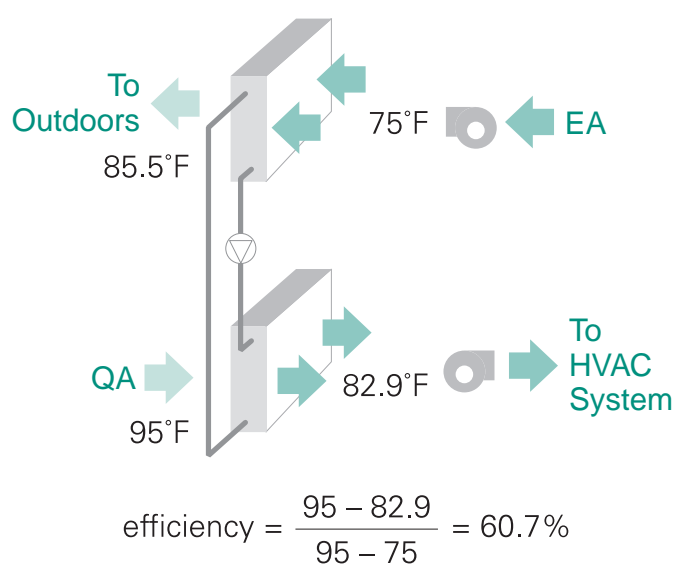

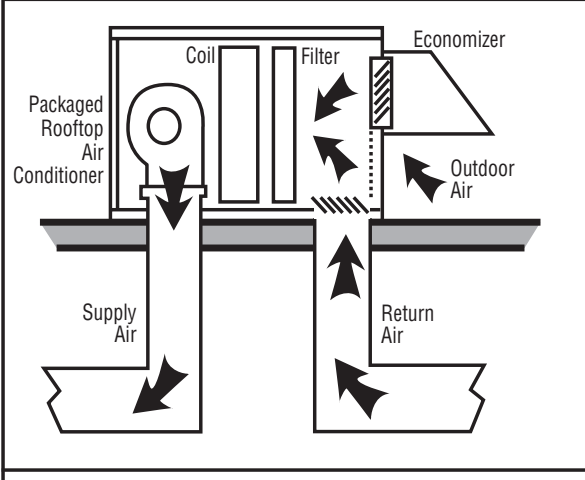

Economizer Cycle Diagram

An air economizer cycle can lower energy consumption by using as much as 100\% outside air.

Exhaust Air Heat Recovery System

An exhaust air heat recovery system is used to reduce energy consumption by capturing the energy that would normally be lost to the exhaust airstream. 


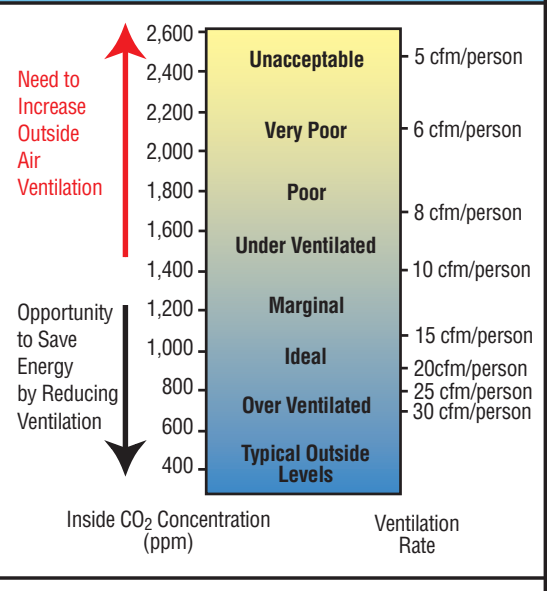

Diagram: TelAir, Goleta, CA

\section{Conditions of Indoor Air Quality}

Carbon dioxide concentration is a factor in determining adequate indoor air quality.

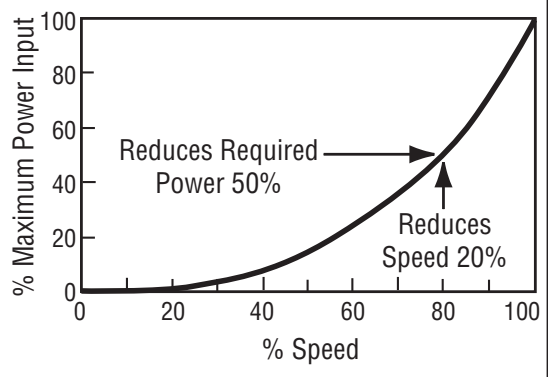

Graphic: Padia Consulting

VAV Fan Speed vs Input Power

Controlling motor speed to control air flow is the more energy-efficient strategy. Variable frequency drive control offers a distinct advantage over other forms of air volume control in variable air volume systems.
- Evaluate the use of an outdoor air economizer cycle that will allow up to $100 \%$ outdoor air to be introduced into the distribution system to provide space cooling.

- Locate outdoor air intakes a minimum of 7 feet vertically and 25 feet horizontally from polluted and/or overheated exhaust (e.g., cooling towers, loading docks, fume hoods, and chemical storage areas). Consider other potential sources of contaminants, such as lawn maintenance. Separate vehicle traffic and parking a minimum of 50 feet from outdoor air inlets or spaces employing natural ventilation strategies. Create landscaping buffers between high traffic areas and building intakes or natural ventilation openings.

- Locate exhaust outlets at a minimum of 10 feet above ground level and away from doors, occupied areas, and operable windows. The preferred location for exhaust outlets is at roof level projecting upward or horizontally away from outdoor intakes.

- Provide filters capable of $60 \%$ or greater dust spot efficiency, and install them in a location capable of intercepting all make-up and return air. In dusty areas, use a higher efficiency filtration system (80\%-85\% by ASHRAE standards with $30 \%$ efficient pre-filters).

\section{Distribution Systems}

Design an air distribution system that is energy-efficient and protects against poor indoor air quality.

- Where individual room control is desired or diverse loads are present, employ variable air volume systems (versus constant air systems) to capitalize on reduced fan loads during times of reduced demand.

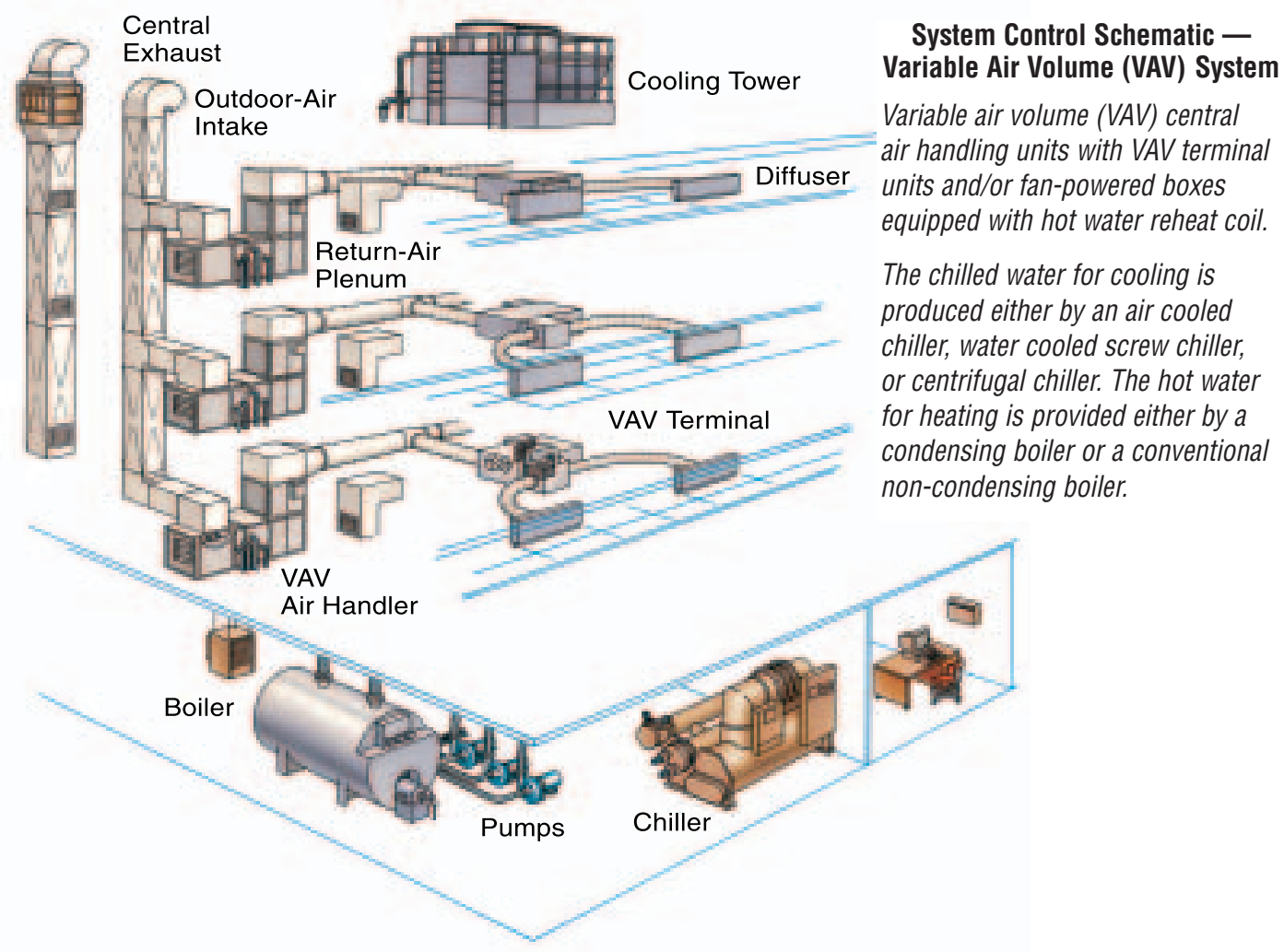


- Use constant volume systems when the load is uniform and predictable (e.g., kitchen).

- If a particular mechanical system serves more than one space, ensure that each space served has the same orientation and fulfills a similar function. Consider independent mechanical rooms and systems on separate floors to reduce ductwork and enhance the balance of air delivered.

- Consider a design that supplies air at lower temperatures to reduce airflow requirements and fan energy.

- Specify ductwork that has smooth interior surfaces and transitions to minimize the collection of microbial growth. Design ductwork and plenums to minimize the accumulation of dirt and moisture and to provide access areas in key locations for inspection, maintenance, and cleaning. Use mastic to seal metal ductwork. Where possible, locate ductwork in conditioned or semi-conditioned spaces.

- Specify duct leakage tests.

- Make sure that air handling units and filters are easy to access and maintain.

- Reduce duct pressures to minimize the amount of fan energy used to distribute the air. Use low-velocity coils and filters.

- To minimize energy consumption, select fans for the highest operating efficiency at predominant operating conditions, and use lower fan speeds to reduce noise levels. Consider direct-drive fans for their improved efficiency.

- Use filters that meet a minimum of $60 \%$ ASHRAE Dust Spot Method Standards.

\section{Controls}

To ensure proper, energy-efficient operation, implement a control strategy that is tied to key energy systems. Include system optimization, dynamic system control, integrated lighting, and HVAC control.

- Use direct digital control systems for greater accuracy, performance, and energy savings.

- Set up the HVAC control system to operate according to need. Limit electrical demand during peak hours by turning off (or rotating) non-essential equipment.

- Establish temperature and humidity set points based on occupancy patterns, scheduling, and outside climatic conditions.

- Install occupancy sensors to reduce ventilation air requirements for unoccupied spaces.

- Make owners aware that they should periodically verify the accuracy of the sensors and control functions and calibrate if necessary.

- Notify owners of the need to periodically audit all computer-controlled HVAC systems to verify performance and calibration.

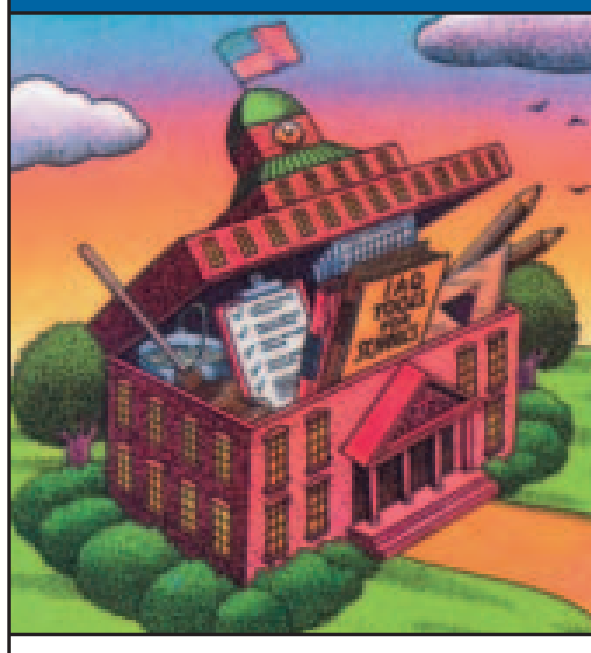

Indoor Air Quality: Tools for Schools

This program is designed to give schools the information and skills they need to manage air quality in a low-cost, practical manner. The kit is published by the US EPA and cosponsored by the American Lung Association.

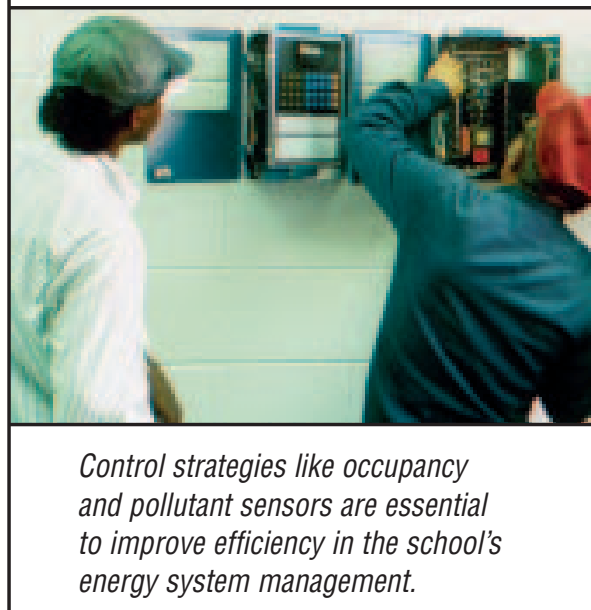




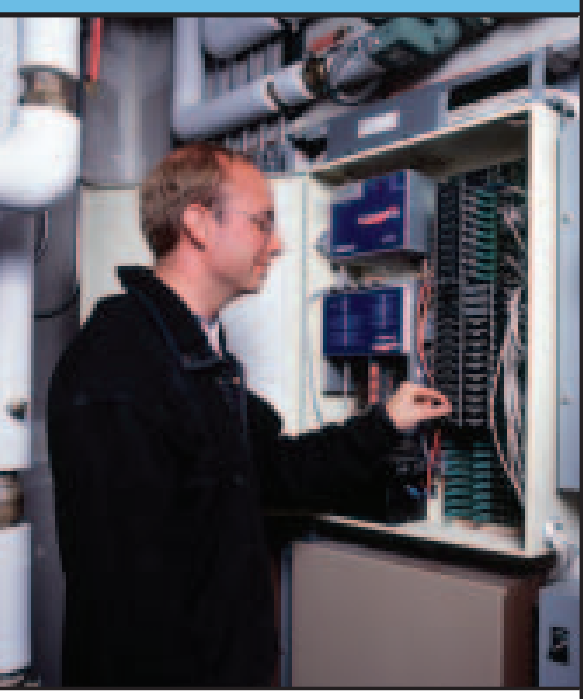

Photo: NREL/PIX09214

An energy management system optimizes mechanical and lighting system operation.
- Install sensors for relative humidity and temperature as close to occupants as possible. Carbon dioxide concentration sensors may be a helpful addition to a properly designed and maintained ventilation system.

- If using VAV systems, set supply-air temperature reset controls based on occupancy of space. Specify VAV controls to ensure that the proper amount of outdoor air is maintained, even when the total air supply is decreased.

- Control strategies for chilled water plant operation should address:

- variable speed drives

- the selection of modular chillers or chillers with multiple compressors

- a chilled water reset

- variable flow through the chillers

- a condenser water reset

- chiller sequencing

- the soft-starting of the chiller motors

- demand control.

- In small schools, consider time clocks with night and weekend setbacks.

- Work with the school system to establish a means to monitor and document the performance of the energy management control system and provide training of future maintenance staff.

\section{Hot and Chilled Water Distribution}

- Carefully select heat exchangers with a low approach temperature and reduced pressure drops.

- In large systems with multiple heat exchangers, designate a separate pump for each heat exchanger to maintain high efficiency at part-load operating conditions.

- Consider primary pumping systems with variable-speed drives because of their effects on a part-load energy use.

\section{Water Heating}

- Consider heat pump water heaters or tankless (instantaneous) water heaters.

- Consider localized versus centralized hot water equipment by evaluating the types of loads served. A remote location may be best served by localized equipment.

- Consider a solar-assisted hot water system.

- Consider heat recovery systems.

- Use tankless water heaters in areas that are remote and require small hot water amounts.

- Minimize the standby heat losses from hot water distribution piping and hot water storage tanks by increasing insulation levels, using anti-convection valves, and using heat traps. 


\section{Renewable Energy}

\section{Systems}

There is no shortage of renewable energy. And renewable energy can contribute to reduced energy costs and reduced air pollution. More importantly, the renewable energy systems that you design into your school will demonstrate to the students the technologies that will fuel the 21 st century.

Over the past two decades, the cost of renewable energy systems has dropped dramatically. Wind turbines can now produce electricity at less than 4 cents per kilowatt-hour - a seven-fold reduction in energy cost. Concentrating solar technologies and photovoltaics have dropped more than three-fold during the past 20 years. And, with improvements in analytical tools, passive solar and daylighting technologies can be implemented into schools with less than a two-year return on investment.

Incorporating renewable energy options into your school design helps students learn firsthand about these cost-effective and energy-efficient options. Input from teachers early in the design process helps to ensure that energy features are incorporated in a way that optimizes the learning experience. Buildings that teach offer students an intriguing, interactive way to learn about relevant topics like energy and the environment.

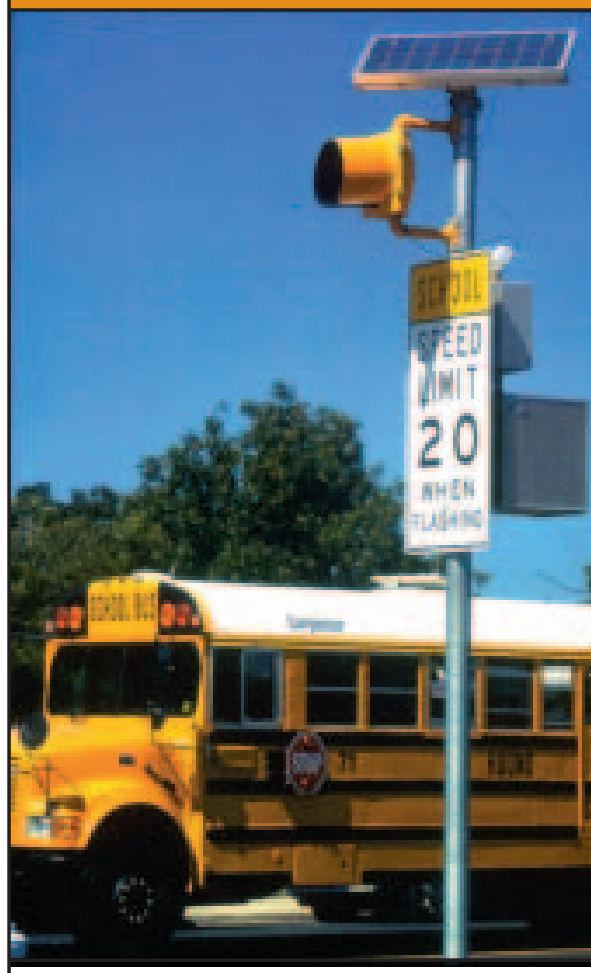

Photo: Glen Bair, by State of Texas Energy Conservation Office

Photovoltaic-powered school zone warning signals can be used as an alternative to traditional electric traffic signals.
Photo: NREL/PIX06461

Nantucket Elementary School, in Nantucket Island, MA, features a roof-mounted photovoltaic array that saves energy and serves as a teaching tool. 


\section{Design Guidelines for Renewable Energy Systems}

\section{Available Renewable Energy Resources}

When evaluating potential renewable systems, use the best available historic climatic data, closest to the school site.

- Because the radiation levels in cool and dry climates are relatively high, consider solar systems as a high-priority energy strategy. The following data show that the region's solar resource is good for solar applications, but state-specific information can be obtained from the State Energy Alternatives Web site, listed in the resources section at the end of this document.

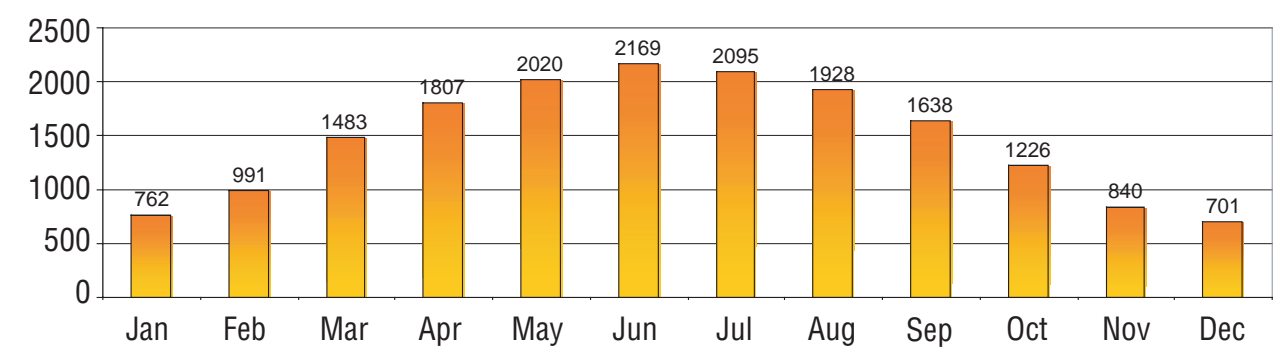

Average Incident Solar Radiation in Denver (Btus/Square Foot/Day) NOTE: Watts/Square Meter x .317 = Btus/Square Foot

Photo: American Wind Energy Association

The wind turbine at Spirit Lake Elementary, in Spirit Lake, IA, saves the school \$25,000 annually.

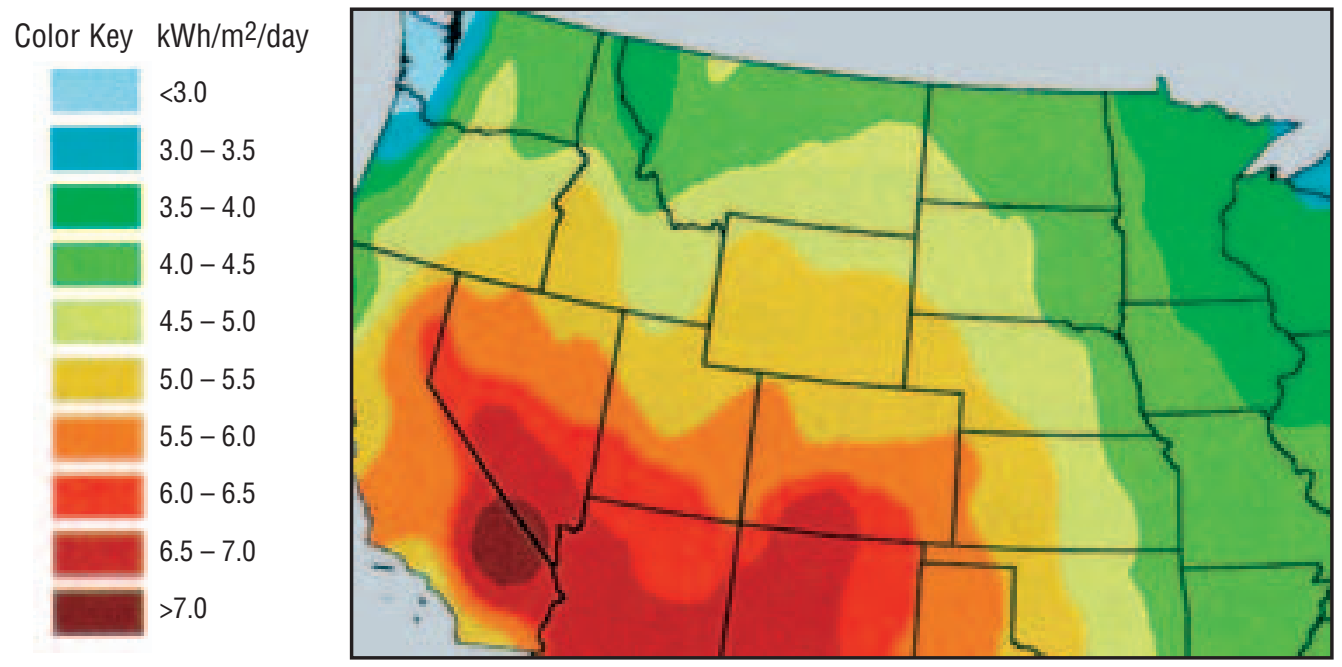

Average Direct Normal Radiation (kWh/Square Meter/Day)

- Wind generation becomes cost-effective in most areas when the average wind speed exceeds 10 miles per hour. In locations where the wind is marginally below this amount, wind systems should still be considered for their educational values.

While Denver's annual mean wind speed is right at 10 miles per hour, there are numerous micro-climatic areas within the region that exceed this wind speed.

Check the US DOE's State Energy Alternatives Web site (see the resources section at the end of this document) to determine the wind resources in your location. 


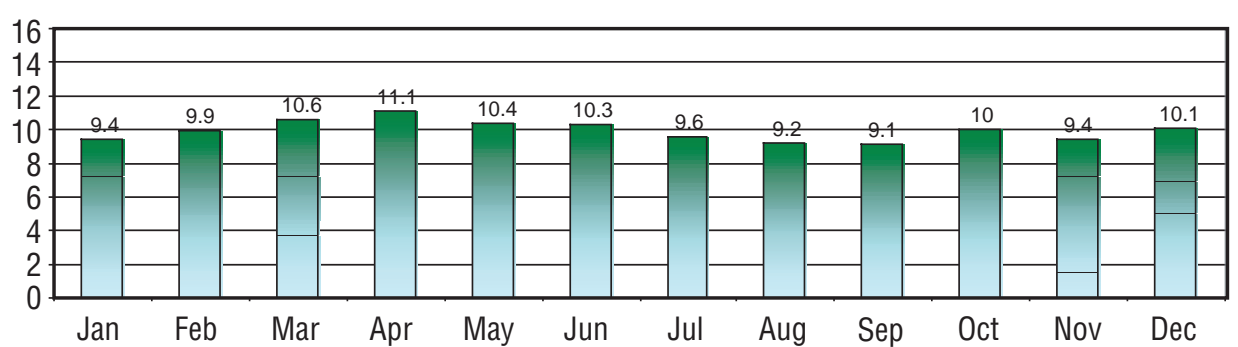

Annual Mean Wind Speed (MPH)

\section{Building Orientation and Solar Access}

Employing renewable energy strategies cost effectively requires the school to be sited to maximize the locally available natural resources.

- Establish the building on an east-west axis that maximizes southern exposure for daylighting and other solar systems. In Denver, true north is $10^{\circ} 1$ ' east of magnetic north (magnetic north is the direction a compass points).

- Ensure that adjacent buildings or trees do not block the intended solar access.

\section{Building-Integrated Approaches}

To maximize cost effectiveness and improve aesthetics, consider integrating solar thermal and photovoltaic systems into the building shell.

- Integrate solar systems into the overall design to allow the system to serve multiple purposes (e.g, a photovoltaic array that can also serve as a covered walkway).

- Eliminate the additional costs associated with a typical solar system's structure by designing the building's roof assembly to also support the solar components.

- Minimize redundant materials by using the glazing of the solar collector as the waterproofing skin of the building.

- Incorporate building-integrated approaches as a strategy to save valuable land.

\section{Renewable Energy Applications for Schools}

A variety of renewable energy applications are effective in cool and dry climates. Daylighting, passive cooling, solar hot water and space heating, solar absorption cooling, photovoltaics, and wind should all be considered as energy-saving strategies that also help to teach students about energy technologies.

\section{Daylighting}

Because of the unique potential of this renewable energy option to provide multiple benefits, daylighting is discussed in a separate section within these guidelines. See the Daylighting and Windows section.

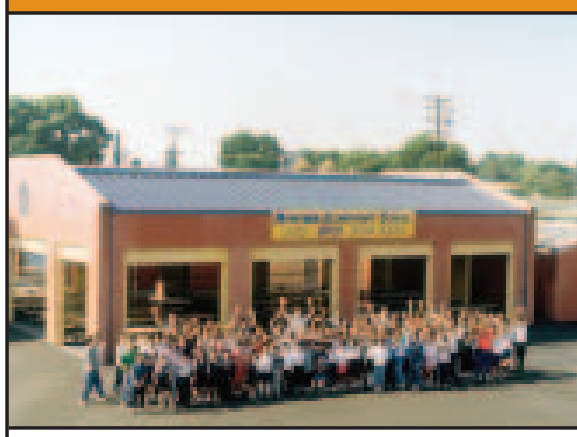

Photo: NREL/PIX08884

This building-integrated photovoltaic system covers the roof of this school's cafeteria. 


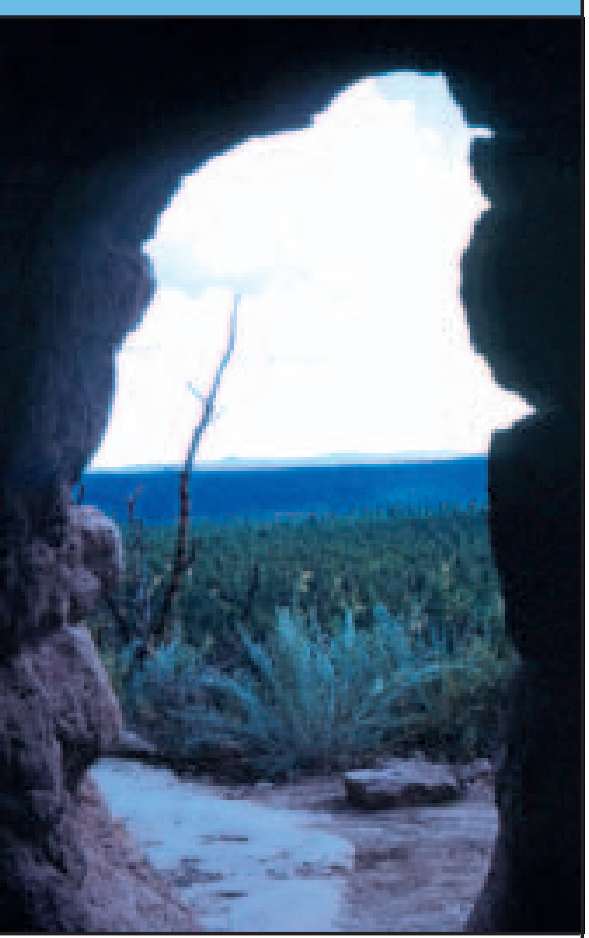

Massive walls have long been used to minimize the impact of midday sun.

\section{Passive Cooling}

- Natural ventilation should be viewed as a practical strategy for many of the warmer months of the year. Consider operable windows to provide the opportunity for natural ventilation when interior building loads dominate.

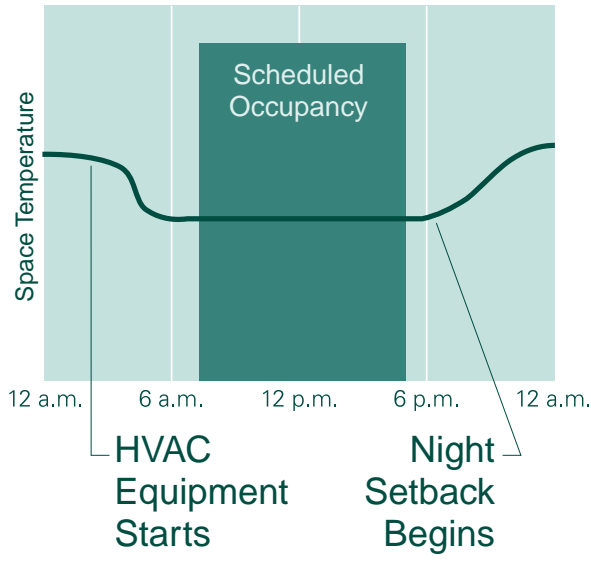

Without Unoccupied Ventilation

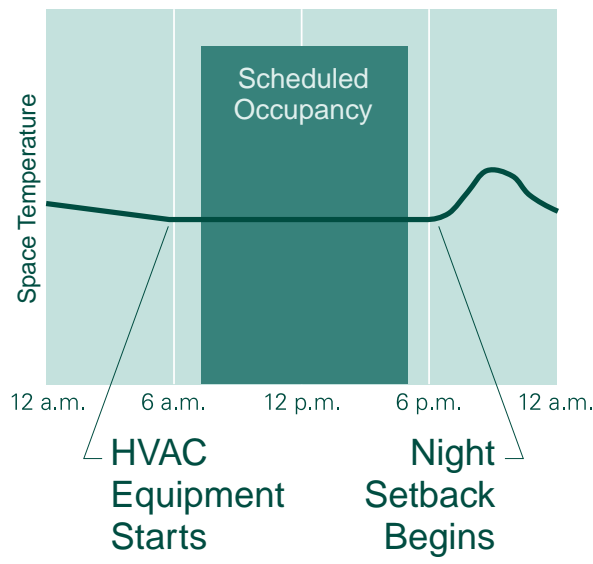

With Unoccupied Ventilation

\section{The Effect of Night Purging}

Using night purging brings cool, outside nighttime air into the building to reduce HVAC startup loads.

- Incorporate night purging as a technique to improve performance. Using either natural, mechanical, or hybrid approaches to purge the air within a school can provide energy and indoor air quality benefits. When the ambient temperature during the nighttime drops several degrees or more below the set temperature, bringing outside air into the building and purging the warmer air can greatly reduce the cooling load on the building the next morning.

- Install massive wall construction to both reduce and stabilize cooling loads by including:

- high-mass walls to increase the lag time of temperature flows

- mass located inside the wall insulation to stabilize internal temperature fluctuation

- light-colored exterior finishes to reflect solar radiation striking walls.

\section{Solar Hot Water}

Because of the high hot water demands associated with cafeterias, solar heating systems are often viewed as important strategies in reducing energy bills. In middle schools and high schools, with showers for gym classes and sports programs, it is even more beneficial to address this significant load.

There are several types of systems that could be used in this region. Two of the more common are "drainback" and "closed-loop" systems. 


\section{Drainback Systems}

- Use "drainback" solar systems in small applications where it is possible to slope the piping back toward a collection tank.

By draining the collection loop, freeze protection can be accomplished when the pump shuts down, either intentionally or non-intentionally.

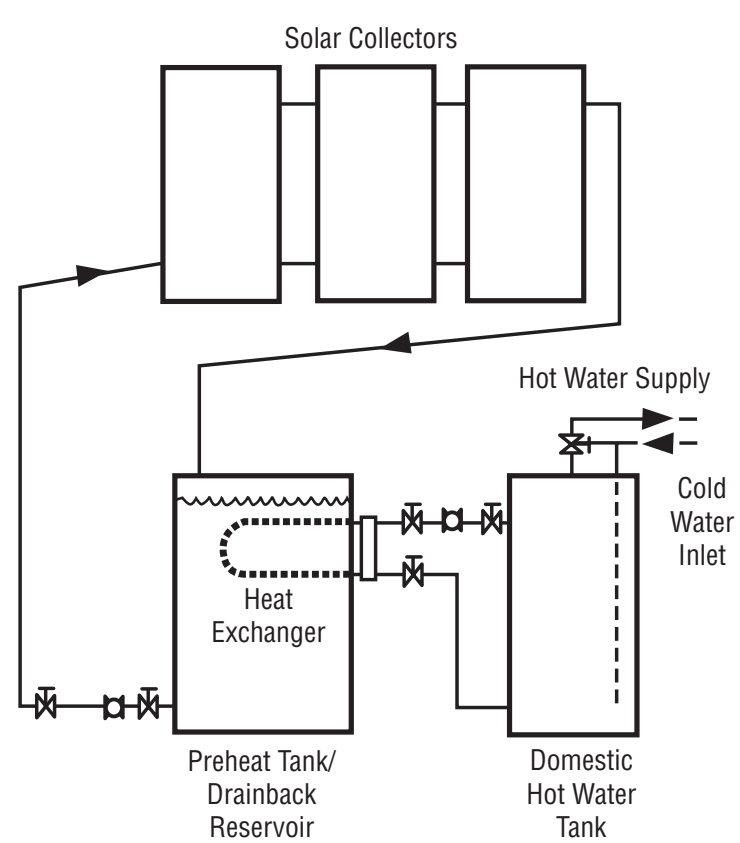

Drainback Solar Hot Water System Diagram

A drainback system pumps water from a storage tank when adequate solar radiation is available.

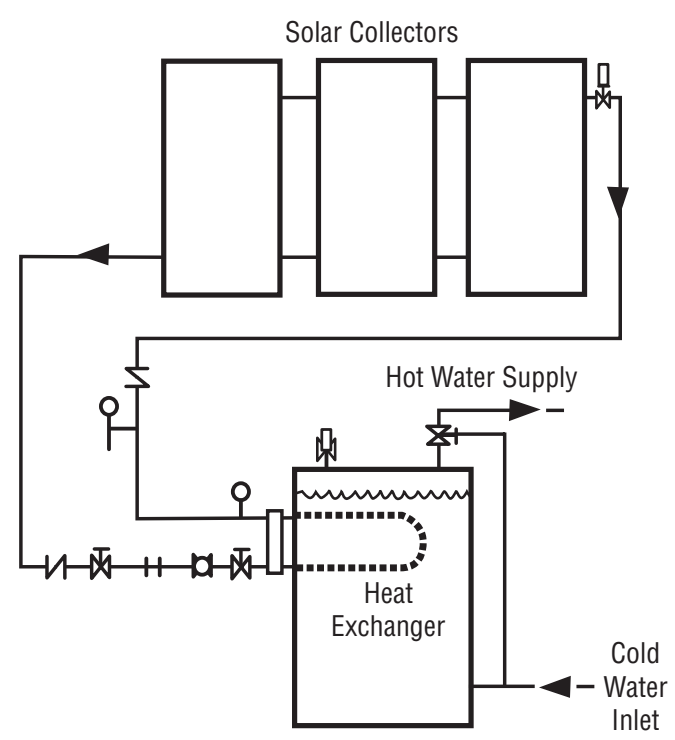

Closed-Loop Solar Hot Water System Diagram

Closed-loop systems use a controller to shut the system down when the temperature differential becomes too small or when the tank reaches a set peak temperature.
This drainback solar domestic water system was added to the school's kitchen roof area and provides the majority of hot water required by the cafeteria.

\section{Closed-Loop Systems}

- Select a closed-loop, freezeresistant solar system if piping layouts make drainback options impractical.

In closed-loop systems, a small pump circulates antifreezeprotected fluids through the collection loop when there is adequate solar radiation and the differential between the collector fluid temperature and the tank temperature justifies the collection mode continuing.

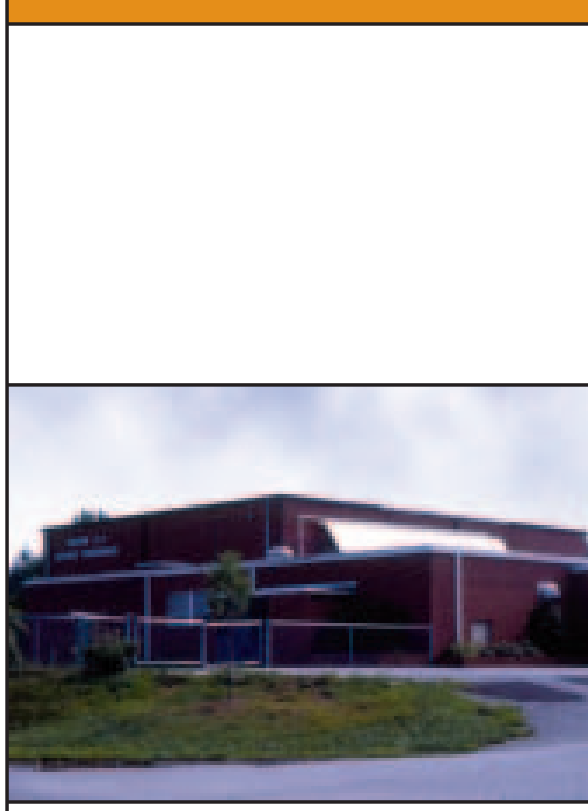




\section{Wind}

Wind turbines convert the kinetic energy in the wind into mechanical power. This mechanical power can be used directly (e.g., water pumping), or it can be converted into electricity.

- Consider wind electric generators as a cost-effective application in areas where the sustained wind speed exceeds 10 miles per hour.

- Consider wind systems for well water pumping.

- Address potential noise problems by properly siting wind installations.

- Consider the educational benefits of installing a windmill or a wind generator on the school site.

\section{Geothermal Heat Pumps}

Geothermal heat pumps work differently than conventional air source heat pumps in that geothermal systems use the more moderately tempered ground as a heat source and heat sink. The result is that geothermal systems are more efficient and more comfortable.

- Use closed-loop systems in areas where well water is not present or adequate.

- Use open-loop systems in regions where sub-surface water can be extracted and reinjected into the ground, through wells, in an environmentally sound manner.

- Conduct a detailed site survey, and thoroughly analyze the heat gain and loss to avoid oversizing.

- Specify high-efficiency heat pumps.

- Avoid using excessive amounts of antifreeze.

- Specify thermally-fused, high-density polyethene (HDPE) for all in-ground piping.

\section{Photovoltaics}

Photovoltaic modules, which convert sunlight into electricity, have numerous school applications and can be designed as "stand-alone" applications or for utility "grid-connected" applications.

Photo: Advanced Energy

Geothermal systems have the added advantage of no outdoor condensing unit or cooling tower. 


\section{Stand-Alone Systems}

- Select stand-alone photovoltaic systems to address small, remotely-located loads. They tend to be more cost-effective than the conventional approach requiring extensive underground wiring. Some of the more appropriate applications include parking and walkway lighting, caution lights at street crossings, security lights, emergency telephone call boxes, and remote signage.

Because these systems are not connected into the utility grid, battery storage is typically required. Depending upon the device being powered, a DC to $\mathrm{AC}$ inverter may or may not be installed.

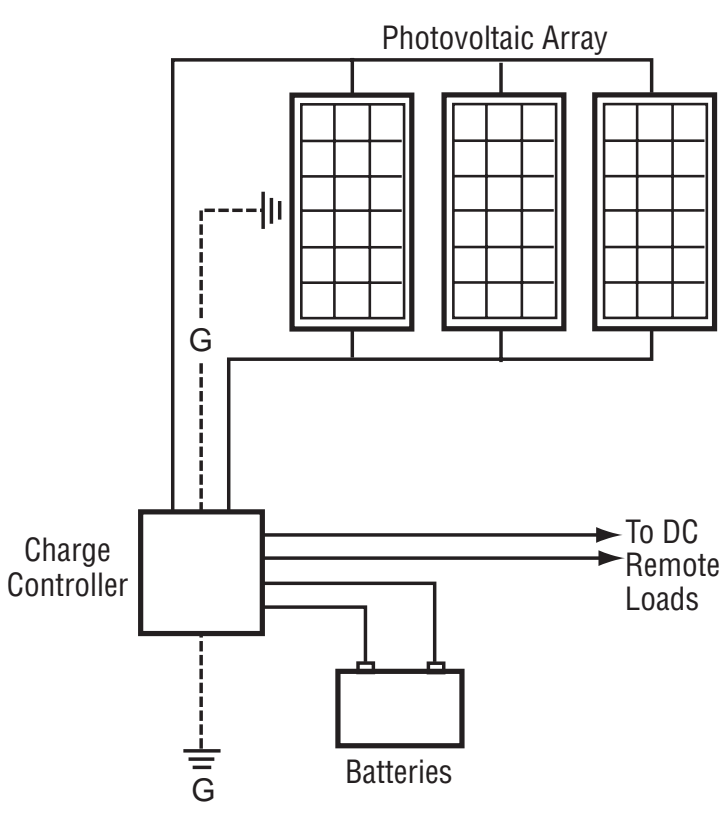

\section{Stand-Alone Photovoltaic System}

Stand-alone systems are ideal for remote loads located away from electrical lines.
Photo: Bluffsview Middle School

Photovoltaic systems can be great teaching tools as well as energy savers.
These stand-alone photovoltaic systems power parking lights. 


\section{Grid-Connected Systems}

- Choose grid-connected systems in large applications where peak load pricing is high or where first cost is an issue. Because these systems typically rely on the utility to provide power when the sun isn't shining, battery cost is eliminated and long-term maintenance is reduced greatly. This strategy, is typically advantageous to both the utility and the school because peak demand will be occurring when the sun is shining.

In these applications, a DC to AC inverter is required. Additionally, in the event of a utility power failure, protection must be provided to ensure that the system does not feed back into the utility grid.

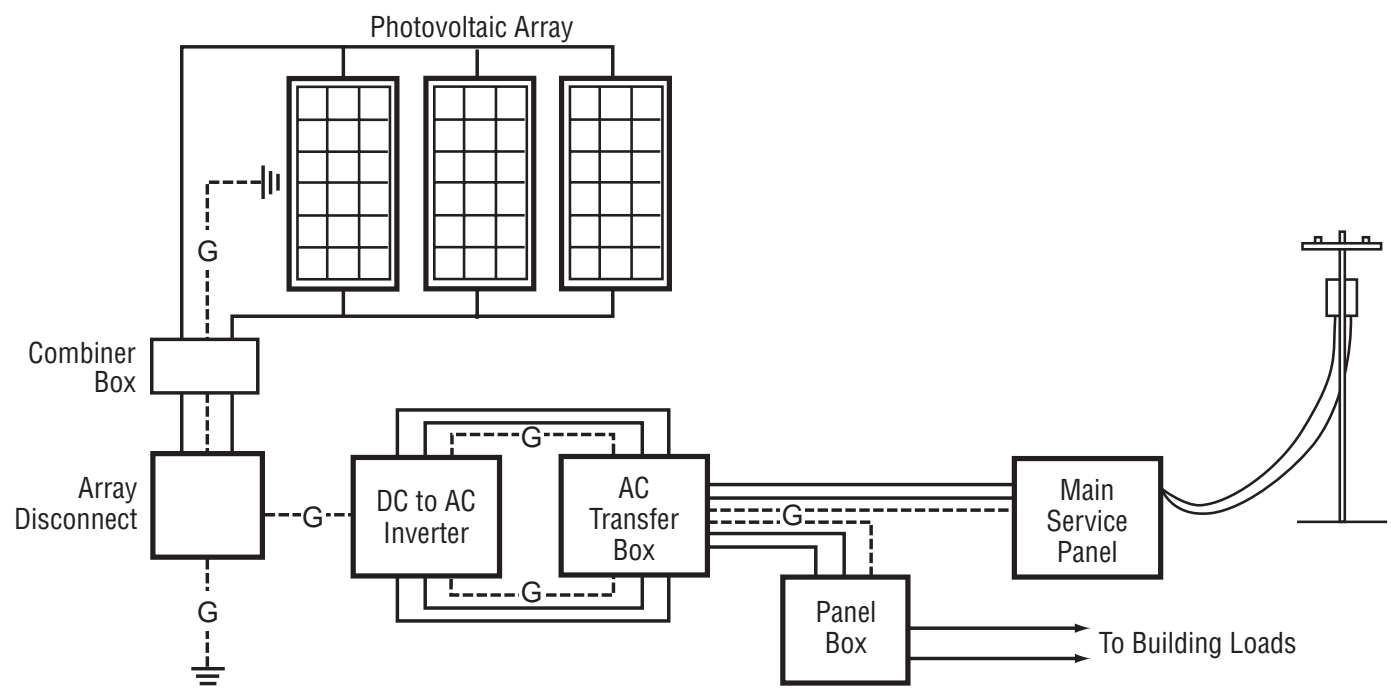

Grid-Connected Photovoltaic System Diagram

Grid-connected systems work well for large loads located near existing electrical service. 


\section{Water Conservation}

Every day the United States withdraws 340 billion gallons of fresh water from streams, reservoirs, and wells — an amount equal to 1,000 gallons per person per day. And as the population grows, so does the demand for water. Combine the impacts of rising population with the demographic shift in people to more arid regions, and the pressure of providing clean water becomes more critical every year.

Water rationing is becoming commonplace in thousands of communities across the country, and the price of water is escalating at unprecedented rates. You can make a considerable difference at your school in reducing community water use. By using water-conserving fixtures, implementing graywater or rainwater catchment systems, and using xeriscape practices, schools can easily reduce their municipal water consumption $25 \%-75 \%$. By saving half of the 1 million to 3 million gallons that each of the 90,000 public schools consume every year, more than 200 million gallons of treated water could be saved each day.

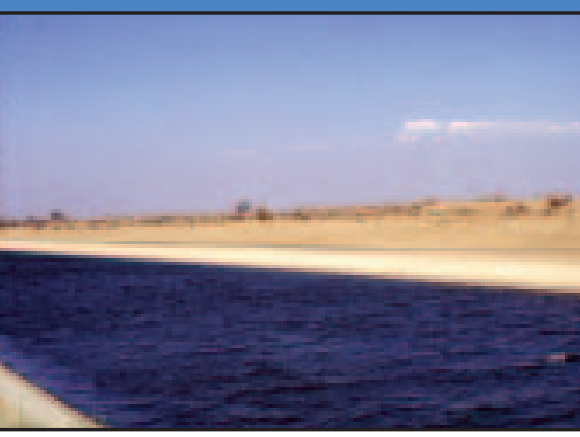

Many areas of the United States have resorted to piping or developing canals to move water from one region to another.
Photo: NREL/PIX00653

This water-conserving sink uses infrared sensors.

The Roy Lee Walker School, in McKinney, TX, collects 700,000 gallons of rainwater each year for toilet flushing and site irrigation. 


\section{Water-Conserving Fixtures}

One of the most effective means to limit demand for water is to reduce the requirements associated with necessary plumbing fixtures.

- Consider the standards of the 1992 Energy Policy Act as a minimum. Specify low-flow toilets that use less than 1.6 gallons per flush.

- Consider showerheads that require less than 2.5 gallons per minute and incorporate levers for reducing flow between 2.1 and 1.5 gallons per minute.

- Use aerators to reduce flow in lavatory faucets to as low as 1 gallon per minute.

- Specify self-closing, slow-closing, or electronic faucets where it is likely that faucets may be left running in student bathrooms.

- Consider waterless urinals or 1-gallon-per-flush urinals.

Projected Water Savings by Installing Waterless Urinals in Schools

\begin{tabular}{|l|c|c|}
\hline & School with Regular Urinals & School with Waterless Urinals \\
\hline Number of Males & 300 & 300 \\
Number of Urinals & 10 & 10 \\
Use/Day/Male & 2 & 2 \\
Gallon/Flush & 3 & 0 \\
School Days/Year & 185 & 185 \\
\hline Water Saved/Year & & 222,000 Gallons \\
\hline
\end{tabular}

Waterless urinals are one way to reduce water usage in your school.

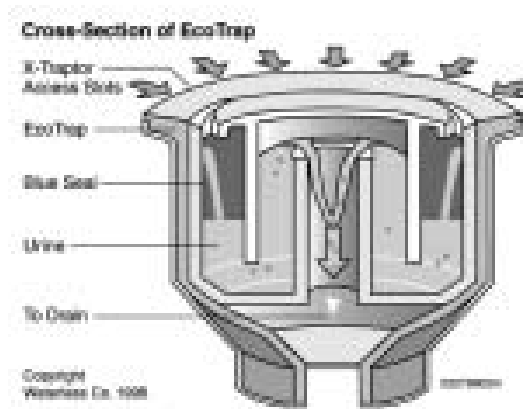

\section{Waterless Urinals}

With waterless urinals, the traditional water-filled trap drain is eliminated, and the unit does not need to be flushed.
Photo: Darrow School

At the Samson Environmental Center of Darrow School, New Lebanon, NY, the Living Machine is used to teach students about onsite biological wastewater treatment systems. This garden uses large tropical plants to create a refuge for the microorganisms that break down nutrients and chemicals in the water and releases water that is treated to tertiary or, if desired, drinking water quality.

Biological wastewater treatment systems, like this living machine, can transform "waste" into a resource that can be used to improve soil conditions on the site, save water, reduce the need for municipal treatment infrastructure, and address problems directly associated with septic system technologies. 


\section{Rainwater Management}

Rainwater captured off the roof of your school can be harvested and stored in cisterns for non-potable use. In most rainwater catchment systems, the water runs off the roof into gutters and downspouts, which carry the water to a storage device for future use.

- Consider the savings made possible by a reduced need for retention ponds.

- When cost-effective, implement a rainwater collection system to provide water for toilet flushing and irrigation through separate plumbing lines.

- Use a durable storage container, and locate it away from direct sunlight and septic tanks.

Using this cistern, the Roy Lee

Walker Elementary School, in

McKinney, TX, harvests rainwater.

- Design systems so that potable water can be safely added to storage tanks, and guarantee an uninterruptable supply to toilets and irrigation systems.

- Determine the necessary water treatment and filters for your area.

- Install a storage tank underground or in conditioned/semi-conditioned spaces to minimize freeze problems.

Rainwater Catchment Diagram

The initial water collected off the roof is intentionally "dumped" in order to reduce filtration of large particles. A low flow pump and chlorinator are used to stop algae growth. Make-up water, from your typical potable supply, is added to the tank when rainfall is insufficient.

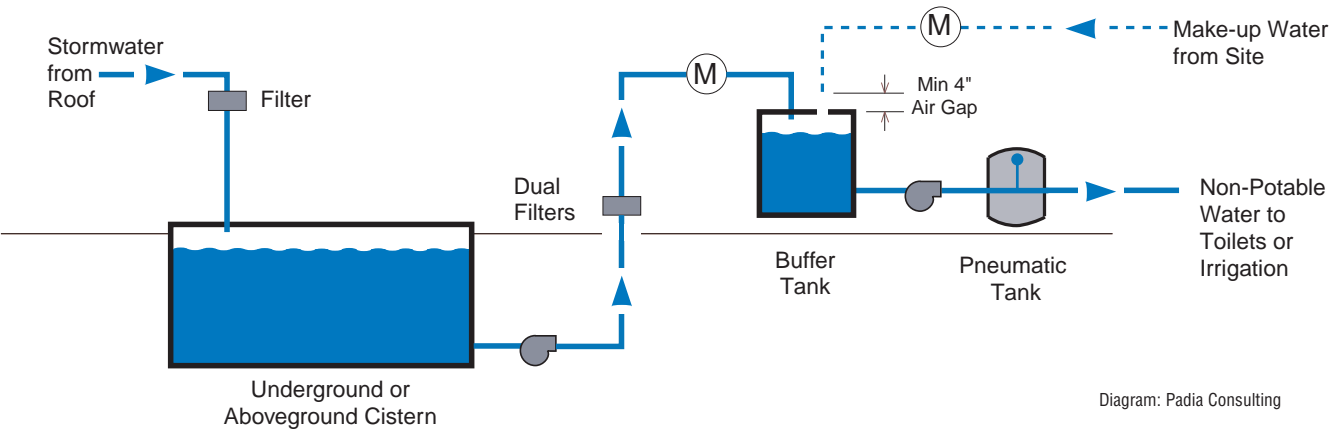

\section{Graywater Systems}

Relatively uncontaminated waste can be easily captured, stored, and used to fulfill non-potable needs.

- Use graywater from lavatories and water fountains for underground site irrigation. Design the system, meeting local regulations, to:

- get the graywater into the soil as soon as possible instead of storing it

- irrigate below the surface of the ground only

- deliver the graywater to biologically activate the soil where organic matter will quickly be broken down.

\section{Graywater System Diagram}

Graywater collects through a separate plumbing system and is treated and stored in an underground tank. The graywater is then pumped into a second hydropneumatic tank that maintains the proper system pressure. When necessary, additional fresh water is brought into the graywater storage tank to maintain the minimum level needed for the circulation pumps. 50 


\section{Recycling Systems and Waste Management}

Public schools across the country are producing billions of pounds of municipal solid waste each year. You can help reduce much of this waste by recycling or composting at your schools. In a compilation of studies of waste generation in Washington State and New York City schools reported by the US EPA, paper was found to account for up to half of waste in schools, organic (compostable) materials up to a third, plastic about $10 \%$, and glass and metals about $7 \%$. To the extent that school buildings can be made more recycling and composting friendly, very high percentages of this waste material can be kept out of the waste stream. In fact, if every school system implemented aggressive recycling efforts, landfills would have 1.5 billion pounds less solid waste each year.

By creating schools in which comprehensive waste recycling can be carried out, your design team has an opportunity to instill the practice of recycling in your school's children. Hundreds of schools throughout the country have embarked on exciting and highly successful hands-on programs to encourage recycling. Often, the students themselves design and manage these programs - and see the fruits of their labors as waste reduction or recycling is quantified. The most successful recycling and waste management programs are integrated into classes, with students making use of mathematical, investigative, and communication skills in implementing these programs.

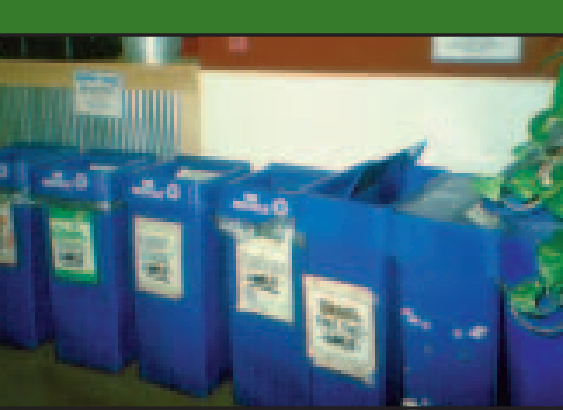

For efficient recycling collection, the recycling bins must be labeled and located in areas easily accessible by students and staff.

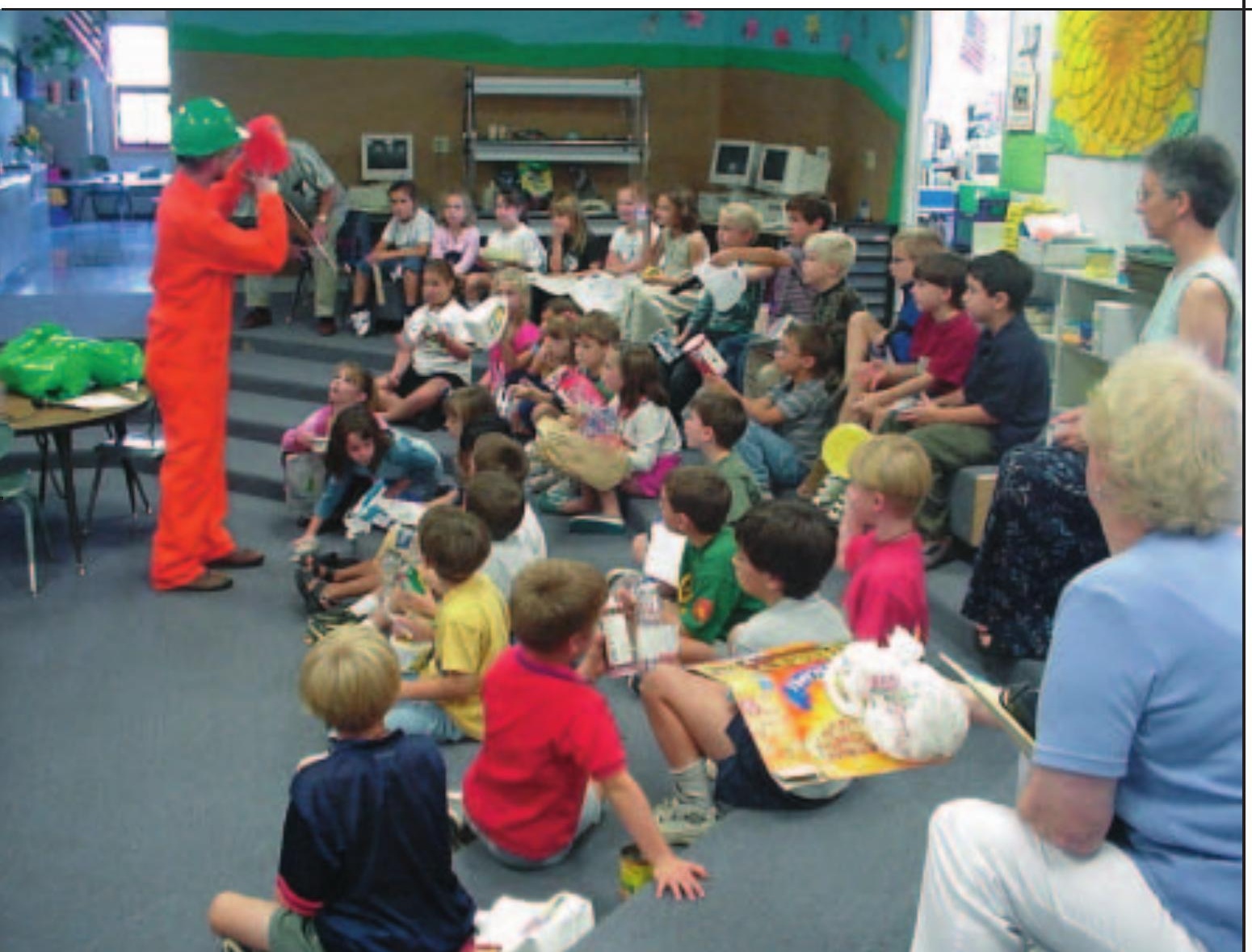




\section{Design Guidelines for Implementing Recycling Systems and Waste Management}

\section{Paper, Plastics, Glass, and Aluminum Recycling}

Students are able and eager to participate in recycling programs. Successful recycling programs teach students recycling skills and save money through reuse of materials and avoided disposal fees.

Paper represents one of the largest components of a school's waste stream. In addition to glass, aluminum, plastic bottles, and cans, even styrofoam can now be recycled.

- Allocate space within each classroom, the main administrative areas, and the cafeteria for white and mixed paper waste.

- Provide central collection points for paper and cardboard that are convenient to custodial staff as well as collection agencies or companies.

Photo: Huntsville High School East Signage can encourage students and staff to actively recycle major waste materials in the school.

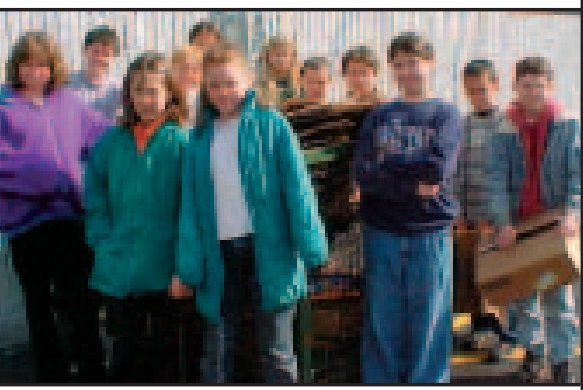

Photo: Mount Baker School District In Deming, WA, the Mount Baker School District's recycling effort is in its eighth year and is now saving $\$ 25,000$ annually. Successful because of its outstanding student participation, the award-winning program has a long list of recyclable or reusable materials. The program is totally self-supporting, and last year the students saved $\$ 18,000$ through recycling and reuse and an additional \$7,000 from avoided disposal fees. In 1999, through the school's efforts, 89,700 pounds of materials were recycled or reused and not put into a landfill.

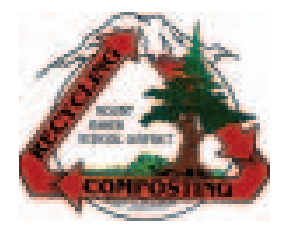

- Place the receptacles for all recyclables where the waste is generated. The best places are in the cafeteria and administrative areas. Receptacles should be made available in public spaces, gymnasiums, and hallways for plastic and aluminum in schools with soda machines.

- Locate convenient bins for other materials being recycled.

In implementing a comprehensive approach to recycling, consider all the aspects needed to make recycling easier and more educational.

- Integrate containers into cabinetry, or have free-standing stations that do not disrupt other functions in the spaces.

- Design bins to be easily dumped into a cart that will be taken by custodial staff to a central collection point.

- Incorporate chutes to accommodate recycling in multi-story facilities.

- Establish a color coding system, and use clearly labeled dispersed containers and centralized bins to distinguish the recycled material.

- Use dispersed receptacles and centralized bins that are easy to clean and maintain.

- Coordinate with a local recycling agency or waste hauler to obtain important information regarding its trucks and how it prefers to access the recycling bins. 


\section{Safe Disposal of Hazardous Waste}

- Provide a secure space within the school to temporarily store hazardous materials (e.g., batteries, fluorescent lights, medical waste) until they can be taken to a recycling center or safe disposal site.

\section{Composting}

About a third of the average school's waste stream is food and other organic materials. Composting is one environmentally friendly way of handling this waste.

- Design a conveniently located composting bin.

- Use vermicompost bins in classrooms as educational tools. The bins use worms to dramatically speed up the decomposition of food.

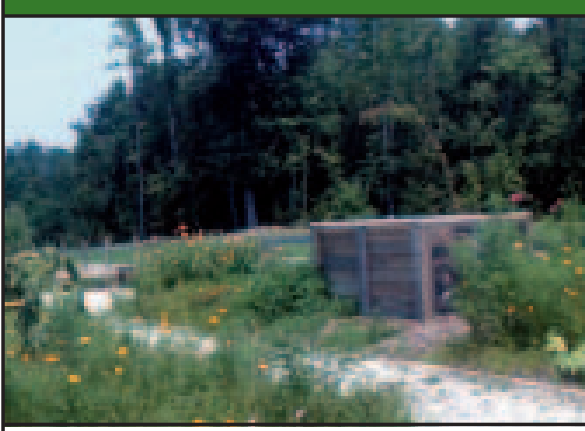

Composted kitchen scraps can be used to fertilize gardens at the school. 


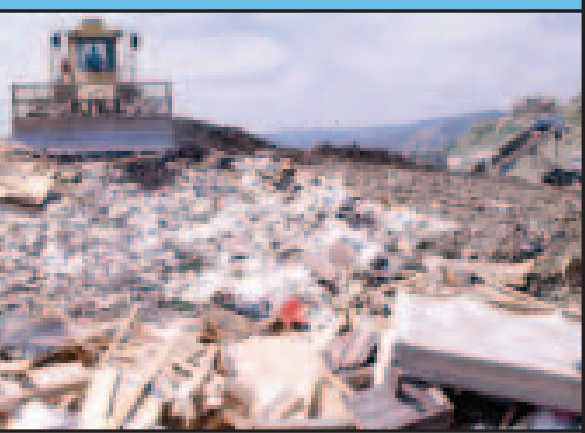

Photo: NREL/PIX05289

Recycling by the contractor during construction should be encouraged to decrease the amount of waste sent to landfills.

\section{Construction Waste Recycling and Waste Management}

Recycling efforts should begin during the construction of the school and engage the general contractor and all sub-contractors.

- Specify the specific job-site wastes that will be recycled during construction (corrugated cardboard, all metals, clean wood waste, gypsum board, beverage containers, and clean fill material).

- Require that the contractor have a waste management plan that involves everyone on the site.

- Stockpile appropriate existing topsoil and rock for future ground cover.

- Monitor the contractor and sub-contractor's recycling efforts during construction.

To minimize the impacts from any hazardous materials or waste used in construction, require that the contractor use safe handling, storage, and control procedures, and specify that the procedures minimize waste.
Photo: Craig Miller Productions and DOE/PIX03494

Construction waste materials, including corrugated cardboard, metals, clean wood waste, gypsum board, and clean fill material like concrete or brick can be recycled or reused.

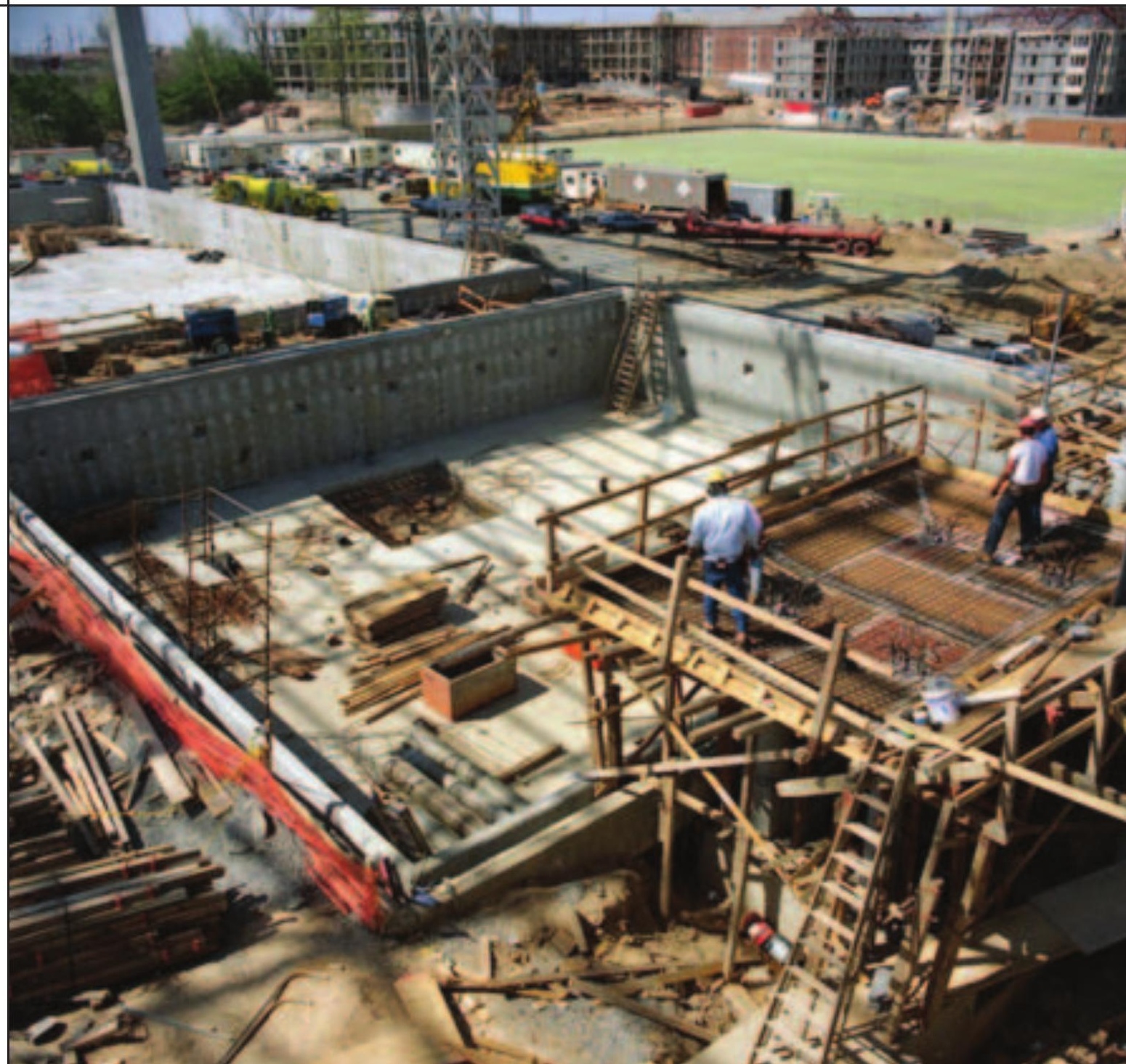




\section{Transportation}

\section{Transportation}

In many school districts across the country, more energy dollars are spent by the school system in transporting students to and from school than in meeting the energy needs of their school buildings. Up to $40 \%$ of morning traffic congestion at schools is a result of parents driving children to school.

Incorporating a network of safe walkways and bike paths that connect into the community's sidewalks and greenways can reduce local traffic congestion, minimize busing costs, and reduce air pollution. And, by incorporating natural gas, biodiesel, methanol, or solar electric buses into a district's existing vehicle fleet, you can help to reduce fuel costs and harmful emissions - lowering fuel costs and contributing to reduced operating and maintenance costs.

Today, nearly $60 \%$ of all school buses run on diesel, a highly polluting transportation fuel that poses considerable health risks. Due to particulate emissions, the use of diesel fuel is increasingly becoming associated with asthma and other lung-related diseases. Alternative fuel buses and school fleet vehicles can be used to provide environmentally friendly alternatives to high-polluting vehicles. Options for alternative fuel buses include electric, hybrid electric, compressed natural gas, ethanol, and biodiesel — all of which are available today. In addition to long-term energy savings, these vehicles serve as great educational tools for the students and the community. The US DOE's Clean Cities Program can help you determine the best alternative fuel vehicles for your fleet.

The design team, developers, and local planning departments must work in close collaboration to maximize the pedestrian access to the school site from the community.
Driving students one at a time to school each day is responsible for 0.5-3.3 tons of carbon dioxide per student being emitted into the air each year. Providing safe pedestrian walkways throughout the surrounding neighborhood allows students who attend a school in their community to walk, reducing busing and single car traffic.

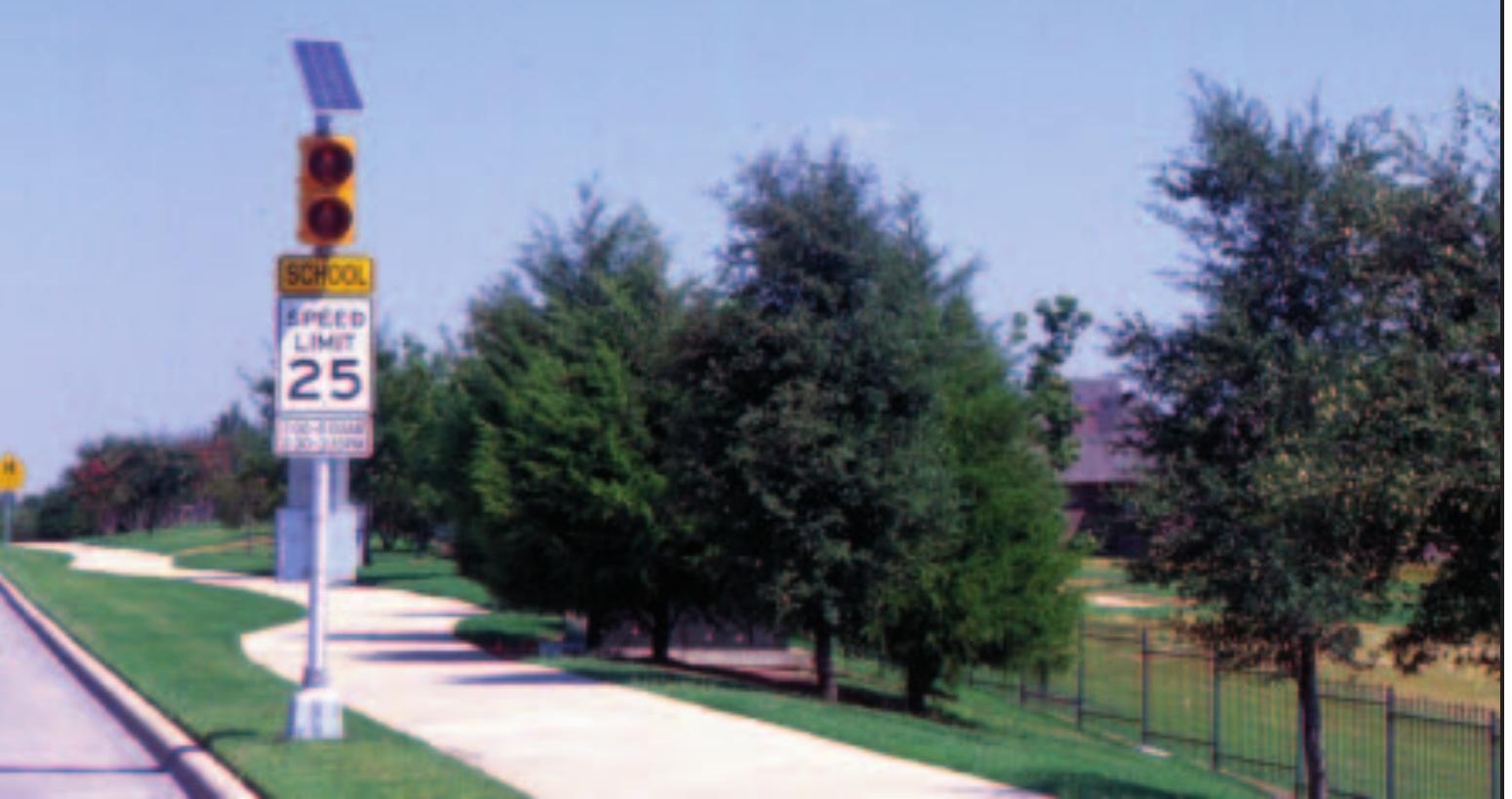




\section{Design Guidelines for Integrating Transportation Considerations into School Design}

\section{Connecting the School to the Community}

One of the measures of success of a school is the degree to which the school is a vital part of the community. If addressed early in the site selection and design phase, a school can be planned to serve not just the students but also the entire community.

- Design the school so that the athletic fields, gymnasium, media center, and classrooms are accessible and can be shared at appropriate times with the community.

- Provide good access to public transit.

- Through good site design, link the school to the surrounding communities through safe bicycle routes, pedestrian pathways, and greenways.

- Incorporate convenient bicycle parking at the school to discourage single car traffic.

In areas of the country experiencing growth, more schools are being built in conjunction with the construction of large subdivisions by local developers. This situation offers the school system and the community an excellent opportunity to coordinate with developers in making the school a more integral part of the community.

- Work with the developer to implement new, safe walkways and bike paths that link the neighborhood to the school.

- Develop a master plan with the community so that the main pedestrian ways to the site do not cross over busy roads. Or, if that cannot be avoided, provide safe and handicap-accessible pedestrian overpasses or underpasses.

- Develop recreational facilities that can be shared with the school.

Photo: Northwest Landing

With the tremendous amount of fuel currently consumed in transporting students, and the resulting pollution, it is critical to locate schools in a manner that minimizes vehicular transportation and maximizes the potential for pedestrian access. This master plan encourages walking instead of driving. Homes are, on average, a 10-15 minute walk from schools. Connecting school sites into the community's walkway system greatly decreases busing and car drop-offs and, in turn, reduces localized air pollution. 


\section{Walkways and Bike Paths}

Safe walkways and bike paths that link the school to the sidewalks and greenways of the surrounding communities offer an easy solution to many of the school's budgetary problems and the community's air pollution and traffic problems. During the early planning of the school, the design team should work with the adjacent developers and local planning officials in implementing strategies to enhance safe pedestrian paths connecting the school and the community.

- If sidewalks provide the main pedestrian access to the school, encourage the developer and/or local planning department to separate them a safe distance from the road.

- Use walkway surfacing materials that are appropriate for handicap access.

- Provide separate bike paths.

- Incorporate caution lights throughout the community to warn drivers of the likelihood of student pedestrian travel.

- Provide controllable crossing lights at the intersections of student pedestrian paths and roadways.

- Provide underpasses or overpasses at the intersection of high-traffic roads and main pedestrian paths.

- On school property, minimize potential conflicts by separating students and vehicular pathways.

\section{High-Efficiency and Low-Emission Vehicles}

In addition to incorporating safe and traffic-reducing elements into your site design, consider the use of high-efficiency and low-emission vehicles in your fleet. Electric vehicles, hybrid electric vehicles, and vehicles using alternative fuels like ethanol and compressed natural gas are cost-effective and proven options.

\section{Electric Vehicles}

Although a school bus can be powered by pure electricity, only a few electric school bus options are available today. However, small maintenance carts and other vehicles that are used by school officials and staff can easily use electricity as a fuel. Electric vehicles typically have limited ranges, so they are great for short trips and stop-andgo driving. Electric vehicles reduce local pollution, but unless they are charged with renewable energy, they are still a source of regional pollution.

Charging areas can be viewable by students to assist with teaching about renewable energy and can include displays to indicate to students the contribution that the station is providing.

- To ensure availability, the school or school system should provide a charging station for electric vehicles.

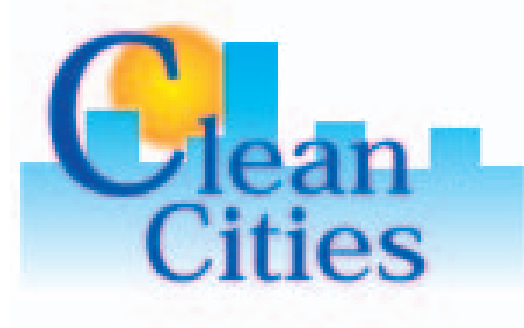

CLEAN CITIES PROGRAM

The Clean Cities Program, sponsored by the US DOE, supports public-private partnerships that help get alternative fuel vehicles into the market and build supporting infrastructure.

Unlike traditional command and control programs, the Clean Cities Program takes a unique, voluntary approach to alternative fuel vehicle development, working with coalitions of local stakeholders to help develop the industry and integrate this development into larger planning processes.

Currently there are 80 Clean Cities coalitions dedicated to getting alternative fuel vehicles on the road. The Clean Cities Program helps educate fleets across the country on which AFVs and fuel types are right for each fleet. Coalitions also assist fleets with understanding incentives and legislation related to AFVs. More information on the Clean Cities Program can be found in the resources section at the end of this document. 


\section{Resource-Efficient Building Products}

A school, like any building, is only as good as the sum of the materials and products from which it is made. To create a high performance school, your design team must choose the most appropriate materials and components and combine these components effectively through good design and construction practices.

Typically, architects and engineers primarily consider the performance of materials and components in terms of how they serve their intended function in the building. While it is appropriate that material function be a top consideration, your design team should also consider the materials from a broader environmental perspective. For example, indoor air quality can be improved by eliminating or minimizing volatile organic compounds in paints, carpet, and adhesives and by minimizing formaldehyde in plywood, particleboard, composite doors, cabinets, and carpet backings.

The best resource-efficient products and systems not only contribute to improving the indoor air quality, energy efficiency, and durability of a school, but they also help reduce harm to the natural environment by minimizing use of limited resources and promoting reuse and recycling.

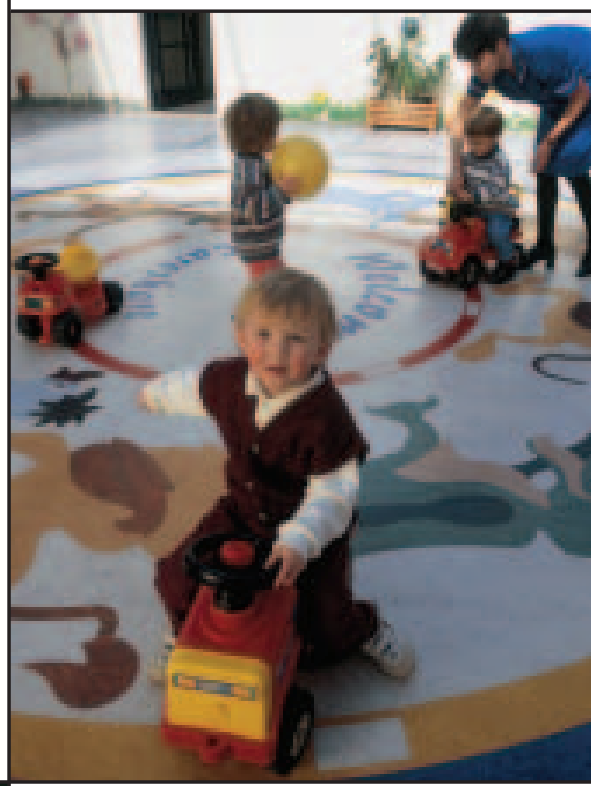

Photo: NREL/PIX03049
Photo: NREL/PIX03050

True linoleum, unlike vinyl flooring, is made from wood flour, cork, and linseed oil. It gets harder over time and makes for an attractive, durable surface. 


\section{Design Guidelines for Resource-Efficient Building Products}

\section{The Life-Cycle Approach}

To select environmentally preferable products, it is necessary to consider environmental impacts from all phases in the product's life cycle. This approach is called life-cycle analysis. A product's life cycle can be divided into the following phases:

- raw material extraction

- manufacturing

- construction

- maintenance/use

Photo: NREL/PIX02213

These ceiling beams are made from recycled wood products.

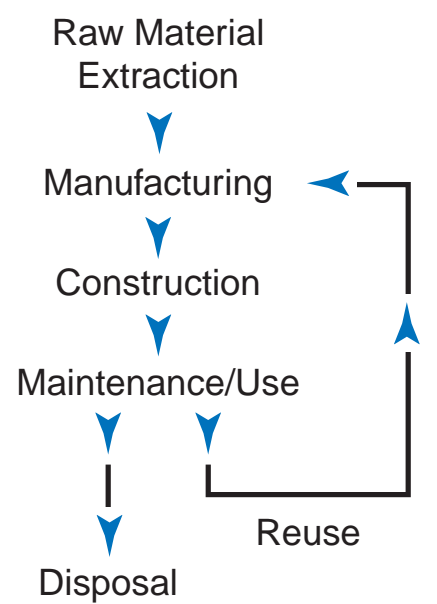

Life-Cycle Analysis

The life cycle of a building product can have significant environmental implications. 


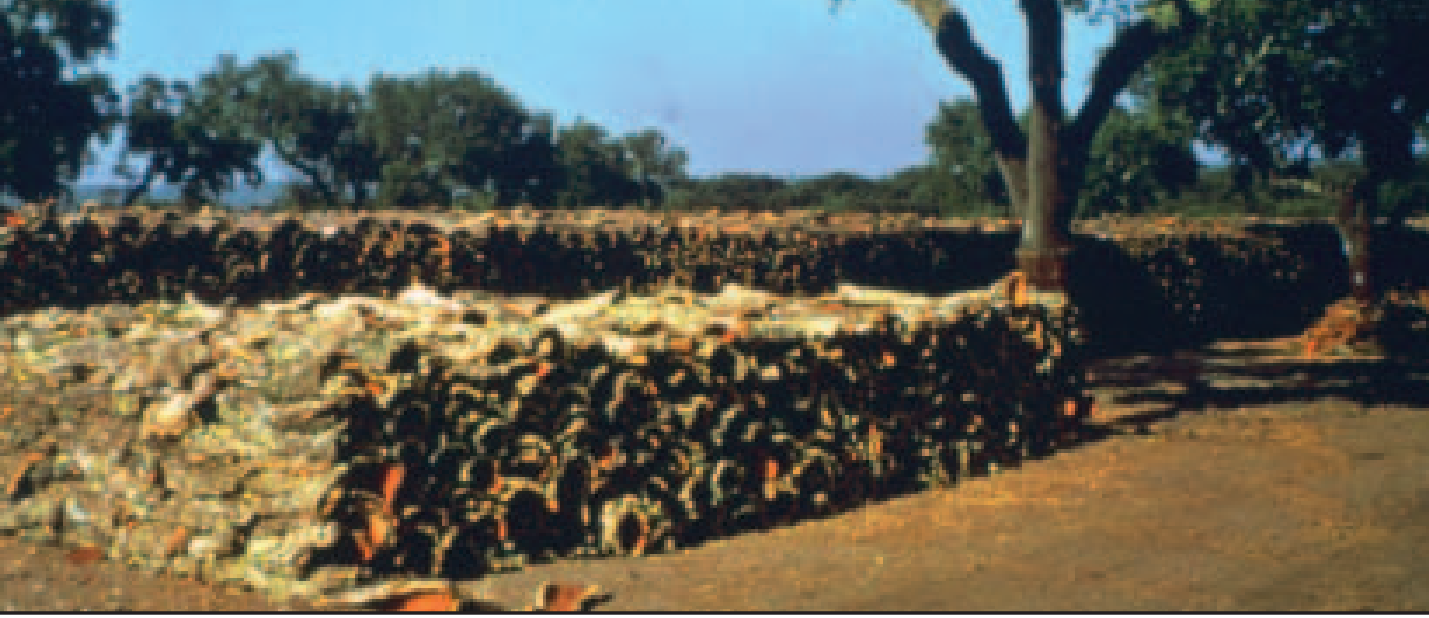

\section{Phase 2: Manufacturing}

Manufacturing operations can vary considerably in their impact on the environment. The manufacturer of one product may rely on numerous out-sourcing operations at separate locations or obtain raw materials from another country. Another, less energy-intensive product may be produced in a single, well-integrated operation at one site with raw materials and components coming from nearby locations. Likewise, a particular manufacturer may use a process that relies on toxic chemicals while a competing manufacturer may incorporate environmentally friendly technologies to accomplish the same end.

- Determine if the manufacturing process results in significant toxic or hazardous intermediaries or byproducts. Most petrochemical-based processes involve some hazardous ingredients, so plastics should be used only when they offer significant performance advantages.

- Specify products that are made from recycled materials.

- Select products that are made from low-intensity energy processes. The manufacture of some materials, such as aluminum and plastics, requires a lot of energy while the "embodied energy" to make other materials is considerably less.

- Select products manufactured at facilities that use renewable energy.

- Consider the quantity of waste generated in the manufacturing process and the amount that is not readily usable for other purposes.

\section{Phase 3: Construction}

To a great degree, the energy and environmental impacts of products and materials are determined by the way they are implemented.

- Avoid products containing pollutants by:

- excluding high volatile organic compound paints (VOC), carpets, and adhesives

- not incorporating products with excessive formaldehyde

- using the least toxic termite and insect control.

- When pesticide treatments are required, bait-type systems should always be preferred over widespread chemical spraying and soil treatments.

- Separate materials that out-gas toxins (e.g., plywood with formaldehyde) or emit particulates (e.g., fiberglass insulation) with careful placement, encapsulation, or barriers.
Resource-Efficient

Building Products
Photo: NREL/PIX03048

Cork is harvested from the cork oak. The bark can be removed from the tree about every 9 years without adversely affecting the tree. Cork is used to make cork and linoleum flooring.
Photo: NREL/PIX03041

This environmentally sound, no-VOC carpet line is leased and maintained by the manufacturer, which reduces waste by recycling and reusing the carpet tiles. The up-front and maintenance costs are lower, and the environmental and health benefits are substantial.

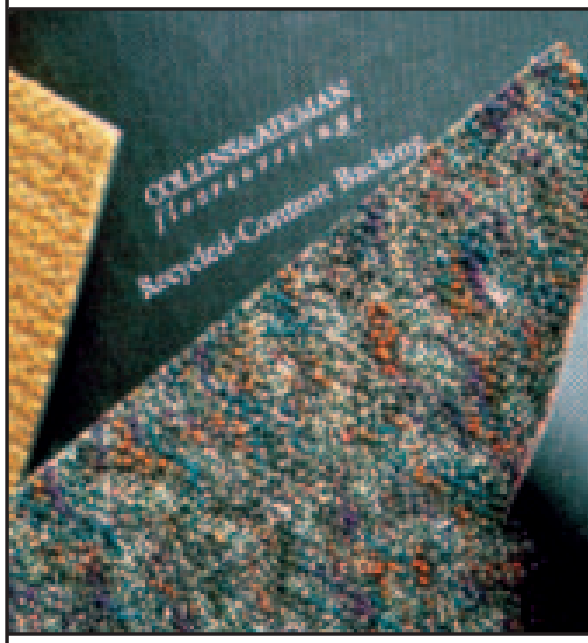

Photo: NREL/PIX03043

Choose carpet backings with low or no formaldehyde to avoid indoor air contamination. 


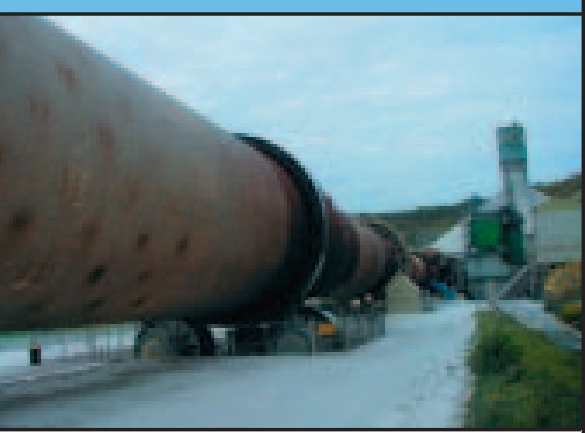

Photo: BuildingGreen Inc.

Cement manufacturing is very energy intensive. The cement kiln is the largest piece of moving industrial machinery in common use, and temperatures inside it reach $2,700^{\circ} \mathrm{F}$.

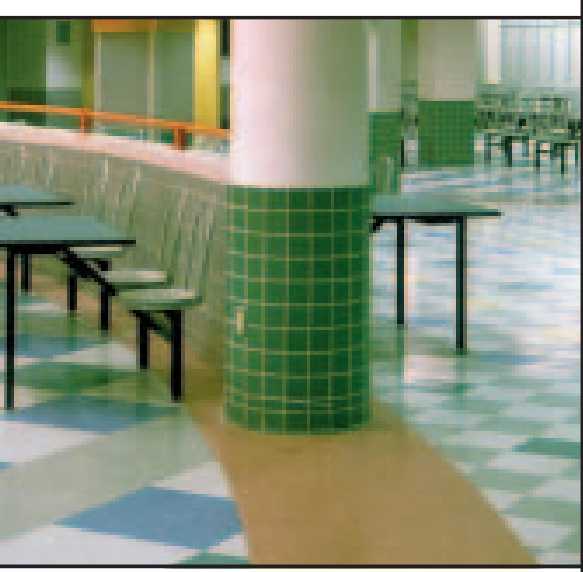

Photo: Barry Halkin Photography

Recycled tiles installed in school hallways and cafeterias require very low maintenance.
- Require the contractor to recycle construction materials.

- Ensure that unconventional products are installed properly.

- Require proper handling and storage of toxic materials at the job site.

- Require that the packaging of products, materials, and equipment delivered to the site be made of recyclable or reusable materials, and discourage unnecessary packaging.

- Ensure that product and material substitutions occurring during construction contain the same energy and environmental benefits.

- Avoid materials that are likely to adversely affect occupant health. Interior furnishings and finishes and mechanical systems all have the potential to affect the indoor air quality for better or worse. Material Safety Data Sheets (MSDS) can be a good source of information on the contents of various products.

\section{Phase 4: Maintenance/Use}

How easily building components can be maintained - as well as their impact on long-term energy, environmental, and health issues - is directly linked to the quality of the materials, products, and installation.

- Select materials, products, and equipment for their durability and maintenance characteristics. Particular attention should be paid to selecting roofing systems, wall surfaces, flooring, and sealants - components that will be subject to high wear and tear or exposure to the elements.

- Avoid products with short expected life spans (unless they are made from lowimpact, renewable materials and are easily recycled) or products that require frequent maintenance procedures.

- Provide detailed guidance on any special maintenance or inspection requirements for unconventional materials or products.

\section{Phase 5: Disposal or Reuse}

Some surfaces in the school, such as carpets, may need to be replaced on a regular basis. The building as a whole will eventually be replaced or require a total renovation. To minimize the environmental impacts of these future activities, designers have to choose the right materials and use them wisely.

- Select materials that can be easily separated out for reuse or recycling after their useful life in the structure. Products that should be avoided include those that combine different materials (e.g., composites) or undergo fundamental chemical change during the manufacturing process.

- Avoid materials that become a toxic or hazardous waste problem at the end of their useful life. Preservative-treated wood, for example, contains highly toxic heavy metals that are contained within the wood for a time but will eventually be released when the wood decays or burns. 


\section{Checklist of Key Issues for Site Design}

\section{Site Design}

- Take advantage of your site's natural resources by:

- orienting the building to optimize solar access and daylighting

- using vegetation and earth formations to your advantage.

- Incorporate strategies to save water, such as the use of rainwater catchment systems and xeriscape landscaping principles.

- Retain and add site features that could become educational resources for teachers to incorporate into their instructional programs.

- Include outdoor teaching and interpretive areas.

- Provide diverse, natural environments for exploration.

- Showcase local natural features.

- Maximize the educational opportunities of the pedestrian pathways from residential areas to the school.

- Provide the school with information on environmental design features.

- Develop the site in a manner that protects the existing landscaping, ecosystems, and wildlife habitat.

- Employ energy-saving strategies, and use renewable energy to reduce air pollution.

- Create earth berms to provide sound barriers.

- Develop on-site erosion control and stormwater management strategies.

- Connect the school's walkways and bike paths directly into greenways and sidewalks surrounding residential areas.

- Design the school as a part of the community by:

- providing easy, safe pedestrian access to surrounding communities and mass transit

- allowing for shared recreational facilities. 


\section{Daylighting and Windows}

- Account for all the financial and environmental benefits associated with daylighting, including:

- reduced electrical lighting and cooling

- decreased electrical service to the site

- less mechanical system maintenance

- fewer lamp replacements

- peak demand and equipment reductions caused by smaller lighting and cooling loads.

- Evaluate and avoid negative impacts associated with window treatments, placement, and types, including:

- glare and direct beam radiation entering teaching and work spaces

- excessive radiation in warmer months

- comfort problems and unnecessary heat loss and gain due to the lack of thermal breaks, poorly insulated windows, and the choice of solar transmission values of glazing

- maintenance.

- Make daylighting strategies obvious to the students.

- Create deliberate connections to the outside environment so that changes in weather conditions are apparent as well as stimulating to students.

- Incorporate daylighting strategies that could be enhanced through student participation and understanding.

- Recognize the importance of daylighting as a strategy to create superior learning environments that:

- have a positive physiological impact on the students and teachers

- provide better quality light

- increase the performance of students and teachers.

- Reduce building materials and cost by integrating daylighting into the overall structural design and roofing system.

- Incorporate controlled daylighting strategies.

- When climatic conditions allow, install operable windows to improve indoor air quality.

- Use daylighting and high performance windows as strategies for reducing long-term energy costs, shifting more financial resources to critical educational needs, and keeping more of your energy dollars within the community. 


\section{Checklist of Key Issues for Energy-Efficient Building Shell}

\section{Energy-Efficient Building Shell}

- Carefully evaluate building shell issues. Many of these components are likely to go unchanged during the life of the facility.

- Consider the wide range of building systems that can improve energy consumption, reduce maintenance requirements, and improve comfort. These include:

- light-colored exterior walls and high-reflectance roofing systems

- radiant barriers (in addition to insulation) in the roof/ceiling assemblies

- massive wall construction

- optimum wall and roofing insulation

- infiltration and weather-resistive barriers

- light-colored interior walls and ceilings.

- Incorporate artwork and graphics in the building that will help to educate students about energy and environmental issues.

- Design energy-efficient building components to make their purpose and function obvious to the students.

- Highlight different wall and glass treatments on each facade to emphasize the appropriateness of different design responses.

- Consider building shell issues that directly impact comfort and health and indirectly affect the performance of students within the classroom.

- Consider the embodied energy of optional building components and implementation strategies.

- Consider the color and finish of interior surfaces in controlling glare and improving visual comfort.

- Employ energy-saving strategies that will result in more energy dollars staying within the community. 


\section{Lighting and Electrical Systems}

- Select high-efficiency lamps, ballasts, lenses, and lighting fixtures that address the specific task requirements.

- Specify high-efficiency appliances and equipment.

- Use long-life lamps to reduce maintenance.

- Develop the primary lighting strategy around a daylighting approach.

- Incorporate controls, occupancy sensors, and dimmable or staged lights to automatically reduce electric lighting during times of adequate daylighting.

- Provide photocell controls on exterior lights to ensure lights are not operating during the day.

- Consider light-emitting diode (LED) exit lights.

- Minimize electrical line losses by installing a high-voltage distribution system.

- Conduct a commissioning process that verifies the proper operation of equipment and systems.

- Implement a regular maintenance schedule to ensure proper operation.

- Use ASHRAE Standard 9.01-1999 to establish lighting power densities (LPDs) for each space within the school.

- Incorporate photovoltaic and solar thermal-electric systems where appropriate.

- Monitor total building energy use and renewable energy system contribution.

- Design lighting to uniformly light each space, minimize glare, and reduce overheating from light fixtures.

- Select lamps with minimal or no hazardous materials.

- Design site lighting in a manner that will minimize "light pollution" by:

- using fixtures with cut-off angles that prevent light from going beyond the specific area to be lighted

- optimizing the height of luminaries for pathways to improve illumination and prevent light from straying onto adjacent properties

- limiting exterior lighting to critical areas only. 


\section{Checklist of Key Issues for Lighting and Electrical Systems}

- Select ballasts that do not contain PCBs.

- Minimize glare and eye strain by:

- incorporating indirect lighting, particularly in computer areas

- using lenses that shield the lamp from direct view and help disperse light more evenly

- evaluating the location of the lighting sources in relationship to the occupants and what the occupants will be viewing

- avoiding reflected glare commonly experienced when viewing a computer screen and seeing the light fixtures

- minimizing situations of "transient adaptation" in which the eye cannot properly adjust when going from one space to another with drastically different light levels.

- Employ energy-efficient lighting and electrical systems that will result in more energy dollars staying within the community.

- Consider life-cycle costs to ensure that the best long-term solutions are implemented. 


\section{Mechanical and Ventilation Systems}

- Implement the most energy-efficient mechanical and ventilation strategies to save energy.

- Consider the initial cost of equipment, anticipated maintenance expenses, and projected operating costs when evaluating the life-cycle benefits of system options.

- Use a computer energy analysis program that simulates hourly, daily, monthly, and yearly energy consumption and effectively accounts for daylighting benefits (i.e., reduced cooling).

- Optimize the mechanical system as a complete entity to allow for the interaction of various building system components.

- Employ the most energy-efficient mechanical systems by:

- not oversizing equipment

- eliminating systems that first cool air and then reheat it or mix cool and hot air

- matching the air supply to the load, without adding a reheat penalty

- considering thermal storage systems

- zoning air handling units so that each unit serves spaces with similar orientation and use patterns.

- Implement a strategy that energy efficiently ensures adequate outside air by incorporating economizer cycles and heat recovery systems.

- Provide safe visual access to mechanical systems to explain how they work.

- Use energy monitoring stations as teaching aids.

- Improve student and teacher performance by ensuring adequate fresh air is provided by:

- complying with ASHRAE ventilation standards

- incorporating pollutant sensors

- using nighttime ventilation strategies in cooling the season to flush out air prior to morning occupancy

- installing ductwork that has smooth internal surfaces and transitions to minimize the collection of microbial growth

- designing ductwork and plenums to minimize the accumulation of dirt and moisture and providing access areas in key locations for inspection, maintenance, and cleaning 


\section{Checklist of Key Issues for \\ Mechanical and Ventilation Systems}

- locating outdoor-air intakes a safe distance from polluted and/or overheated exhaust grilles and away from parking or traffic.

- Implement mechanical and ventilation strategies that control humidity and address all physical, biological, and chemical pollutants.

- Incorporate renewable energy systems to provide for absorption cooling, space heating, hot water, and electricity.

- Address the impacts of CFCs and HCFCs when selecting refrigerants for cooling systems.

- Implement indoor air quality strategies that can provide for healthier learning environments.

- Design the mechanical and ventilation systems to maximize the comfort of the students and teachers.

- Employ energy-efficient mechanical and ventilation systems that will result in more energy dollars staying within the community. 


\section{Renewable Energy Systems}

- Consider the wide range of renewable options, including:

- daylighting

- passive cooling

- solar hot water and space heating

- solar absorption cooling

- photovoltaic

- wind.

- Consider daylighting your highest priority.

- Incorporate solar systems to reduce peak cooling loads.

- Employ photovoltaic and wind systems as educational tools that demonstrate the opportunities for converting sunlight and wind into electricity.

- Incorporate solar hot water and absorption systems, and provide a view that will illustrate how sunlight can be converted into thermal energy and provide cooling.

- Use daylighting and passive ventilation strategies to show students the importance of working with, instead of against, nature.

- Integrate displays showing total energy use at the school and the percentage of energy being provided by renewable energy sources.

- Use renewable energy systems as stimulating, educational tools involving multiple subject areas.

- Use on-site, renewable energy systems to help make the link between saving energy and helping our environment.

- Use renewable energy systems in conjunction with battery storage to provide for emergency power.

- Use photovoltaic systems to reliably power:

- parking and walkway lighting

- caution lights at street crossings and remote signage

- security lights

- emergency telephone call boxes

- electric charging stations.

- Employ renewable energy and energy-saving strategies that will result in more energy dollars staying within the community.

- Install renewable energy systems at schools to serve the community in times of natural disasters and utility outages. 


\section{Water Conservation}

- Encourage the general contractor to conserve water during construction.

- Incorporate indigenous vegetation to minimize irrigation requirements.

- Install water-conserving fixtures.

- Incorporate graywater systems.

- Consider rainwater collection systems.

- Provide more localized hot water heaters, closer to the loads in the school, to avoid wasting water and energy.

- Use educational signage and graphics to help inform students and staff about the need to conserve water and instruct them on what they can personally do to save water.

- Install monitoring devices, sight glasses in storage tanks, and energy management systems that can be used by students to monitor school usage and see the benefits of using graywater.

- Adequately insulate hot water supply piping.

- Ensure that the water is clean and lead-free.

- Implement water-conserving strategies that will reduce the need to provide water from non-sustainable aquifers and water sources not within the immediate region.

- Consider installing an on-site biological wastewater treatment system.

- Check the condition of all existing plumbing lines and fixtures for sources of potential contamination, particularly lead.

- Use only lead-free materials in the potable plumbing system to avoid lead-related impacts such as lower IQ levels, impaired hearing, reduced attention span, and poor student performance.

- Verify the condition of the potable water supply.

- Install separate plumbing lines that will allow the school to irrigate by using reclaimed water, avoiding the costs, chemicals, and energy associated with treating water to potable levels but still achieving health standards for discharging into streams. 


\section{Recycling Systems and Waste Management}

- Implement a comprehensive recycling strategy that involves all major recyclable waste materials in the school.

- Allocate space throughout the building for recycling receptacles to reduce waste hauling and disposal costs.

- Provide outdoor recycling bins accessible to collection agencies or companies.

- Allocate space for yard waste composting to further reduce landfill tipping costs.

- Ensure that recycling receptacles are designed and labeled so as not to be confused with trash receptacles.

- Design recycling receptacles as attractive components, wellintegrated into the overall design but still obvious to the students.

- Incorporate recycling receptacles that are easily accessible to students and custodial staff and designed to be used by students.

- Develop a recycling system that allows students to monitor their waste stream and that teaches them about waste reduction.

- Require a detailed waste management plan from the contractor to minimize the disposal of recyclable or reusable construction waste.

- Monitor construction waste management throughout the construction process to minimize the landfilling, incineration, or improper disposal of recyclable materials.

- Design recycling systems that will enable the school to recycle as much daily waste as possible.

- Consider incorporating a compost center that allows food waste to be used in gardens or landscaping.

- Select recycling containers that are made of recycled materials.

- Ensure that recycling receptacles are designed and installed so as not to create a physical hazard.

- Design recycling receptacles for easy cleaning.

- Provide documentation on cleaning procedures and maintenance requirements associated with the recycling receptacles.

- Locate local companies or services that can benefit from the use of recycled materials or construction waste. 


\section{Transportation}

- Work with developers and local planning departments to design easy, safe pedestrian access throughout the community to the school site.

- Use high-efficiency buses and service vehicles.

- Use graphics and signage to help educate students and the community about the environmental benefits of the energy efficient and low-emission approaches to transportation implemented by the school.

- Give high priority to the placement of bicycle racks and use personalized nameplates for regular bikers.

- Incorporate a highly visible solar electric and/or wind-powered charging station for electric buses and service vehicles.

- Design sidewalks and bike paths throughout the community and school site to help reduce air pollution associated with busing and single car drop-offs.

- Use low-emission methanol, biodiesel, natural gas, and solar electric buses and service vehicles to reduce air pollution.

- Stress safety when designing walkways and bike paths.

- Use photovoltaic systems to reliably power:

- parking and walkway lights

- caution lights and street crossings

- electric charging stations.

- Allow for handicap access.

- Encourage recreational activities by providing access to athletic facilities that can be shared with residents of the local community.

- Provide pedestrian ways to and a mass transit stop at the school site so that the school is more easily accessible to the community.

- Implement energy-efficient transportation options that keep energy dollars in the community, strengthening the local economy.

- Choose high-efficiency and low-emission vehicles as the best long-term solution to protect against future energy cost escalation. 


\section{Resource-Efficient Building Materials}

- Use products that are energy-efficient.

- Choose fixtures and equipment that conserve water.

- Specify building systems, components, and materials with low maintenance requirements.

- Incorporate less-polluting materials, the result being a reduced requirement for mechanically induced fresh air and better energy efficiency.

- Incorporate pollutant sensors to reduce ventilation air exchange during non-occupied times.

- Design environmentally sound building components to make their purpose and function obvious to students.

- Use products and systems that save water in explicit, visible ways.

- Incorporate locally harvested or mined materials as prominent design elements.

- Avoid materials containing toxic or irritating compounds that negatively impact the indoor air quality.

- Specify products, materials, and equipment that can be maintained in an environmentally friendly way.

- Select products made from renewable energy and low-polluting processes.

- Specify products harvested from well-managed forests.

- Avoid products harvested or mined from environmentally sensitive areas.

- Select products that are made from recycled materials and/or are recyclable.

- Specify products made with a minimum of process (embodied) energy.

- Minimize the environmental impact of the building's operation by evaluating the environmental life-cycle impacts.

- Incorporate energy-efficiency and renewable energy systems.

- Use water-saving fixtures and appliances, and implement rainwater catchment and graywater systems.

- Avoid products that produce indoor air pollution. 


\section{Checklist of Key Issues for Resource-Efficient Building Products}

- Separate polluting materials from exposed surfaces.

- Incorporate indoor planting strategies.

- Avoid equipment that requires toxic or irritating maintenance procedures.

- Provide detailed guidance on preferable maintenance procedures to minimize exposure of staff and students to toxic and irritating chemicals.

- Work with the school system to develop an indoor pollutant source assessment and control plan.

- Choose products and materials that are locally produced or made from readily available materials.

- Choose products and building procedures that maximize local labor.

- Select indigenous materials, and implement designs that enhance the connection to "place."

- Select materials that can be reused or recycled, minimizing impacts on landfills. 


\section{Poudre School District, Fort Collins, Colorado}

\section{Contact:}

Stu Reeve, Energy and Technical Systems Manager Poudre School District 2407 LaPorte Ave.

Fort Collins, CO 80521

Phone: (970) 490-3502

Email:stur@psd.k12.co.us

Benefits:

$\$ 200,000$ in annual energy savings in the district

Water conservationreduction in water needed for irrigation

$\checkmark$ Improved classroom lighting and ventilation
Several elementary schools in the Poudre School District in Colorado were awarded the ENERGy Star label. Many new schools in the district are following suit, replicating some of the design elements that made these schools stellar examples of energy efficiency. The design of one of the schools, Johnson Elementary, was replicated eight times in the district.

The design elements that helped to earn these schools the ENERGY STAR label include:

- the conversion of old steam heating systems to modern hot-water heating systems

- the replacement of natural gas steam heating with heat registers

- the installation of energy-efficient doors and operable windows with motorized shades

- the extensive application of energy-efficient glazing in all classrooms

- the installation of high-efficiency fluorescent lighting with dimming systems

- enhanced daylighting design with high ceilings and operable windows.

High schools and junior high schools in the district have also experienced success in energy and environmental conservation. Fort Collins High School shares a pond with the City of Fort Collins, reducing the amount of domestic water needed for irrigating school lawns. Lincoln Junior High School has a state-of-the-art energy management system that ensures all systems are functioning properly and efficiently.

Poudre School District is committed to retrofitting older schools and constructing new facilities with energy conservation as a top priority. It has established an energy efficiency team that has completed 72 projects since 1994. As a result of this dedicated effort, Poudre School District saves \$200,000 annually. 


\section{Inez Science and Technology Magnet Elementary School, Albuquerque, New Mexico}

The Inez Elementary School has installed a rainwater collection system for drip irrigation. The rainwater is harvested from the roof and collected in cisterns to provide for irrigation. Planting has been located in the runoff areas. Because of the project's success, two additional schools in Albuquerque Public Schools System are now being designed with rainwater harvesting strategies.

\section{Contact:}

Leon Bartels, Principal 1700 Pennsylvania $N E$ Albuquerque, NM 87110 Phone: (505) 299-9010

Benefits:

$\checkmark$ Water savings

$\checkmark$ Environmental impacts 


\section{The Effect of Daylighting on Student Performance - Heschong Mahone Group, Colorado, California, Washington}

"Daylighting in Schools - An Investigation into the Relationship Between Daylighting and Human Performance" is a 1999 study conducted by the Heschong Mahone Group that looked at the effect of daylighting on human performance. It isolated daylighting as an illumination source and separated illumination effects from other qualities associated with daylighting from windows. This research established a statistically compelling connection between daylighting and student performance.

Student performance data from three elementary school districts were obtained, and correlations were investigated between the performance data and the amount of daylight provided within each student's classroom environment. Data from second through fifth grade students in elementary schools was used because there was extensive information available from highly standardized tests administered to these students and because elementary school students were generally assigned to one teacher in one classroom for the school year. Thus, it was reasoned that if the physical environment does indeed have an effect on student performance, such a correlation could be established by looking at the performance of these elementary school students.

The research analyzed test score results for more than 21,000 student records from the three districts, located in Orange County, California; Seattle, Washington; and Fort Collins, Colorado.

Photo: Heschong Mahone Group 


\section{Oquirrh Hills Elementary School, West Jordan, Utah}

In 1995, Oquirrh Hills Elementary School was destroyed by fire. But this accident provided Jordon School District new opportunities, and out of these ashes was built a new state-of-the-art, energy-efficient school. Built on the original foundation, the new 61,200 square-foot school has a light colored roof to reduce the cooling loads and R-30 rigid insulation. Exterior windows have low-E glass. The interior finishes are light colored to reduce the lighting requirements. Comfort and energy savings were further enhanced with T-8 fluorescent lamps with electronic ballasts, energy management control. Through the incorporation of these simple, cost-effective solutions, the new school spends about $\$ 22,000$ Les per year in operating costs compared to the old school.

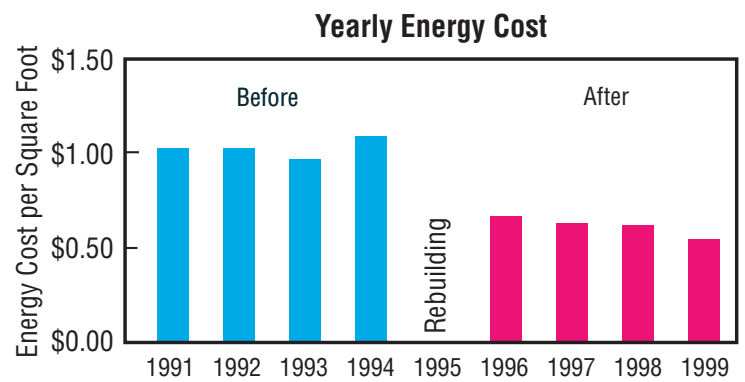

\section{Owner:}

Jordon School District 9150 South 500 West

Sandy, UT 84070

\section{Contact:}

Duane Devey

Phone: (801) 567-8770

\section{Benefits:}

Reduced cooling loads and lighting requirements

Reduction in annual operating costs of $\$ 22,000$

Increased comfort and energy savings 


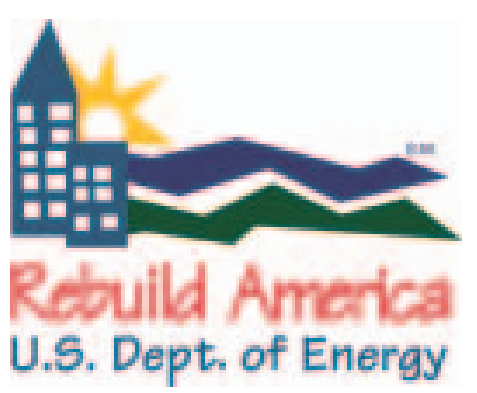

EnergySmart Schools is part of the Rebuild America program, a national US DOE initiative to improve energy use in buildings. This means that if your school is part of a Rebuild America community partnership, you're ready to benefit from EnergySmart Schools.

Be sure to ask about energy improvements and educational materials for your bus fleet as well as your buildings. Rebuild America focuses on buildings, but its representatives can also direct you to resources for buses. After all, the goal of EnergySmart Schools is a comprehensive one: a nation of schools that are smart about energy in every way.

\section{Web Resources for More Information}

\section{EnergySmart Schools Web Site: www.energysmartschools.gov}

\section{Comprehensive Sources}

www.ase.org/greenschools/newconstruction.htm — Alliance to Save Energy's Green Schools Program

www.eren.doe.gov/EE/buildings.html — US DOE's Energy Efficiency and Renewable Energy Network buildings site

www.advancedbuildings.org/ — Advanced Buildings, Technologies, and Practices

www.edfacilities.org/rl/ — National Clearinghouse for Educational Facilities

www.epa.gov/building/schools — US EPA’s ENERGY STAR for Schools

\section{Introductory Section}

www.rebuild.org — US DOE's Rebuild America program, with energy-efficient solutions for communities

www.eren.doe.gov/buildings/energy_tools/doe_tools.html — DOE energy simulation software www.usgbc.org — US Green Building Council

\section{Site Design}

www.epa.gov/glnpo/greenacres/natvland.html — EPA's site on native landscaping www.water.az.gov - Arizona Department of Water Resources

\section{Daylighting and Windows}

windows.lbl.gov/daylighting/designguide/designguide.html — Lawrence Berkeley National Laboratory's "Tips for Daylighting with Windows"

www.eren.doe.gov/erec/factsheets/windows.html — US DOE's “Advances in Glazing Materials for Windows"

www.nfrc.org — National Fenestration Rating Council

www.daylighting.org — Daylighting Collaborative

aa.usno.navy.mil/data/docs/AltAz.html — US Naval Observatory's sun or moon altitude/azimuth table

\section{Energy Efficient Building Shell}

www.nrel.gov/buildings_thermal/ — National Renewable Energy Laboratory's Center for Buildings and Thermal Systems

www.ornl.gov/roofs+walls/index.html — Oak Ridge National Laboratory's Building Thermal Envelope Systems and Materials Program

gundog.lbl.gov/dirsoft/d2whatis.html — Lawrence Berkeley National Laboratory's DOE-2 energy simulation software

\section{Renewable Energy Systems}

www.eren.doe.gov/state_energy/ — US DOE's State Energy Alternatives

www.eren.doe.gov/greenpower/ — US DOE's Green Power Network

www.nrel.gov — National Renewable Energy Laboratory

www.schoolsgoingsolar.org — The Interstate Renewable Energy Council Schools Going Solar program 


\section{Lighting and Electrical Systems}

www.iaeel.org — International Association for Energy-Efficient Lighting

eetd.lbl.gov/btp/lsr/ — Lawrence Berkely National Laboratory's Lighting Systems Research Group

\section{Mechanical and Ventilation Systems}

www.epa.gov/iaq/schools/ — US EPA's Tools for Schools Indoor Air Quality program www.eren.doe.gov/buildings/energy_tools/energyplus/ — US DOE's EnergyPlus energy simulation program

epb1.lbl.gov/EPB/thermal/ — Lawrence Berkeley National Laboratory's information on Resource Efficient Building Conditioning

\section{Resource-Efficient Building Products}

www.sustainable.doe.gov/buildings/rescon.shtml — US DOE's resource list of resourceefficient building products

www.ciwmb.ca.gov/GreenBuilding/Materials — California Integrated Waste Management Board's site on green building materials

www.ciwmb.ca.gov/ConDemo/Products/default.asp - California Integrated Waste Management Board's site of Recycled-Content Building Products Database

\section{Water Conservation}

www.epa.gov/ow/ - US EPA's Office of Water

www.water.az.gov - Arizona Department of Water Resources

www.amwua.org/conservation-school.htm - Arizona Municipal Water User Association's "Water in Our Desert Community," an instructional resource for middle school students

\section{Recycling and Waste Management}

www.epa.gov/globalwarming/actions/waste/warm.htm - US EPA's Waste Reduction Model to calculate greenhouse gas emissions

www.p2pays.org/ref/01/00626.htm - North Carolina Division of Pollution Prevention and Environmental Assistance's "Beyond Recycling: A Waste Reduction Manual for Schools"

www.cfe.cornell.edu/compost - Cornell University, "Cornell Composting: Composting in Schools"

www.epa.gov.gov/epaoswer/non-hw/reduce/food/food.html - U.S. EPA Office of Solid Waste, "Don't Throw Away that Food: Strategies for Record-Setting Waste Reduction"

\section{Transportation}

www.ccities.doe.gov — US DOE's Clean Cities Program

www.ott.doe.gov/ - US DOE's Office of Transportation Technologies

www.ctts.nrel.gov — National Renewable Energy Laboratory's Alternative Fuels Web site
Photos Credits:

All photographs not specifically credited were taken by Innovative Design.

\section{For helpful resources or more information:}

Call DOE's energy clearing house: 1 (800) DOE-3732

Ask a question about saving energy in your school or request information about the EnergySmart Schools campaign. You may want to inquire about the availability of the following EnergySmart Schools resources:

\section{Publications and Videotapes}

- Design Guidelines for New Schools and Major Renovations

- Portable Classroom Guidelines

- Decisionmaker Brochures

- Designing Smarter Schools, a 30-minute videotape that originally aired on the CNBC television network

- Educational CD-ROM featuring teaching and learning materials

- The High Performance Schools 30 -minute video is also available by calling one of these three numbers: (303) 443-3130 Ext. 106, (202) 628-7400, or (202) 857-0666

\section{Services}

- Technical assistance

- Regional peer exchange forums

- State-based forums for school decisionmakers

- Financing workshops

- Technology workshops

This publication, and additional information, is available online at: 


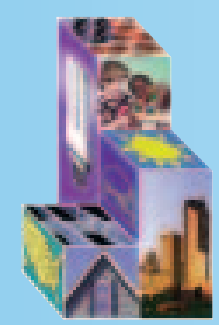

Office of Building Technology, State and Community Programs Energy Efficiency and Renewable Energy US Department of Energy

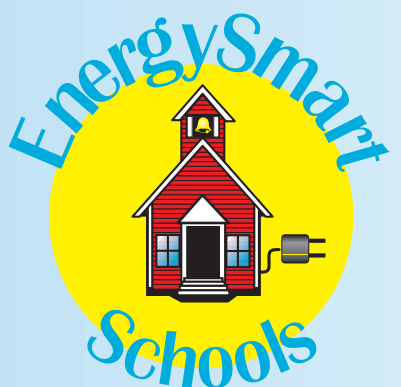

Rebuild America Schools U.S. Department of Energy 